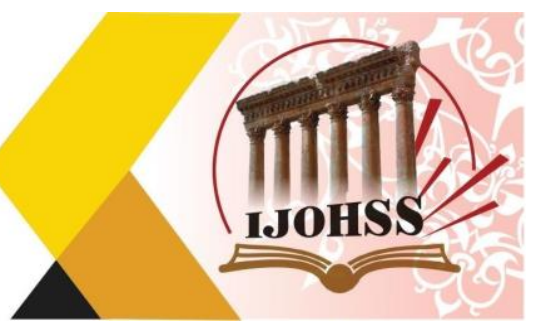

\title{
فقه الأسرة ودوره في المعالجة التشريعية للعنف الأسري في إقليم كوردستئن إمان
}

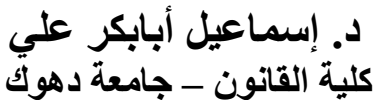

$$
\begin{aligned}
& \text { قسم القانون } \\
& \text { العراق - إقليم كوردستان }
\end{aligned}
$$

$$
\begin{aligned}
& \text { د. سنامي جلال حسين } \\
& \text { وزارة الداخلية } \\
& \text { المديرية العامة للايوان } \\
& \text { العراق - إقليم كوردستان العاديوان }
\end{aligned}
$$

الملخص

إن فقه الأسرة له دور بارز في معالجة العديد من المشاكل والنزاعات الأسرية، ودوره يبرز بصورة أوضح في

كيفية معالجة العنف الأسري داخل الأسرة.

إن مكافحة العنف الأسري في فقه الأسرة لا يبدأ بعد العنف. و إنما يرسخ هذا الفقه في أذهان الزوجين وجميع

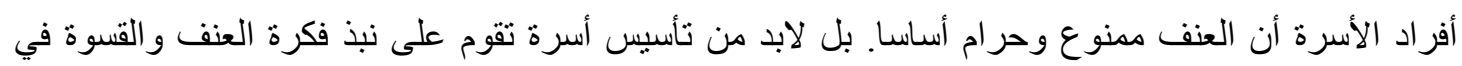

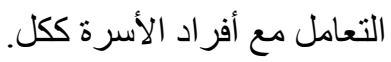
إن فقه الأسرة من خلال منظومة فقهية متكاملة يمنع صور العديدة من العنف من خلال تحريمه نماذج معينة من عقود الزو اج، و عدّها أنكحة فاسدة، كالإكراه في الزواج، و الطلاق بالإكر اه، وتزويج الصغار ، و التزويج بدلاً عن هن

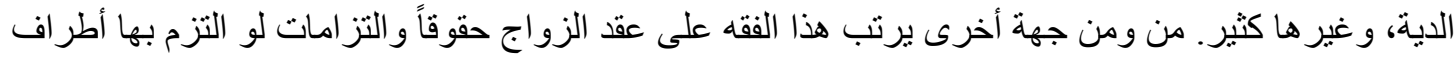
العلاقة من الزوجين والأولاد لأدى ذلك إلى خلق أسرة قوية متماسكة تقوم على المودة والحب، مما يساعد وبصورة فعالة على مكافحة العنف الأُسَري ومعالجته و الوقاية منه. 


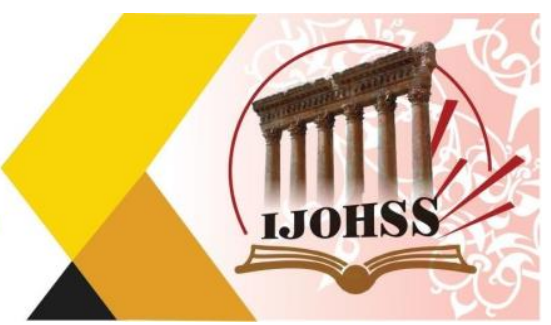

\title{
Family jurisprudence and its role in the legislative treatment of domestic violence in the Kurdistan Region
}

\author{
Dr. Sami Jalal Hussein \\ Ministry of Interior \\ General Directorate of the Diwan \\ Iraq - the Kurdistan Region
}

\author{
Dr. Ismail Ababaker Ali \\ College of Law - University of Duhok \\ Law Department \\ Iraq - the Kurdistan Region
}

\begin{abstract}
Family jurisprudence has a prominent role in addressing many problems and family conflicts, and the role of this jurisprudence more clearly in how to address domestic violence within the family.

The combating domestic violence in family jurisprudence does not begin after the occurrence of violence, but it establishes in the minds of the spouses and all members of the family that violence essentially is forbidden. Rather, a family must be established based on the rejection of the idea of violence and cruelty in dealing with family members as a whole.

Family jurisprudence through an integrated system of jurisprudence prevents many forms of violence based on the prohibition of certain forms of marriage contracts, and makes them illegal marriage, such as forced marriage, forced divorce, early marriage, the marriage instead of blood money, and many others.

On the other hand, in Islamic jurisprudence Marriage contract are followed by some duties rights and obligations. If committed by the parties of the relationship of spouses and children, this would create a strong family based on affection and love, which effectively helps to combat violence, treatment and prevention.
\end{abstract}

Keywords: jurisprudence of the family, domestic violence, Kurdistan Region. 


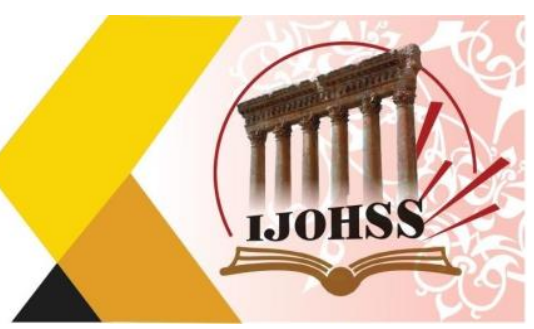

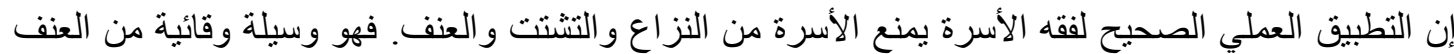

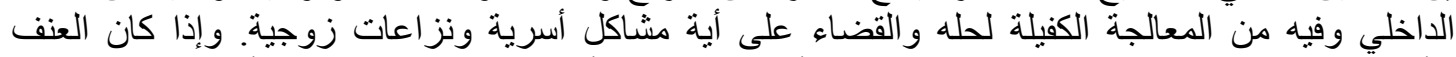

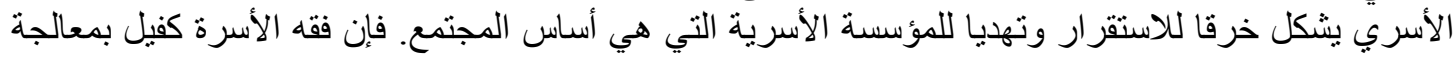

ذللك العنف.

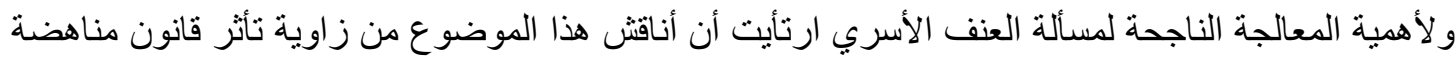

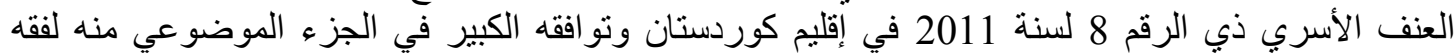
الأسرة " قانون الأحو ال الثخصية".

هدف البحث

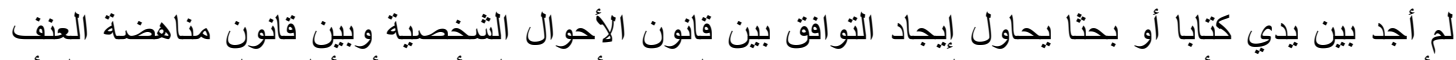

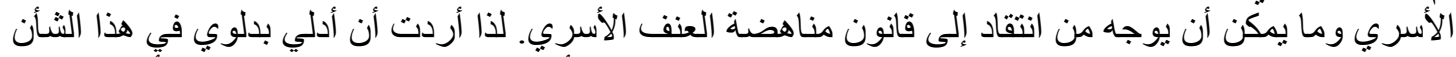

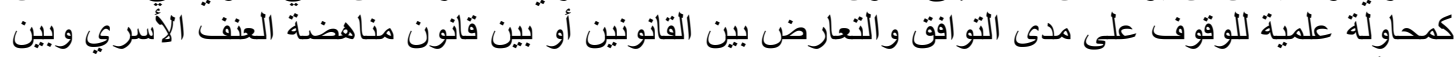

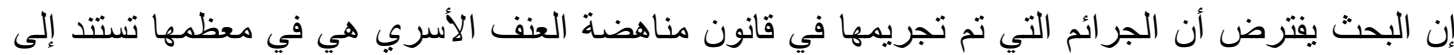

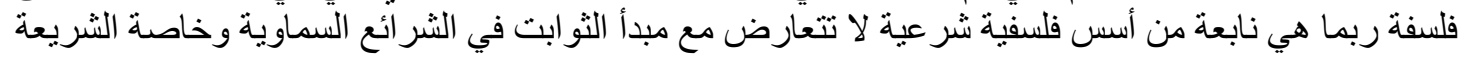

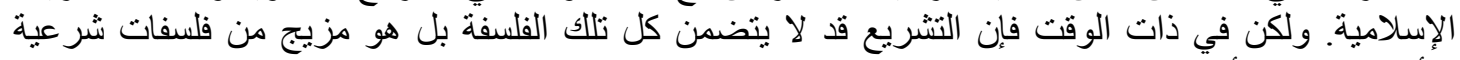

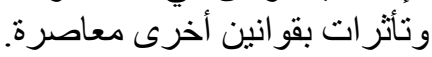

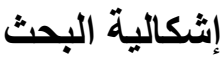

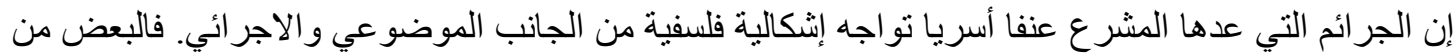

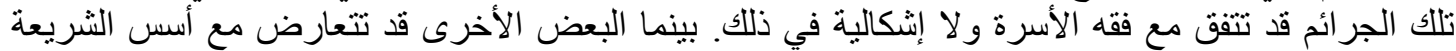

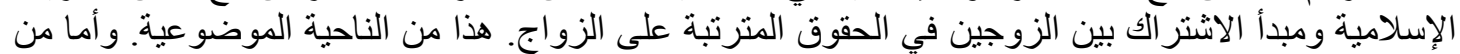

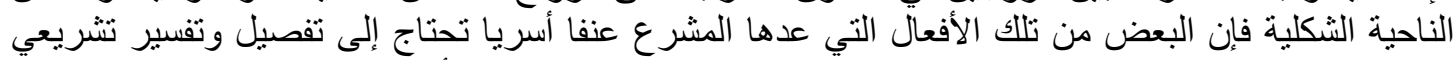

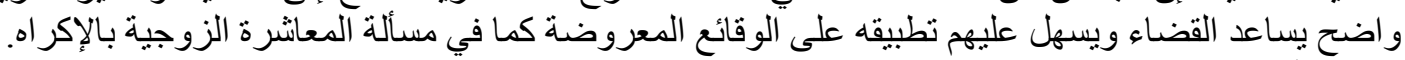

منهجية البحث

يحاول الباحث في هذا البحث دراسة وتحليل النصوص القانو البحنية الخاصة بتجريم بعض الأفعال في كل من قانون مناهضة العنف الأسري وقانون الأحوال الثخصية وفقه الأسرة ومن ثم إجر اء المقارنة بينها فهي دراسة تحليلية الألية

خطة البحث

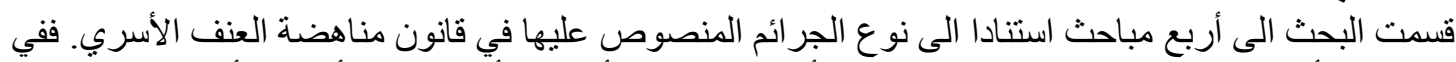

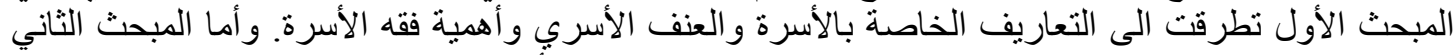

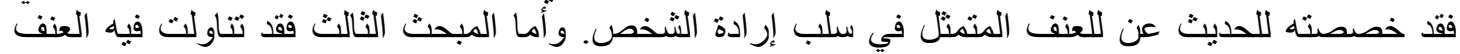

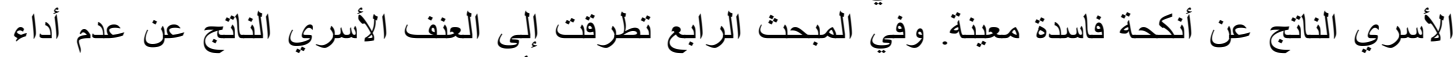

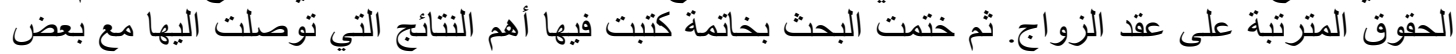
المقترحات. و الله ولي التوفيق عليق النقات 


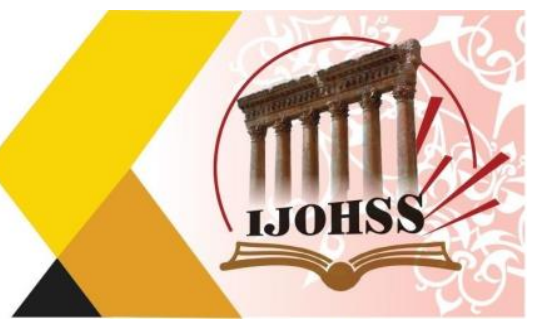

\section{المبحث الأول \\ ماهية فقه الأسرة والعنف الأسرى}

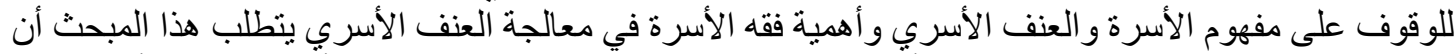

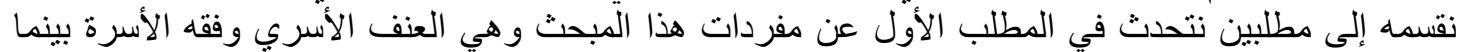
يتطرق المطلب الثاني إلى أهية دور فقه الأسرة في معالجة العنف الأسري.

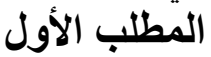

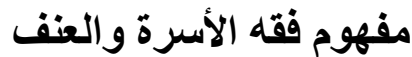

تعريف الفقه

الفقه: العلم بالثيء و الفهم له، والفقه في الأصل الفهم. يقال: أوتي فلان فقها في الدين أي فهما فيه. قال الله عز

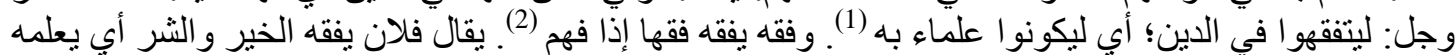

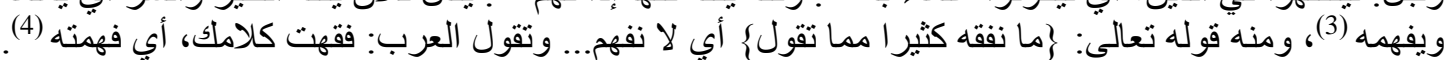
وفي معنى الفهم هنا عدة معان أحدها: مطلق الفهم. الثاني: فهم الأشياء الدقيقة. الثالث: فهم غرض الثالث المنكلم من كلاميه (5)

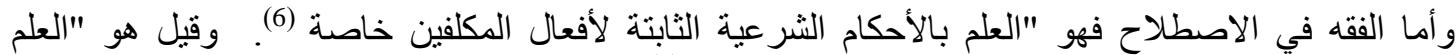

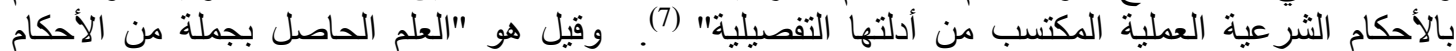

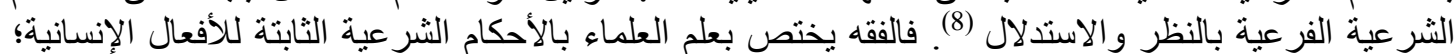

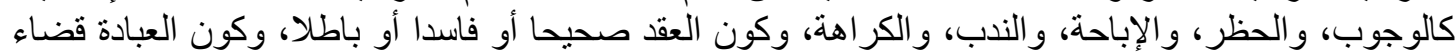

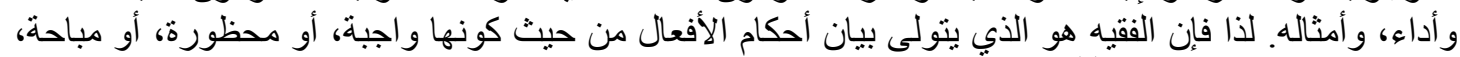

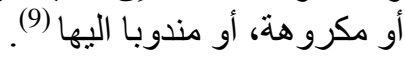

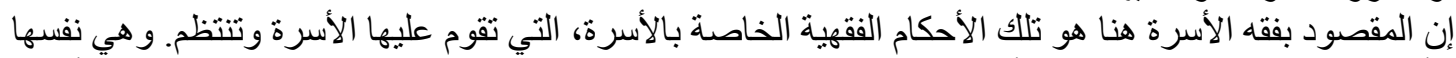

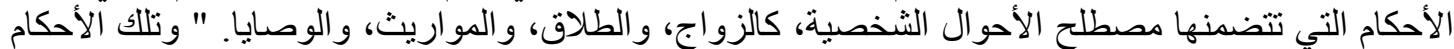

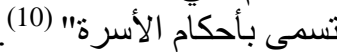

(1) محمد بن مكرم بن على، أبو الفضل، جمال الدين ابن منظور الأنصاري الرويفعى الإفريقي (المتوفى:

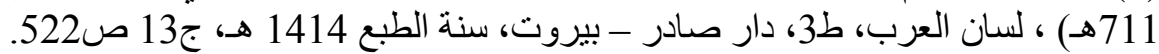

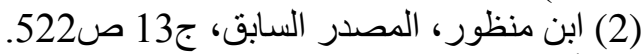
(3) أبو حامد محمد بن محمد الغز الّي الطوسي (المنوفى: 505هـ) ، المستصفى، تحقيق: محمد عبد السلام عبد (4) أبو الحسن سيد الألى الدين علي بن أبي علي بن محمد بن سالم الثُعلبي الآمدي (المتوفى: 631هـ) ، الإحكام في

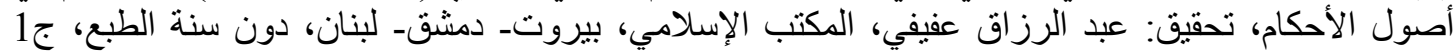

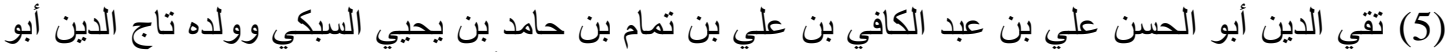

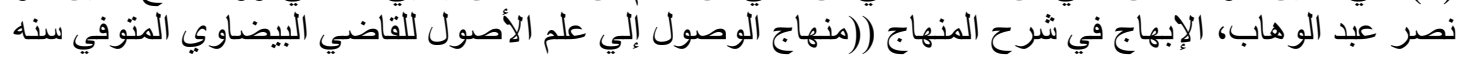

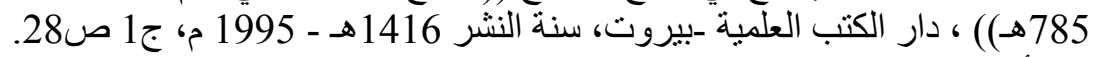

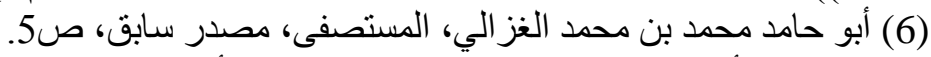

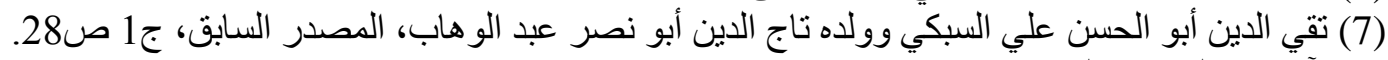

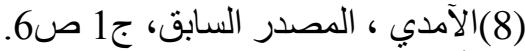

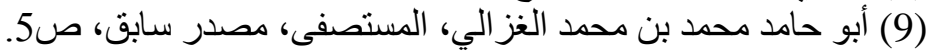
(10)ينظر محمد بن إبراهيم بن إن عبد الله التويجري، موسوعة الفقه الإسلامي، بيت الأفكار الدولية، الطبعة:

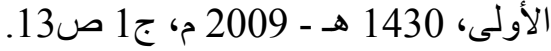




\section{المجلة الحولية اللهلور الأسانية والإمتهاعية}

International Journal of Humanities and Social Sciences website:www.ijohss.com Email:editor@ijohss.com مارس 2021 العداد (19) ISSN: $2415-4822$

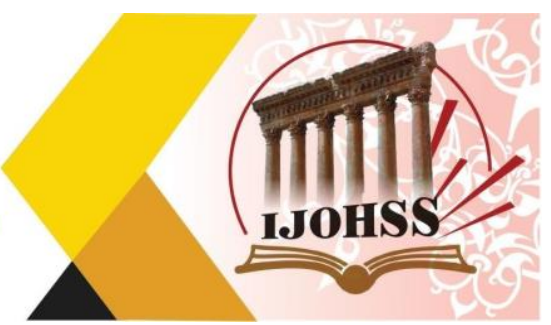

إن فقه الأسرة وأحكامها أو الأحوال الثخصية مصطلح حديث، ينظم العلاقات بين أفراد الأسرة الواحدة. وقد

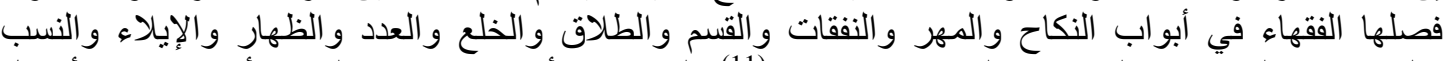

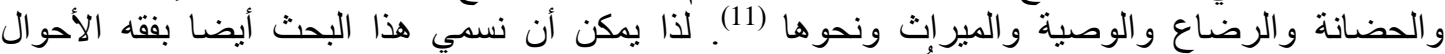

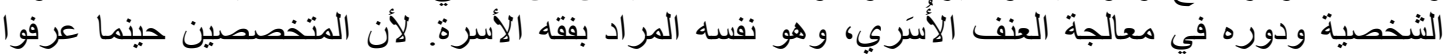

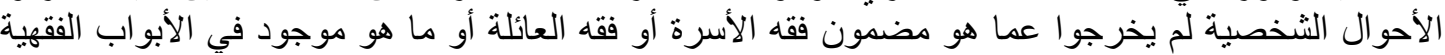

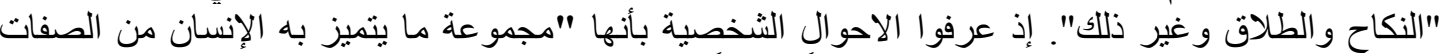

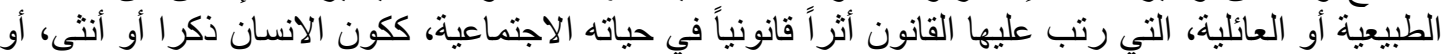

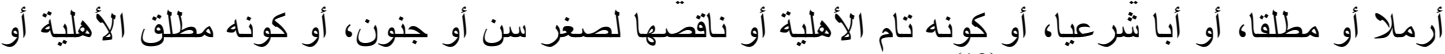
مقيد ها بسبب من أسبابها القانونية" (12). فققه الأسرة هو: الأحكام الثر عية الخاصة بالأسرة بدءا من تكوينها ومرور ا باستمر اريتها وتوسيعها وتفريعاتها، و انتهاء بانتهائها وما يترتب على الألى انتهائها من آثار.

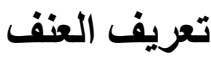

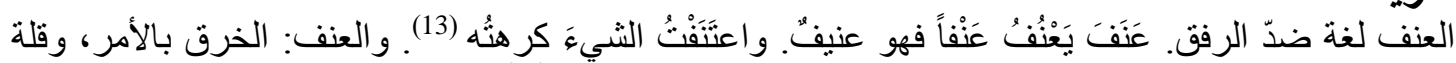

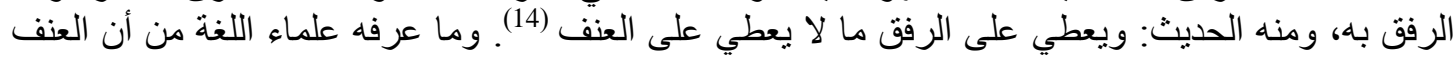

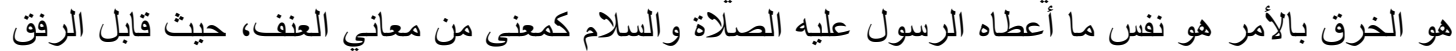

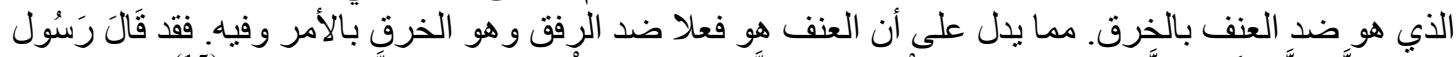

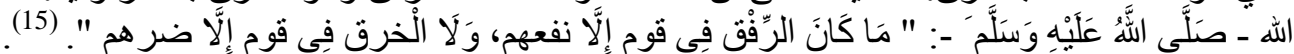

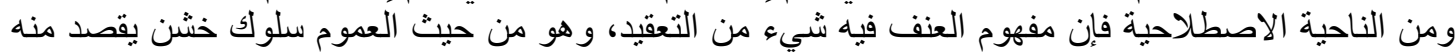
إيذاء الغير دون وجه حق و وقد يكون فعلا أو امتناعا عنه.

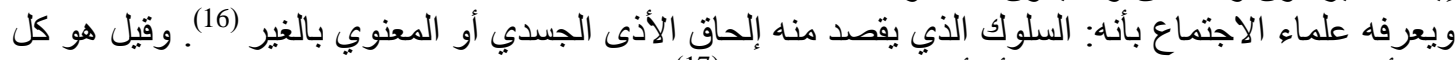

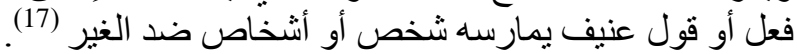

(11) وزارة الأوقاف و الثئون الإسلامية ـ الكويت، الموسوعة الفقهية الكويتية، الطبعة: (من 1404 - 1427

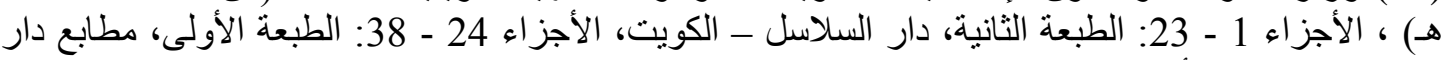

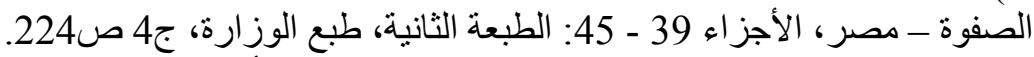

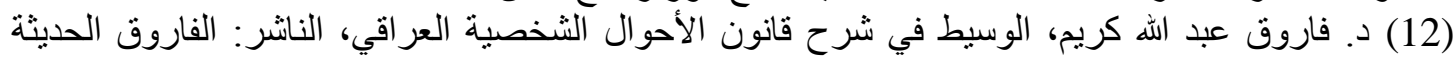

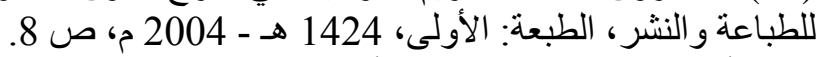

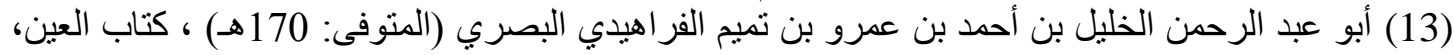

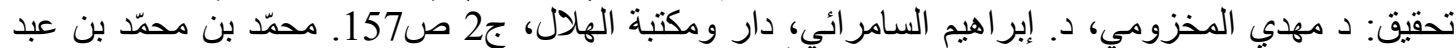

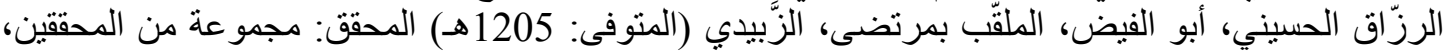

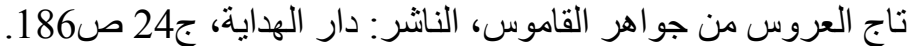

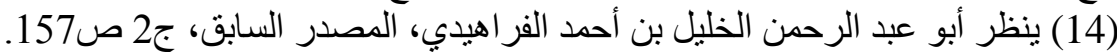

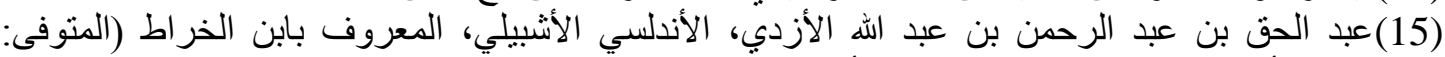

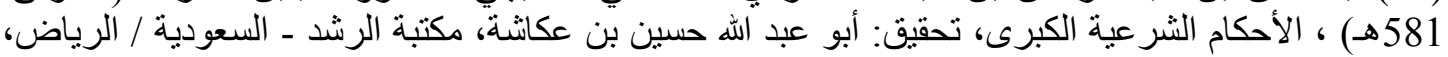

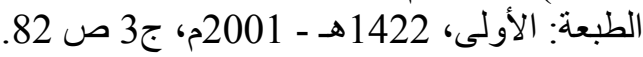
(16) ينظر دليلة بو جمعة، العنف الجسدي ضد صد المر أة في المجال الأسري دراسة حالة لعينة من النساء

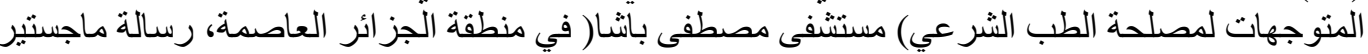

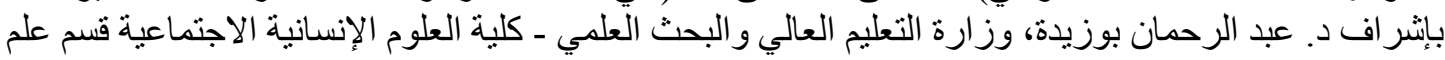

Ronald H. Bailey: Violence et agression, édition الاجتماع.

Time Life, Paris, 1977, p 10. 


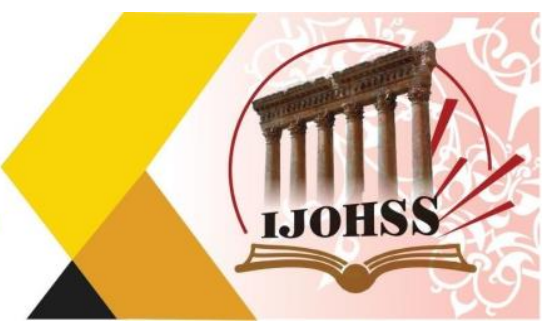

وقيل هو "القوة التي يستخدمها شخص ما لإجبار غيره على عمل ما، سواء أكانت القوة فعلا ماديا أو ضغطا

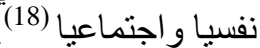

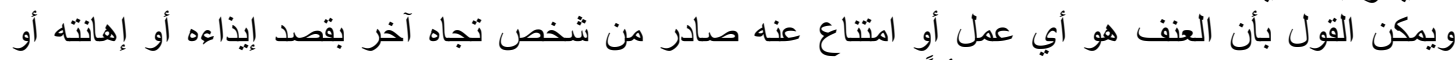
الإضر ار بما يخصه ويلحق الضرن الضر به أياً كانت الوسيلة. تعريف الأسرة الأسرة: بالضم: الدرع الحصين، والأسرة من الرجل: الرهط الأدنون و عشيرته، والأسرة، أقارب الرجل من قبل أبيه (19)

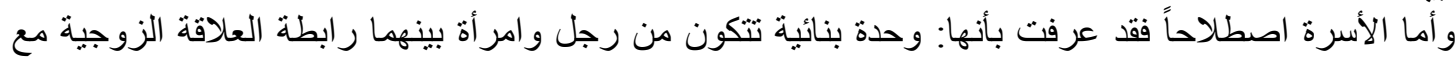

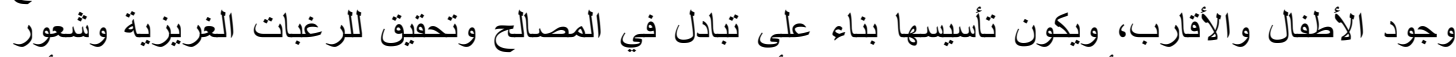

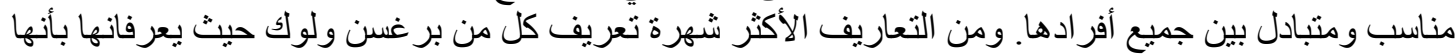

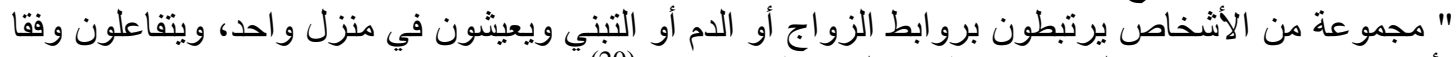

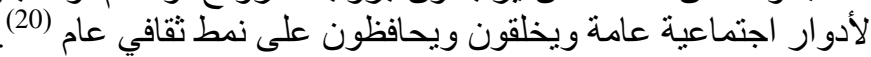

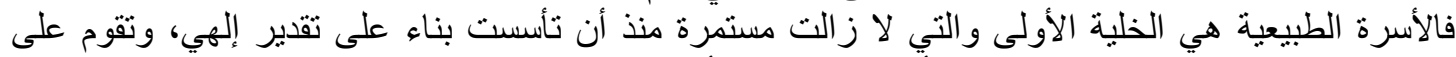

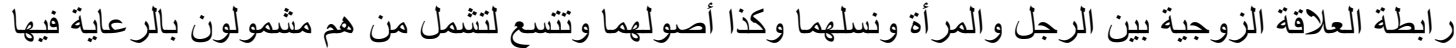

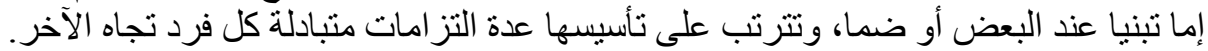

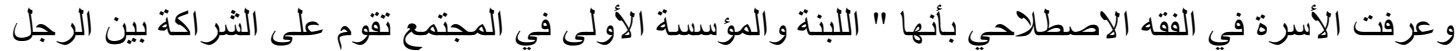

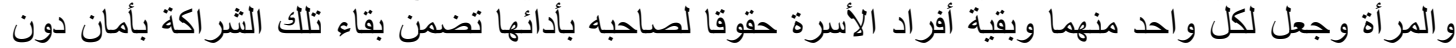
تهديد لاعائمها سو اء من الداخل وأم أم من الخارج (21).

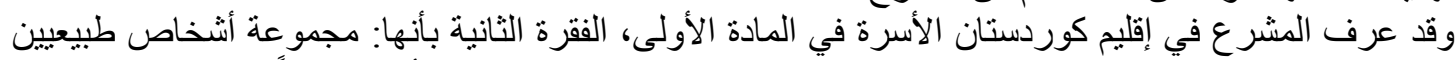

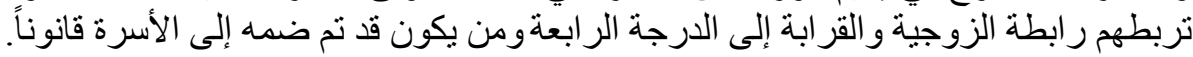

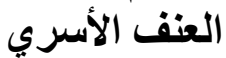

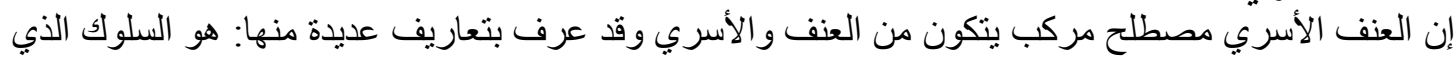

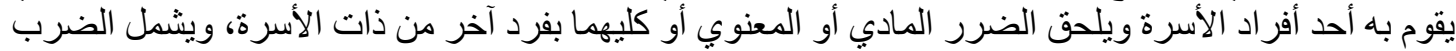

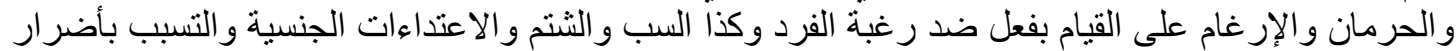
جسدية أو نفسية أو كليهما.

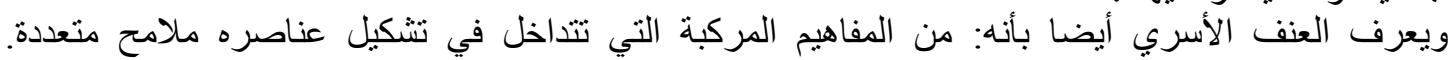

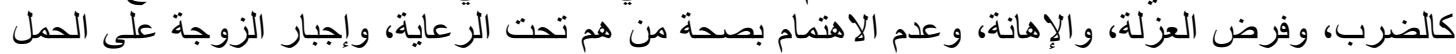

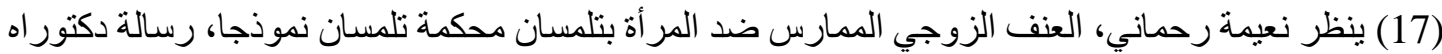
مقدمة إلى كلية العلوم الإنسانية و الاجتماعية - جامعة أبي بكر بلقايد ـ تامسان، بإنشر اف الدكتورة مليكة بن بن

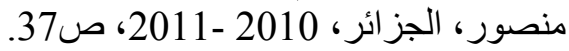
(18) ينظر العقبد د. نايف بن محمد المرواني، العنف الأسري در اسة مسحية تحليلية في منطقة المدينة المنورة،

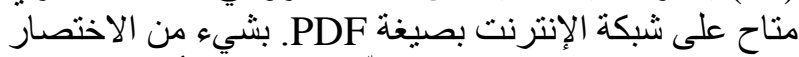

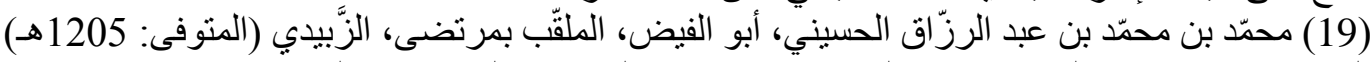

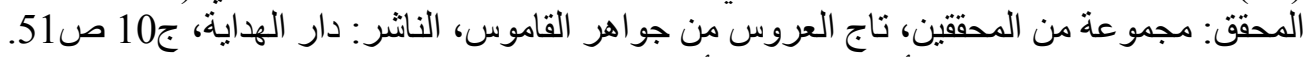

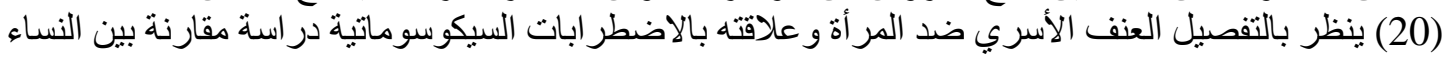

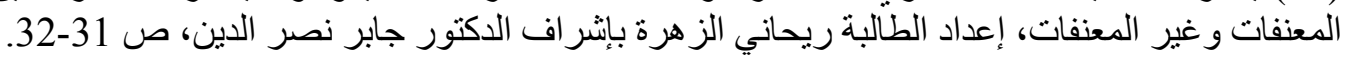

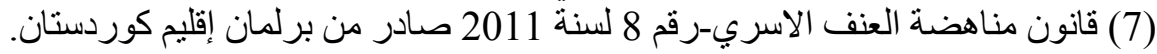

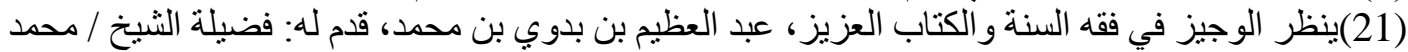
صفوت نور الدين وآخرون، دار ابن رجب ـ مصر ، الطبعة: الثالثة، 1421 هـ - 2001 م. ص: صني 299. 


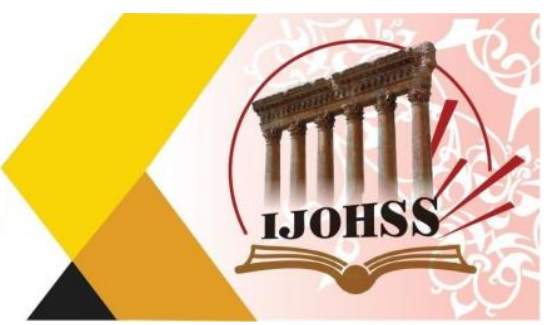

دون الأخذ بنظر الاعتبار قدرتها وصلاحيتها للحمل و الانجاب، وكذا كل أنواع المعاملة السيئة والقاسية وغير ها

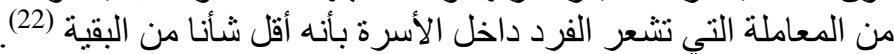

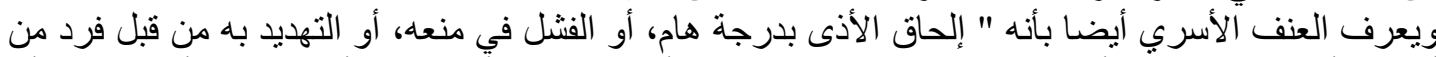

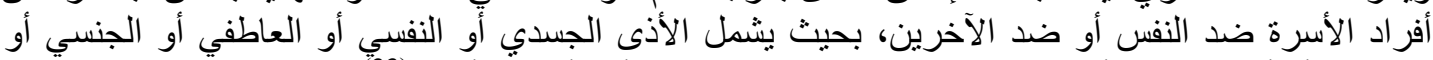

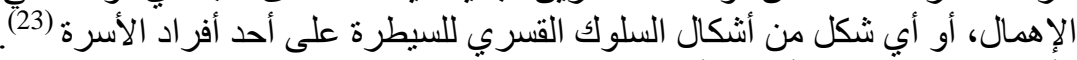

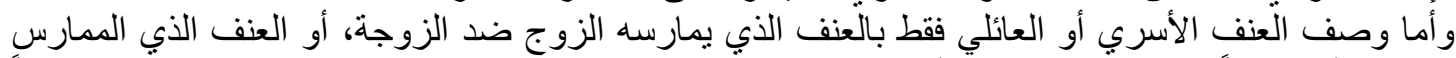

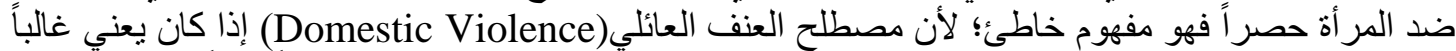

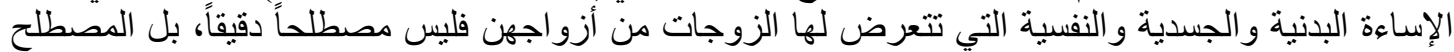

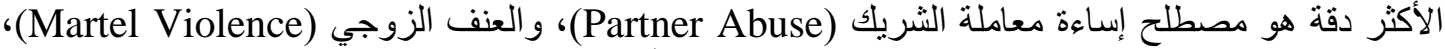

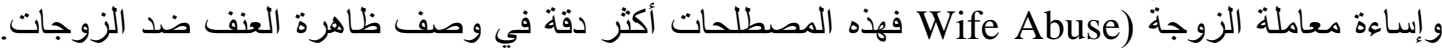

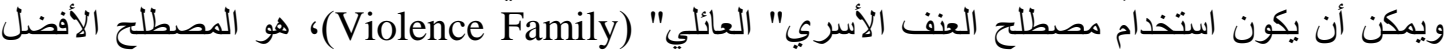

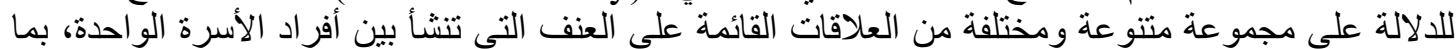

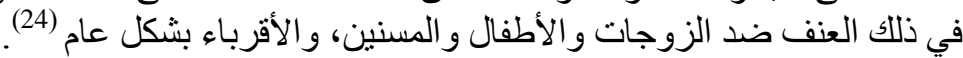

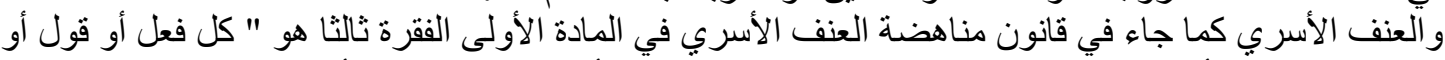

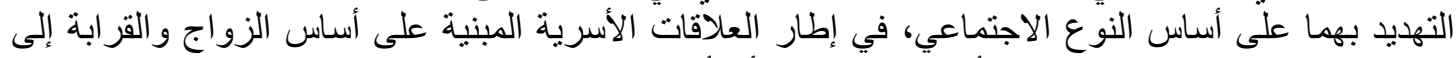

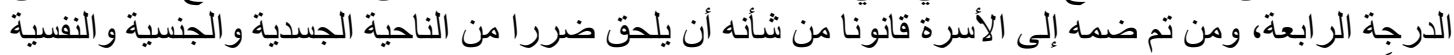

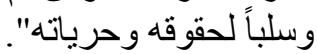

\section{أهمية فقه الأسرة في معالجة المطبّ العنف الأسري}

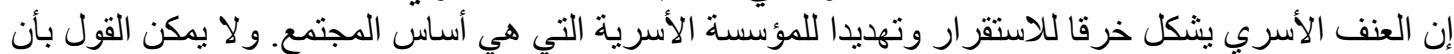

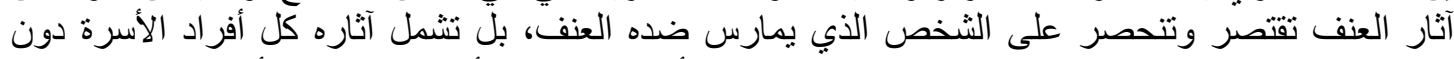

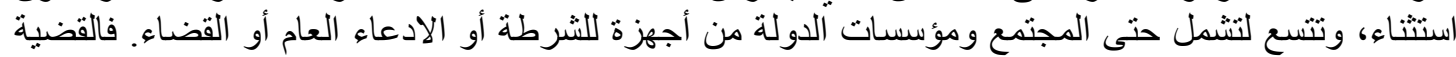

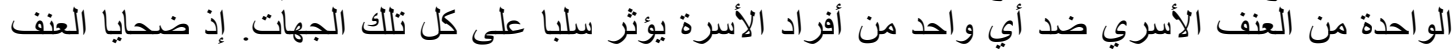

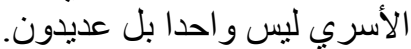

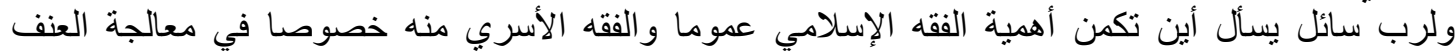

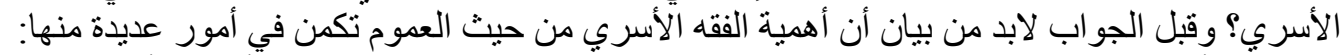

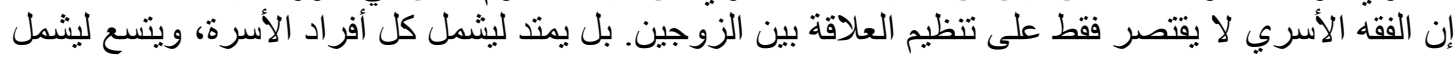

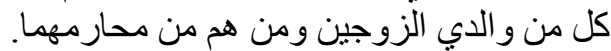

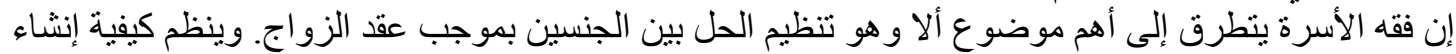

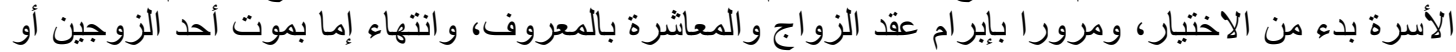

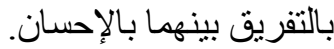

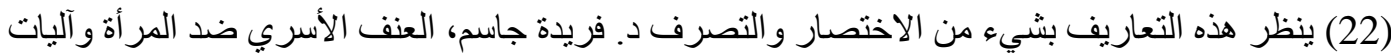

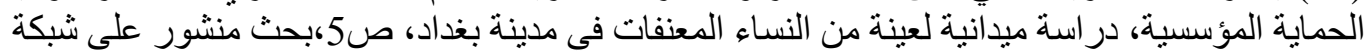
الإنترنت بصيغة pdf على الموقع التالي http://iwsaw.lau.edu.lb/files/Faridajassem2.pdf

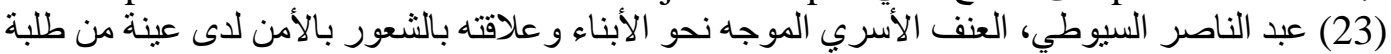

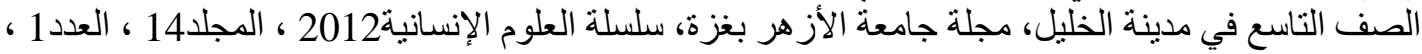

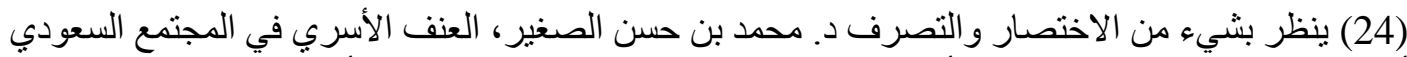

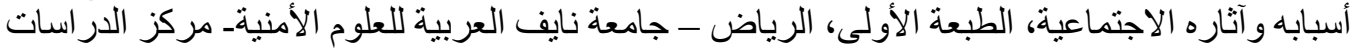

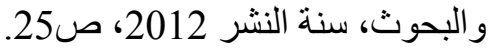




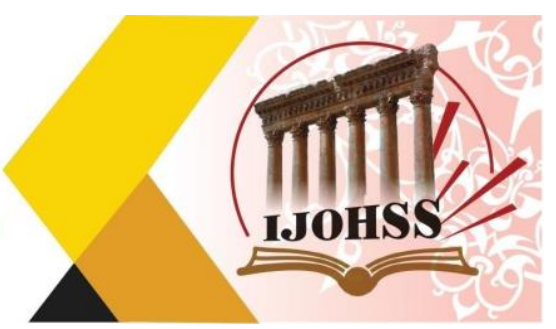

إنه يتطرق تفصيلا إلى كل تلاك الحقوق و الآثار المثرتبة على عقد الزواج وما يجب الإب على كل واحد من الزوجين

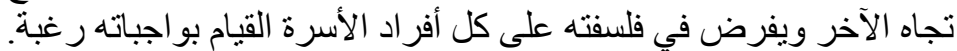

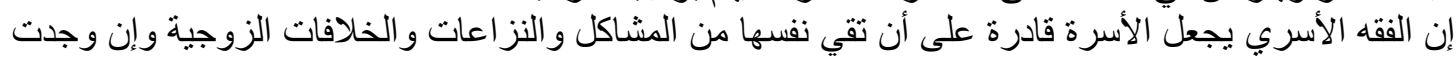

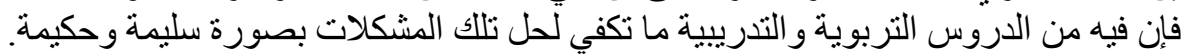

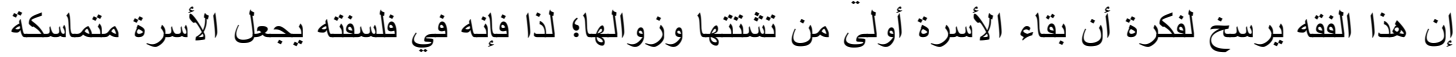

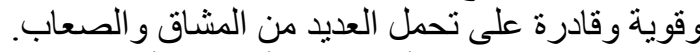

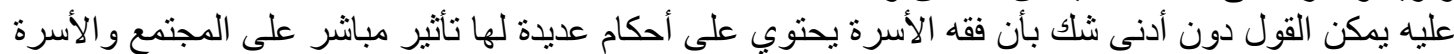

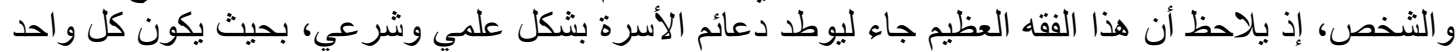

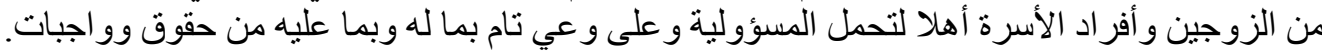

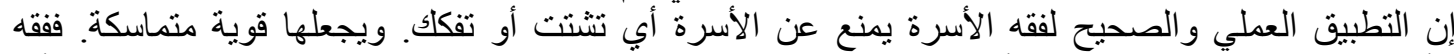

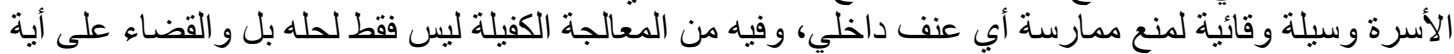

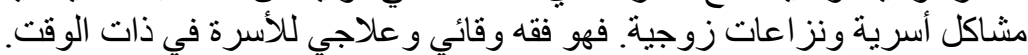

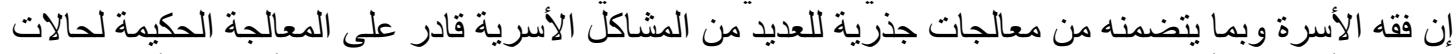

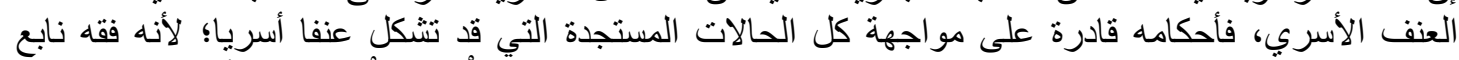

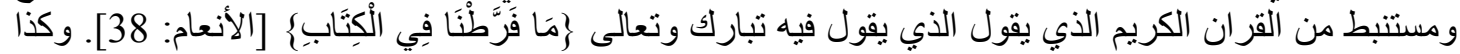
من السنة النبوية الثريفة. عليه فإن المشرع في إقليم كوردستان وهو يعالج مسألة العنف الأسري لم يجد بدا من الاستعانة بما هو موجود في في الإني

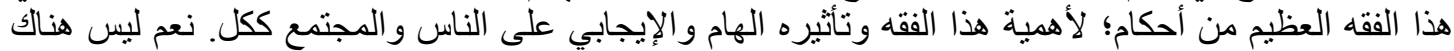

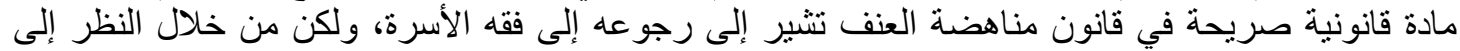

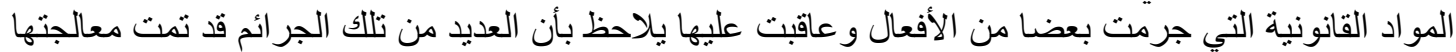

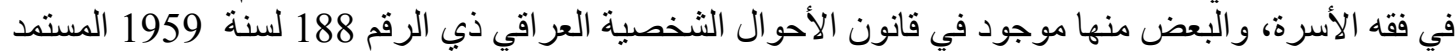

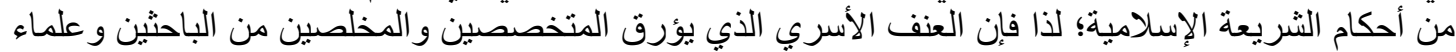

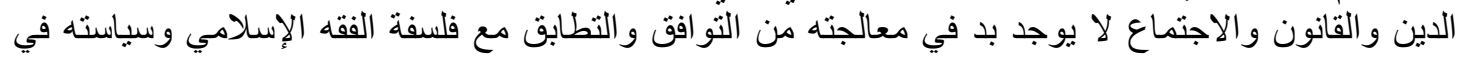

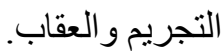
إن النص على تجريم فعل بكون التزام ام الناس به أسر ع و أكثر لو علمو ا بأنه محرم أساسا في الثربعة الإسلامية،

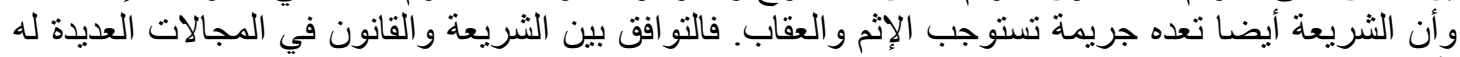

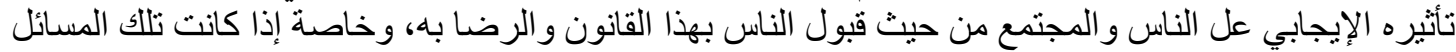
متعلقة بالعلاقات الأسرية.

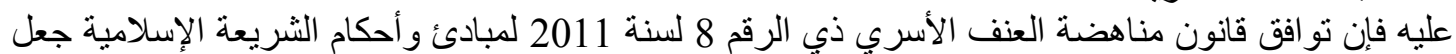

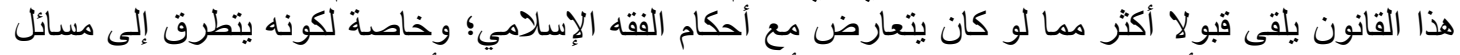

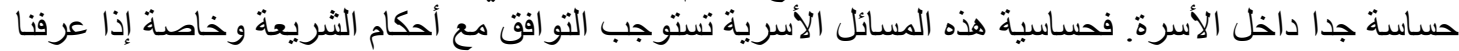

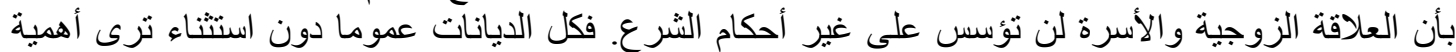
دور أحكام الدين في تأسيس الأسرة التبداء وان وانتهاء.

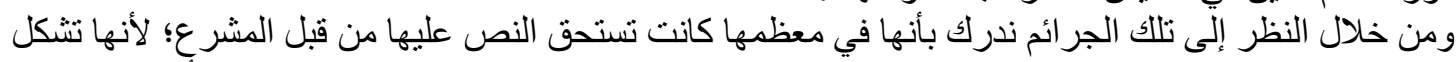

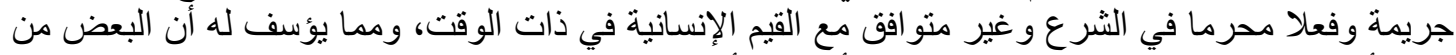

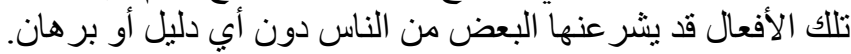

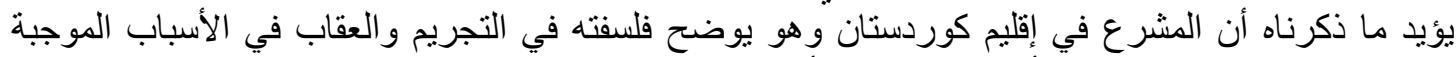

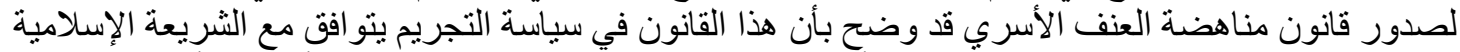

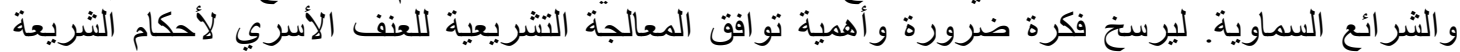

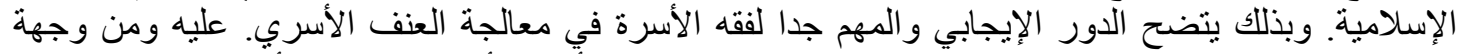

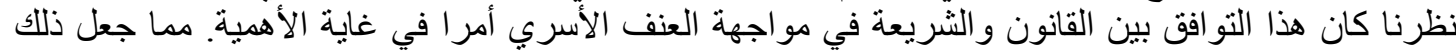

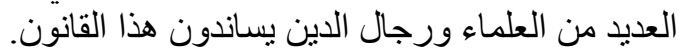




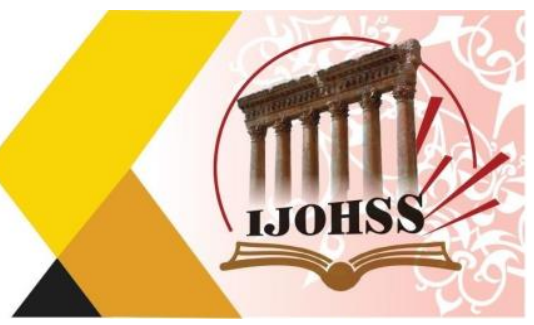

\section{المبحث الثناني

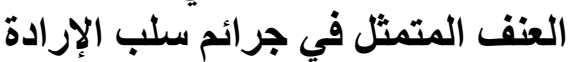

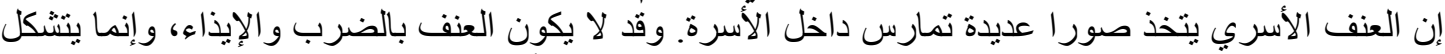

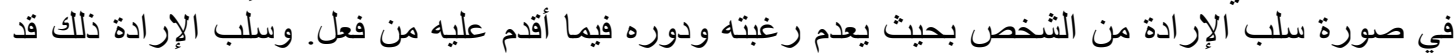

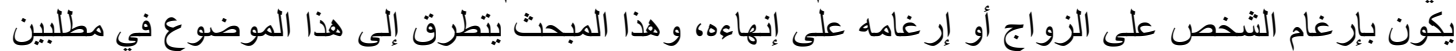

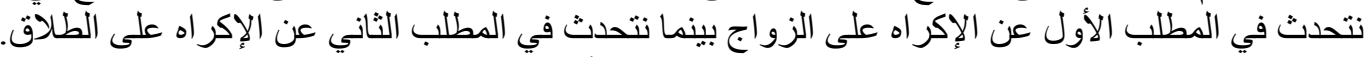

$$
\begin{aligned}
& \text { المطلب الأول } \\
& \text { الإكراه على الزواج }
\end{aligned}
$$

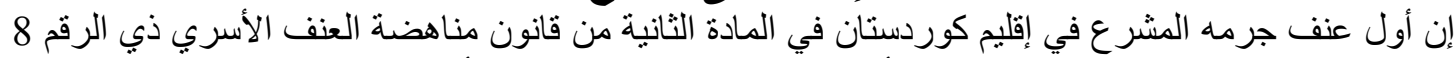

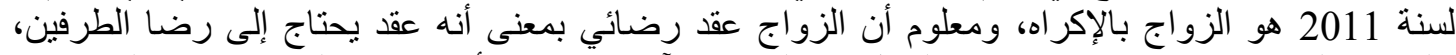

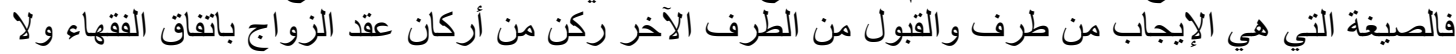

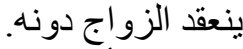

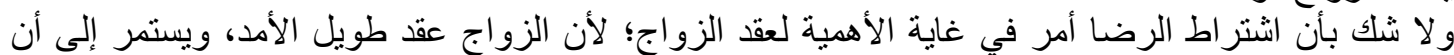

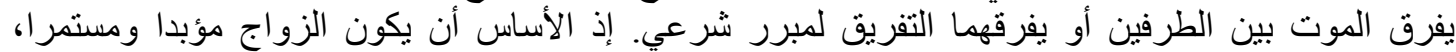

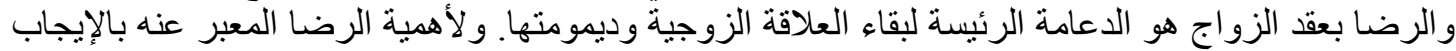

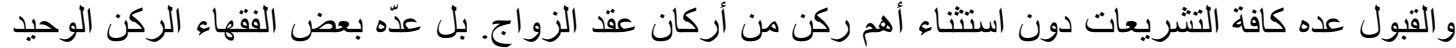

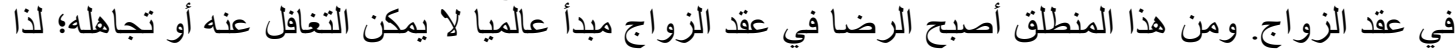

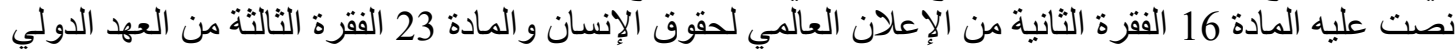

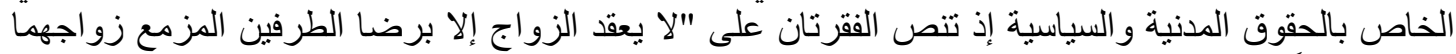

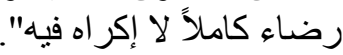

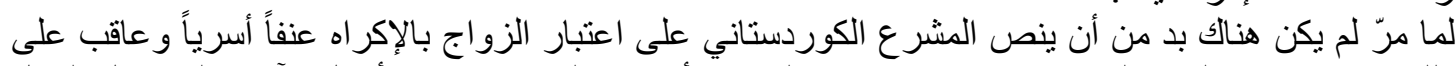

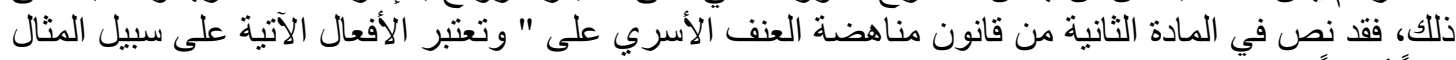

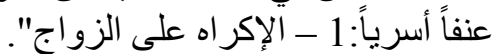

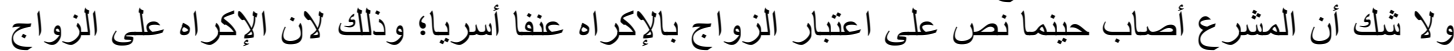

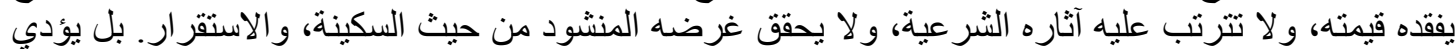

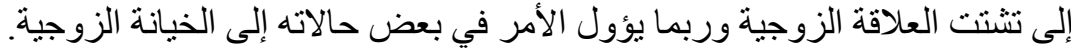

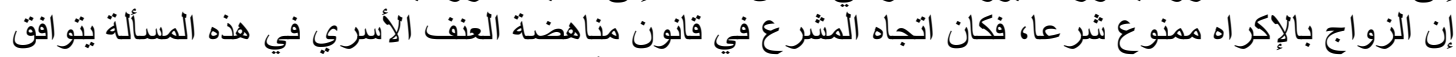

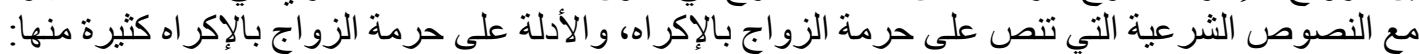

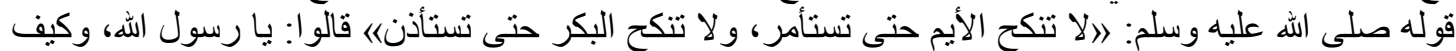

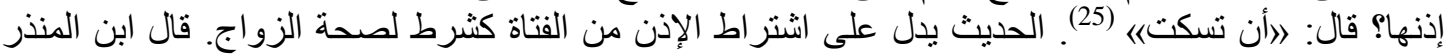

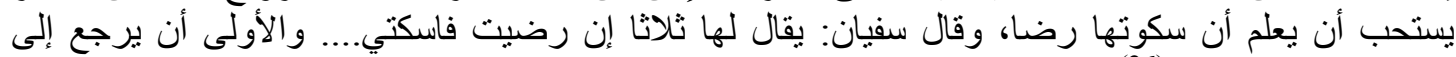

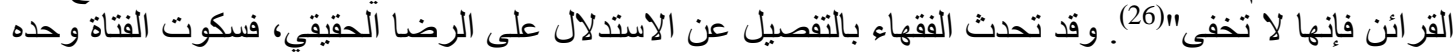

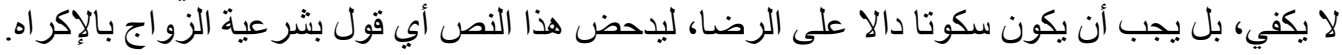

(25) صحيح البخاري (7/ 17). المسند الصحيح المختصر بنقل العدل عن العدل إلى رسول الله صلى الله عليه وسلم، مسلم بن الحجاج أبو الحسن القتنيري النيسابوري (المنوفى: 261هـ)، المحقق: محمد فؤاد عبد النيد الباقي،

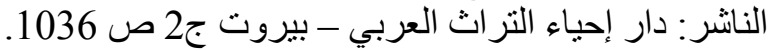

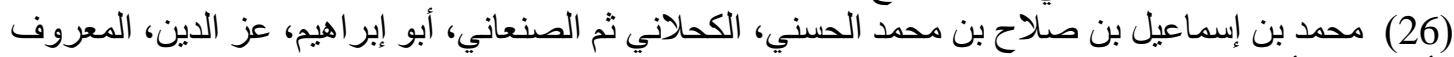

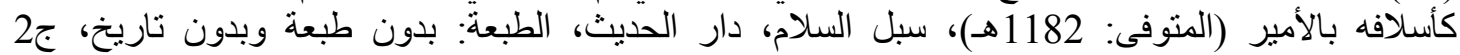




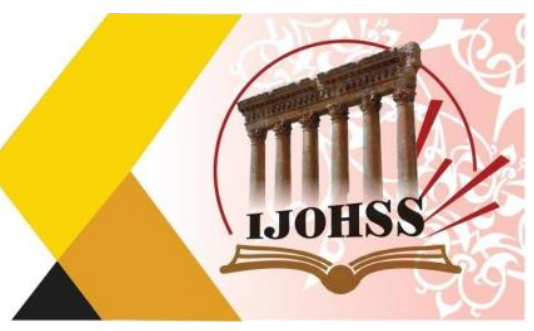

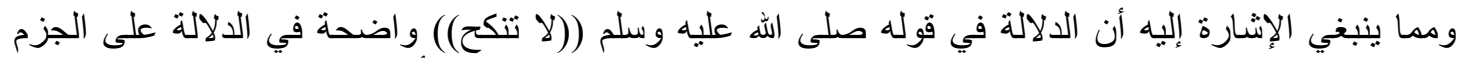

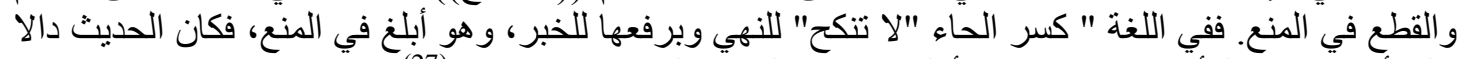

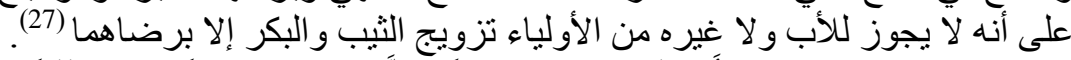

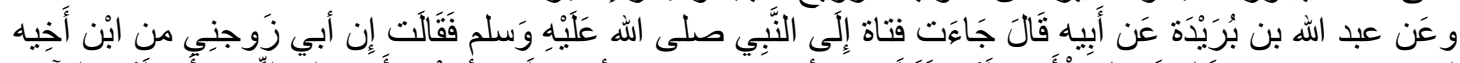

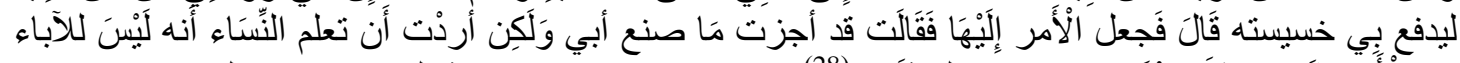

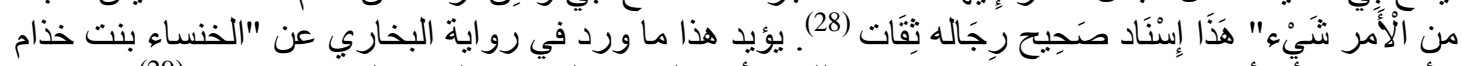

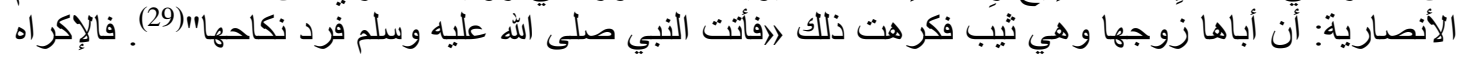

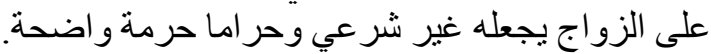

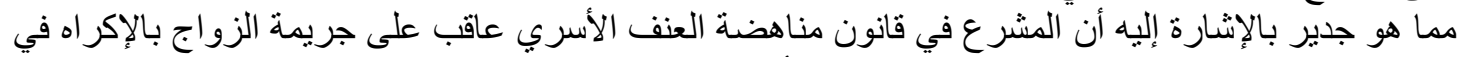

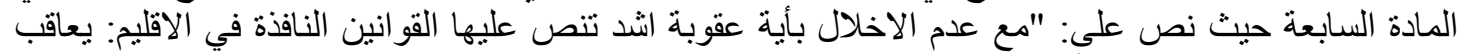

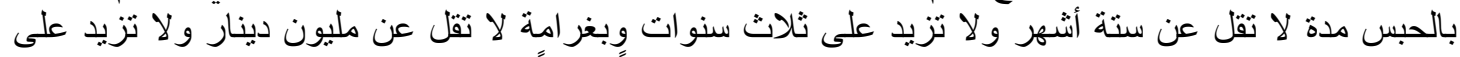

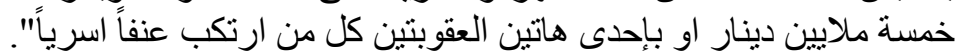

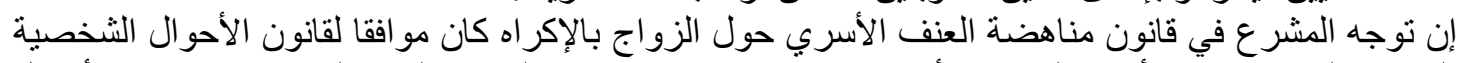

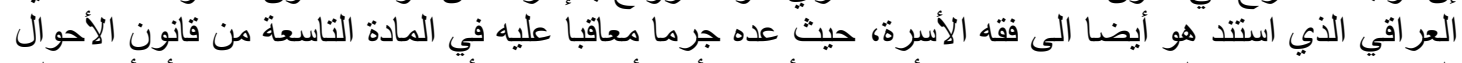

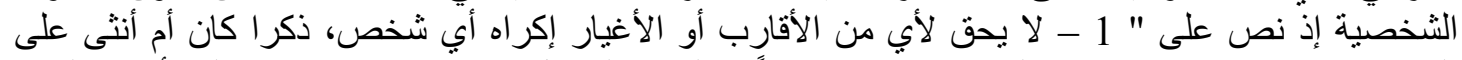

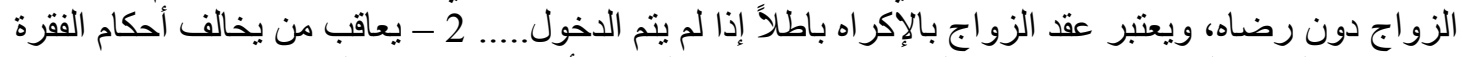

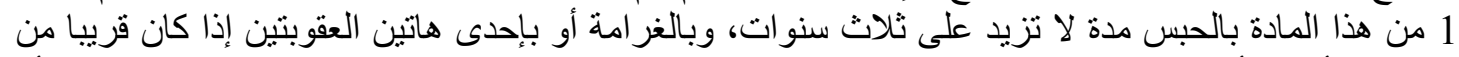

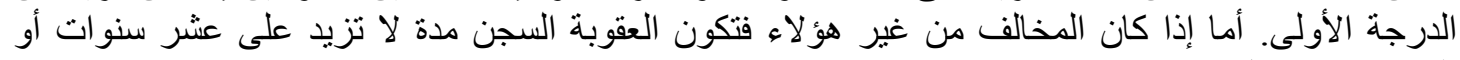

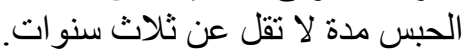

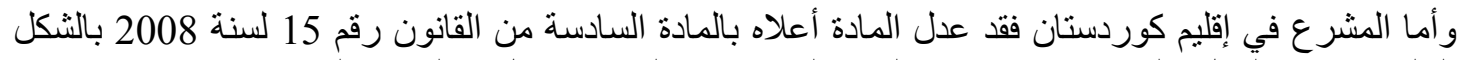

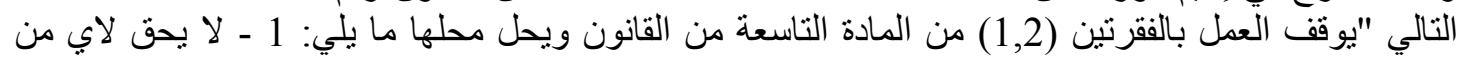

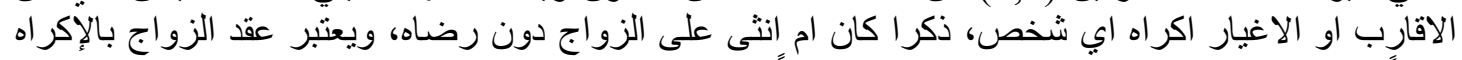

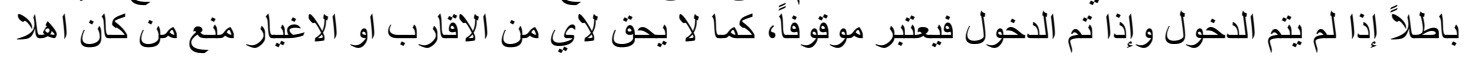

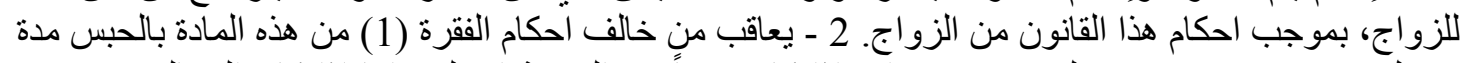

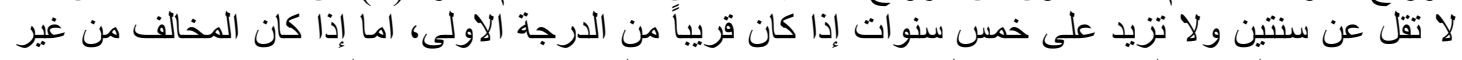

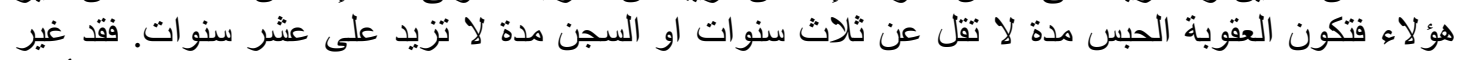

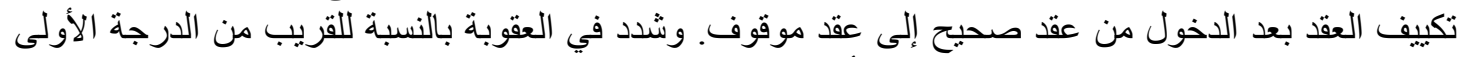

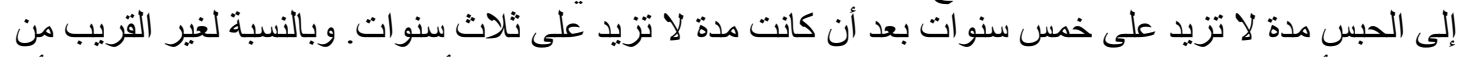

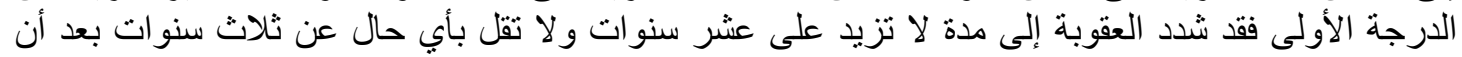

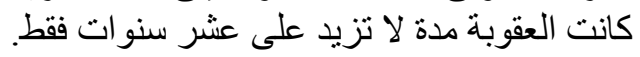

(27) ينظر فيصل بن عبد العزيز بن فيصل ابن حمد المبارك الحريملي النجدي (المتوفى: 1376هـ)، خلاصة

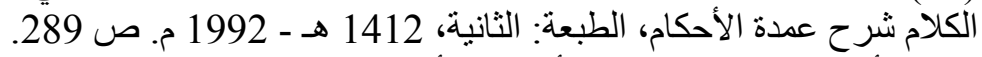

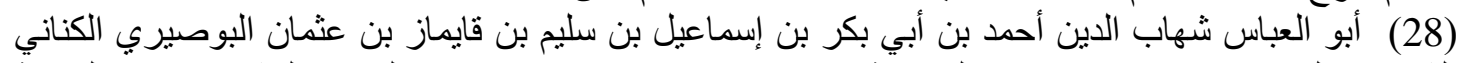

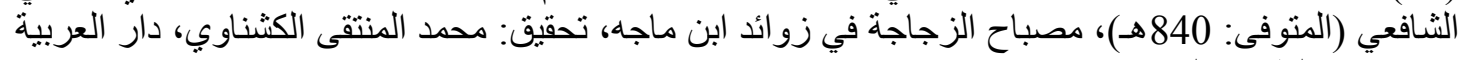

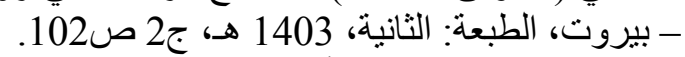

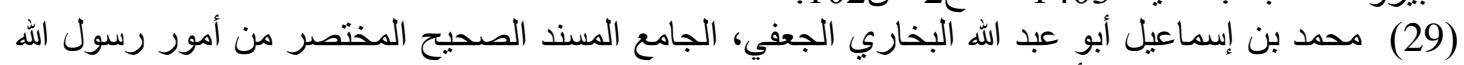

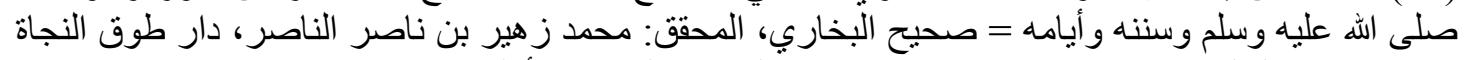

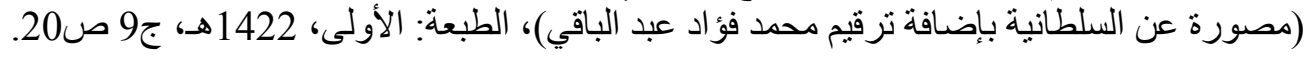




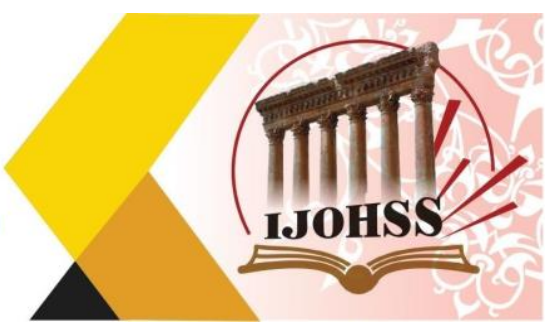

$$
\text { الطلاق بالإكراهي الثطاه }
$$

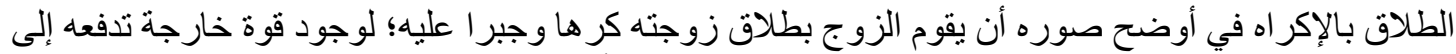

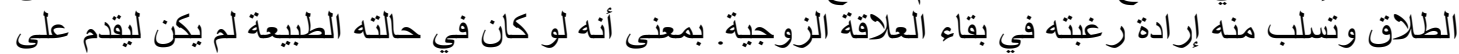

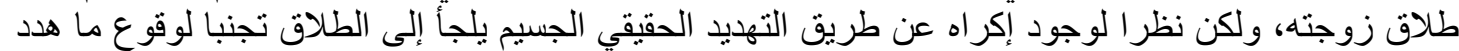

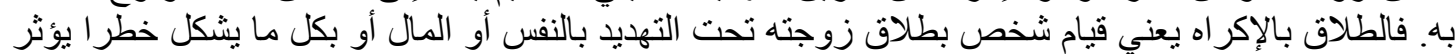

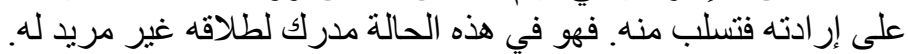

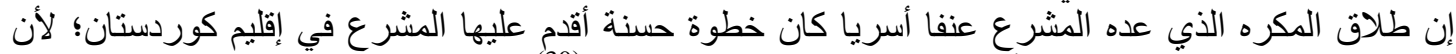

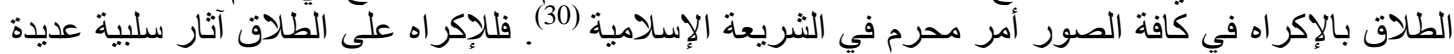
على الثخص و على الأسرة والمجتمع. فوجود حالات الإلىر الإكراه على الطلاق يعني في أبسط حالاته تهديدا

ل إستقر ار الأسري و المجتمعي.

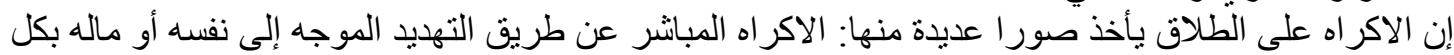

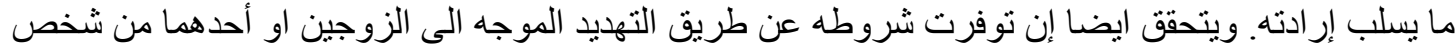

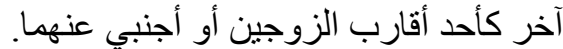

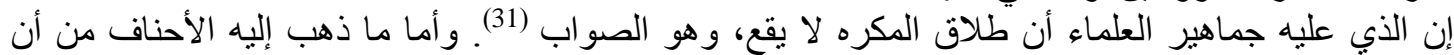

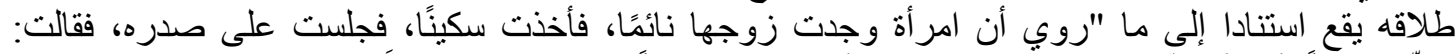

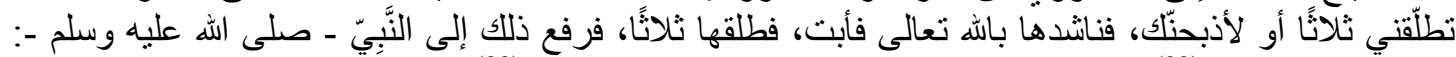

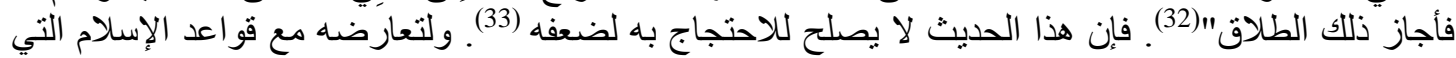

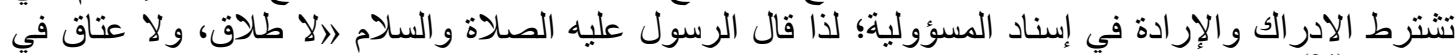

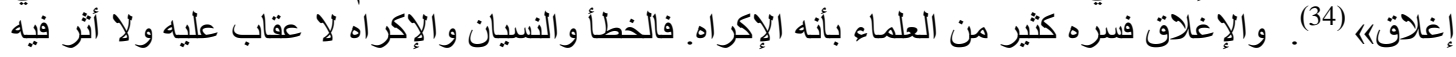

(30) هناك حالات أخرى يجبر فيها الزوج على الطلاق و إن لم بطلق الزوج تطلق زوجته جبر الزبل عليه، كما في

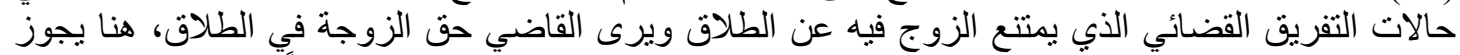

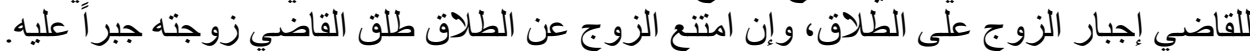

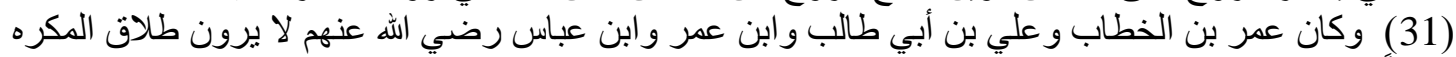

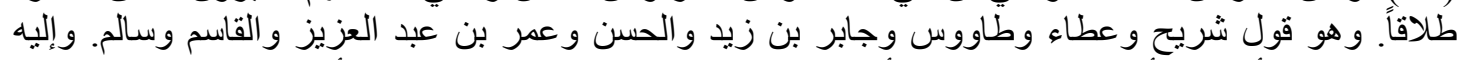

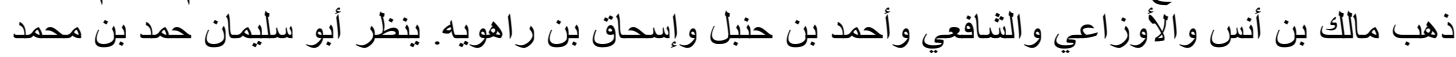

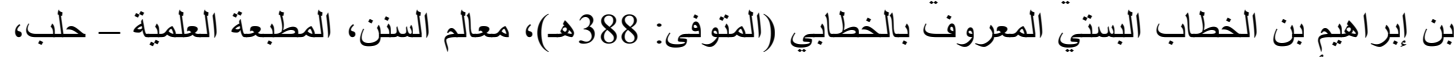

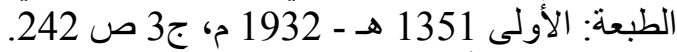
(32) جار الله أبو القاسم محمود بن عمر الزمخشري (467 هـ - 538 هـ)، رؤوس المسائل 》المسائل الخلافية

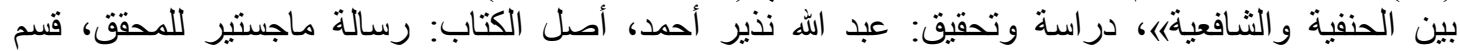

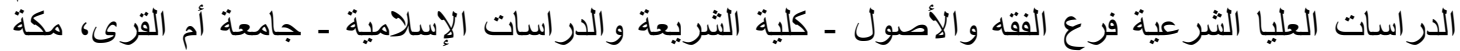

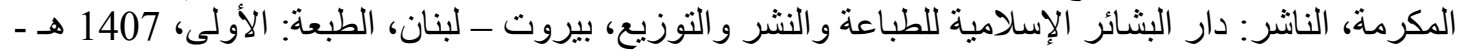

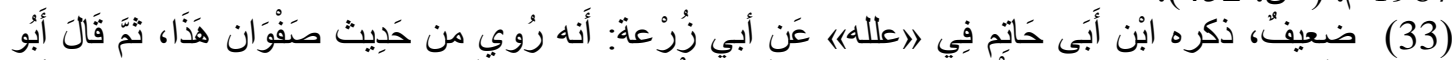

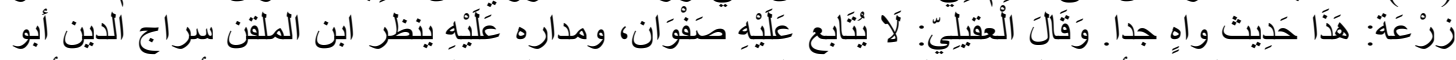

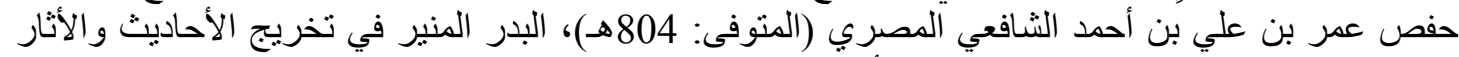

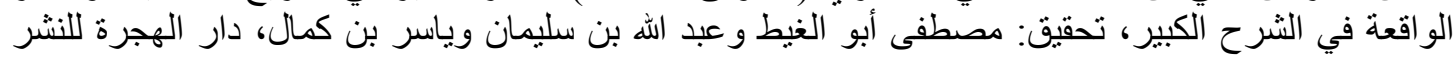

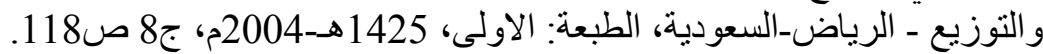

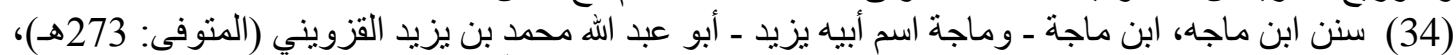

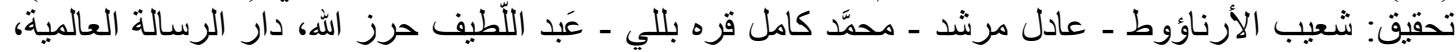

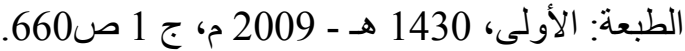




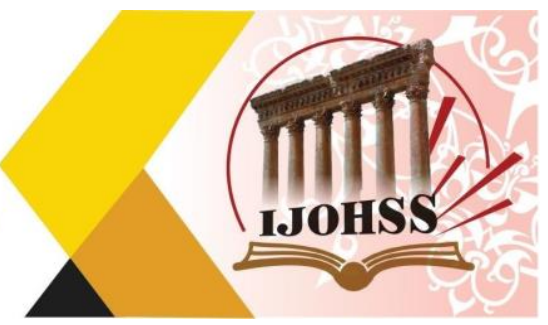

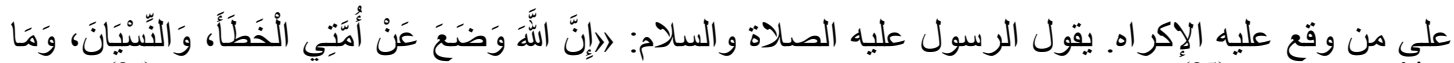

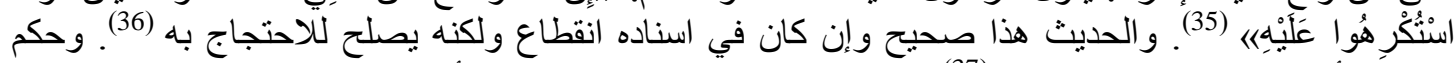
الثيخ الألباني بصحة هذائه الحديث (37). وهو من حيث العموم يتو افق مع أسس المسؤولية في الفلسفة والفقه الإسلامي.

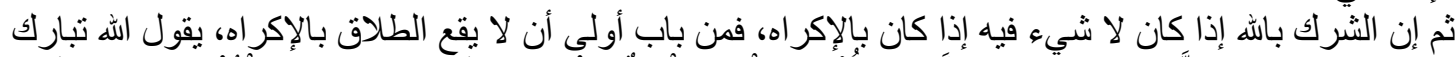

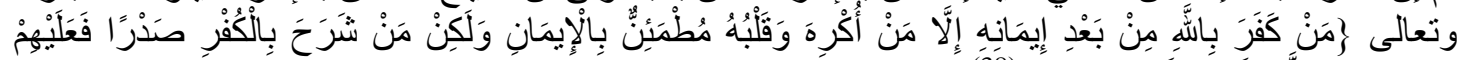

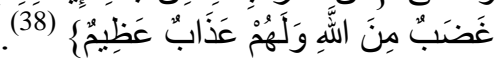

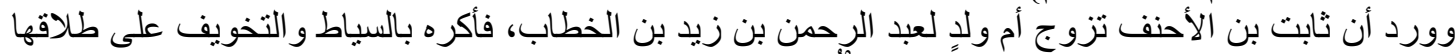

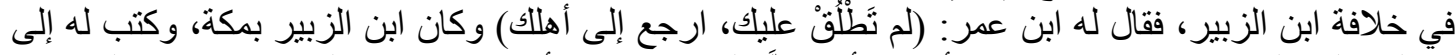

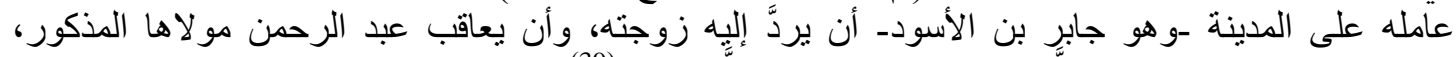

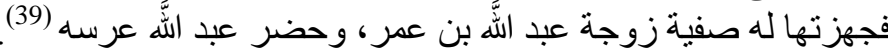

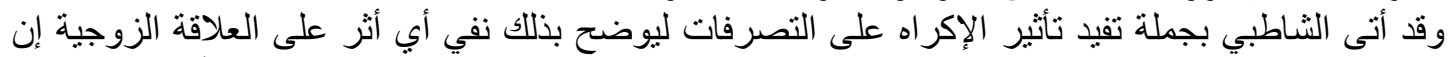

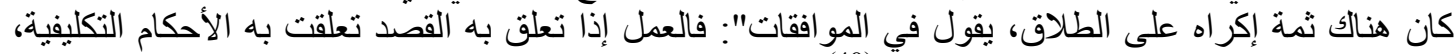

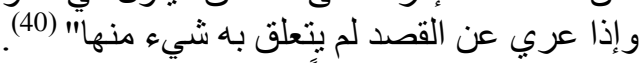

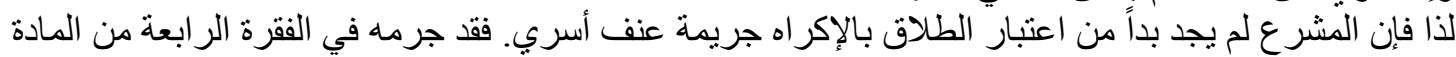

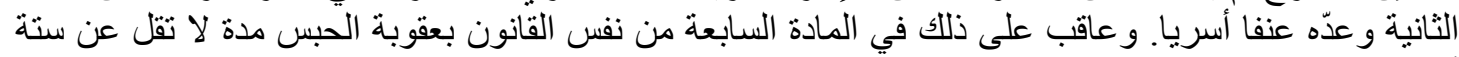

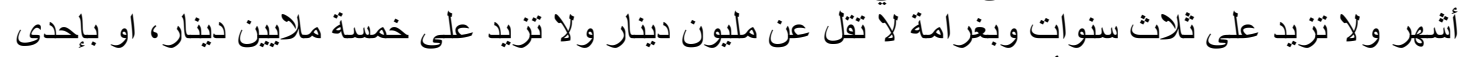

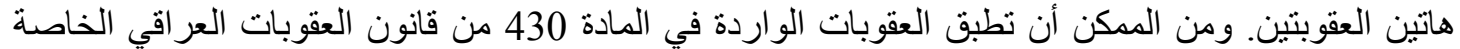

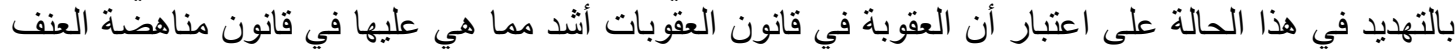

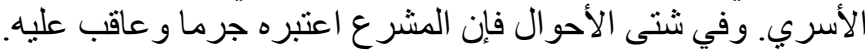

\section{المبحث الثالث المبر

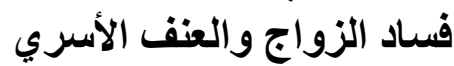

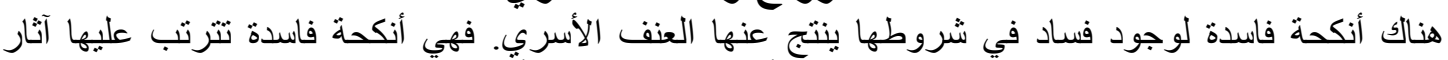

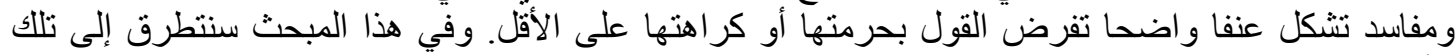

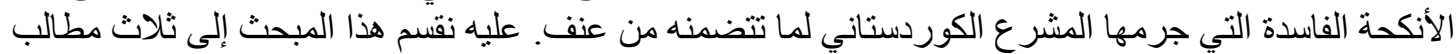

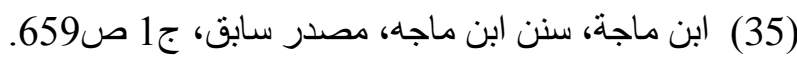

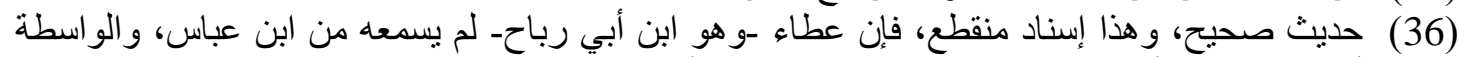

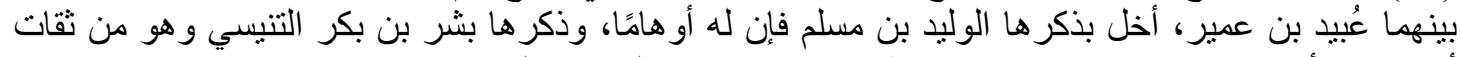

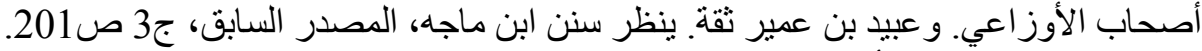

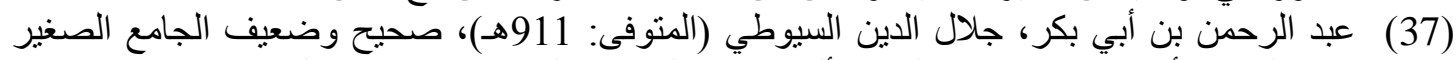

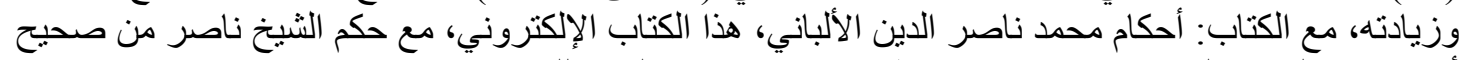

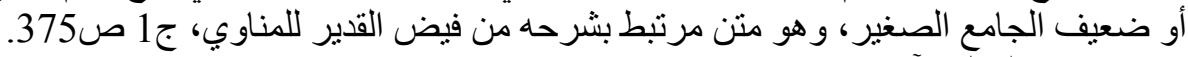

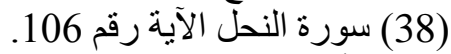

(39) أحمد بن محمد بن علي بن حجر الهين الهيتمي السعدي الأنصاري، شهاب الدين شيخ الإسلام، أبو العباس

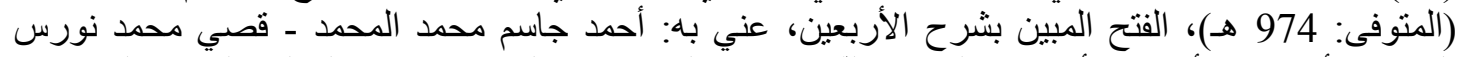

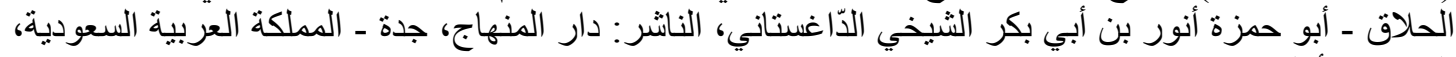

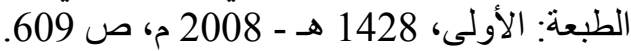

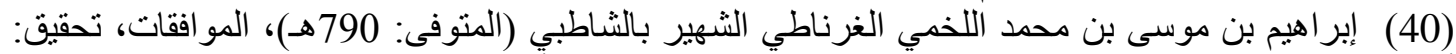

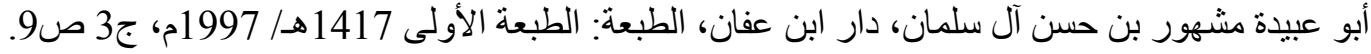




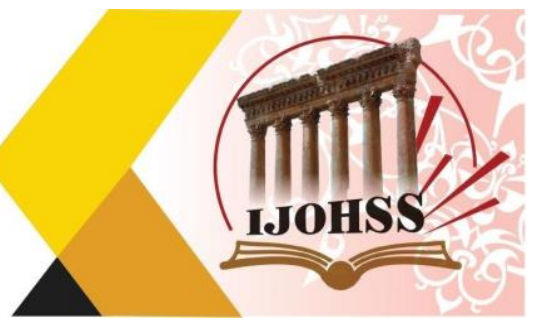

نخصص المطلب الأول لنكاح الثغار بينما نخصص المطلب الثاني لزو اج الصغار وأما المطلب الثالث فسنتطرق المطلب الأول فيه إلى التزويج بدلاً عن الدية الإول

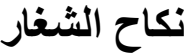

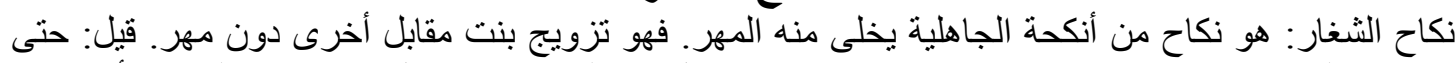

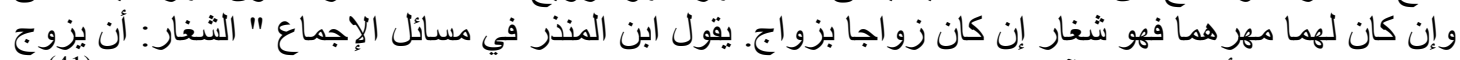

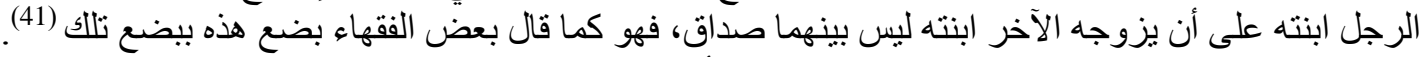

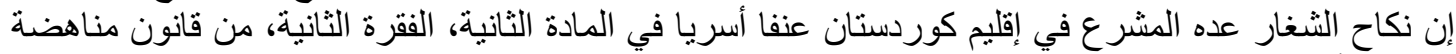

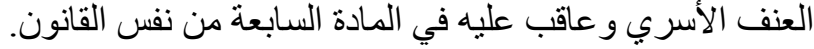

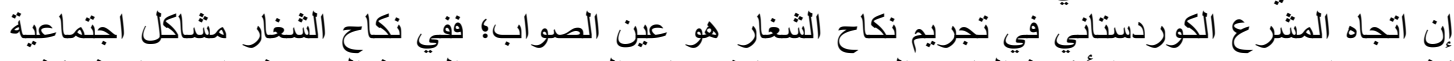

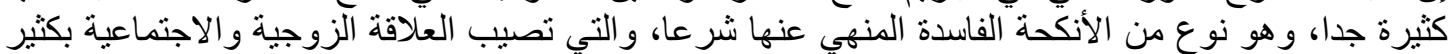

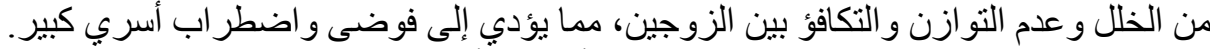

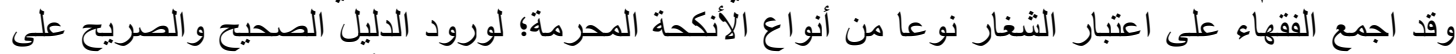

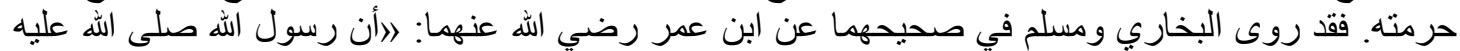

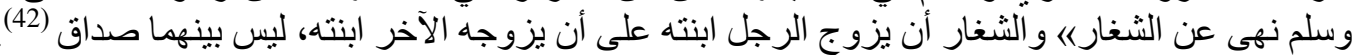

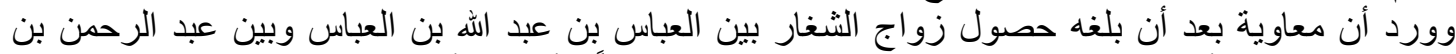

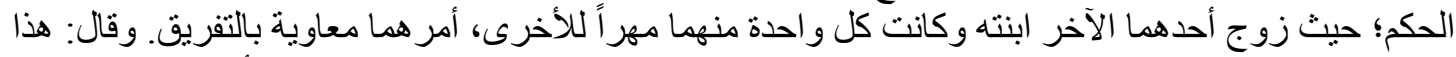

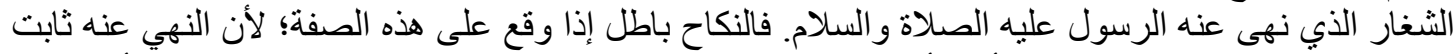

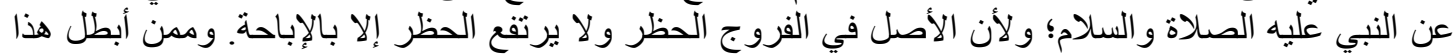

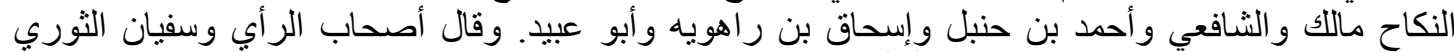

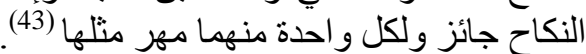

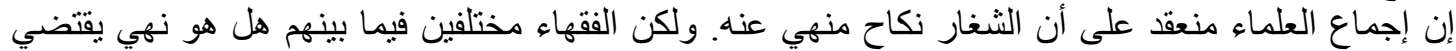

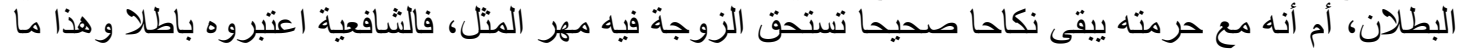

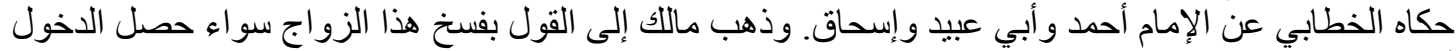

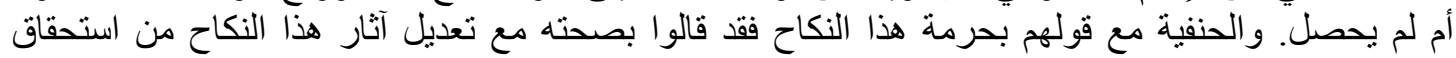

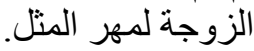

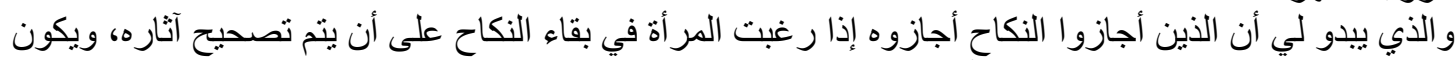

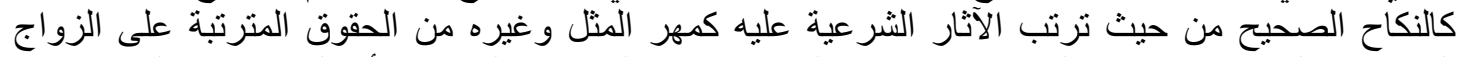

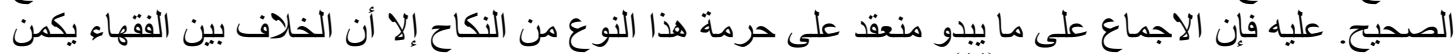
فيما يترتب على هذا النكاح من آنثار (44).

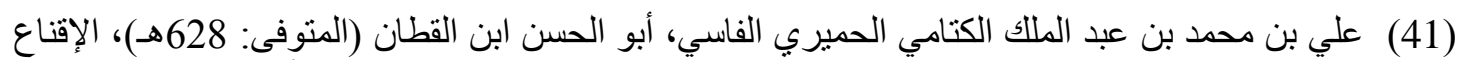

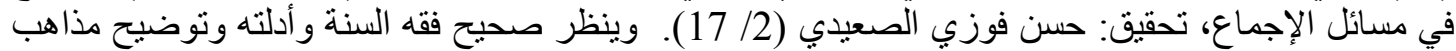

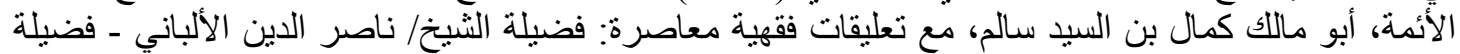

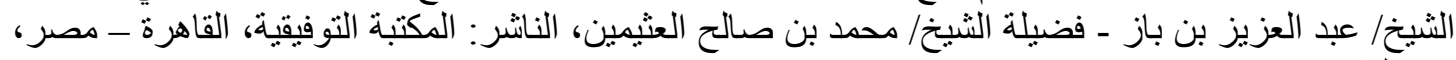

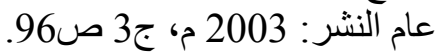

(42) البخاري ، صحيح البخاري، مصدر سابق، ج7 ص12034. الامام مسلم، صحيح مسلم، مصدر سابق، ج2

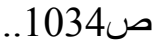

(43) ينظر أبو سليمان حمد بن محمد بن إبر اهيم بن الخطاب البستي المعروف بالخطابي، المصدر السابق، ج3 .192 صن

(44) ينظر أبو زكريا محيي الدين يحيى بن شرف النووي (المتوفى: 676هـ)، المنهاج شرح صحيح مسلم بن النيان

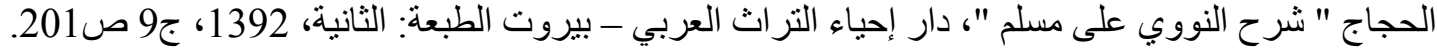




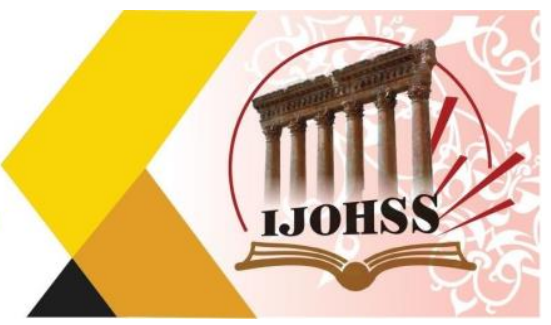

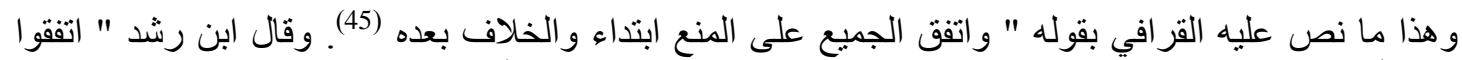

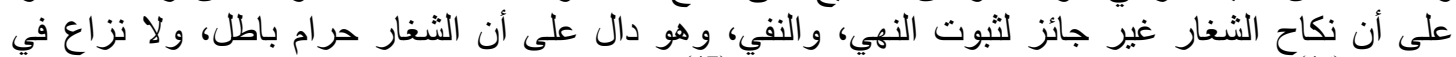

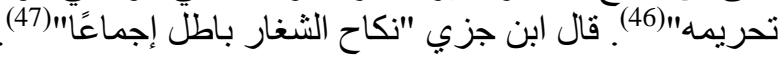

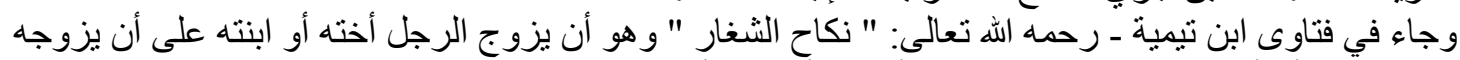

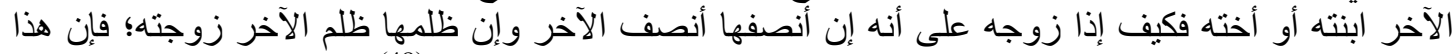

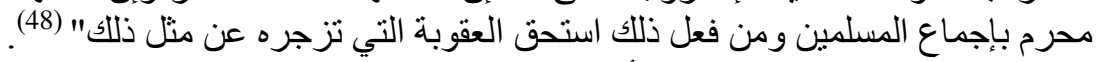

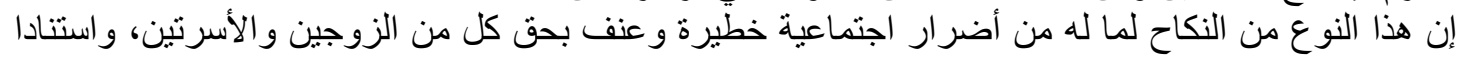

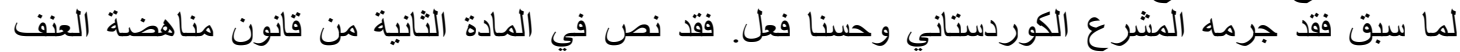

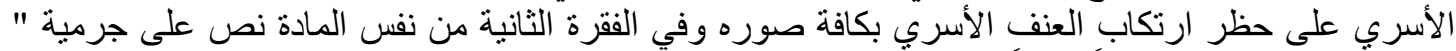

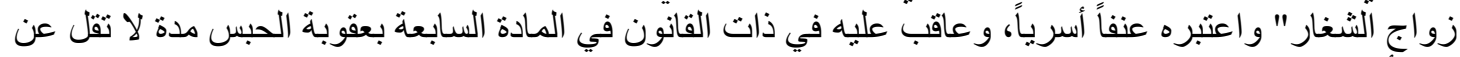

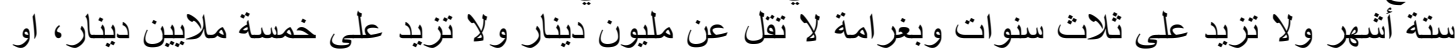

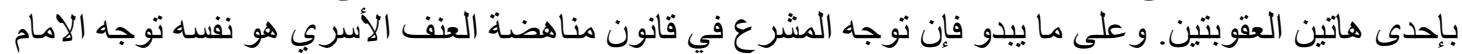

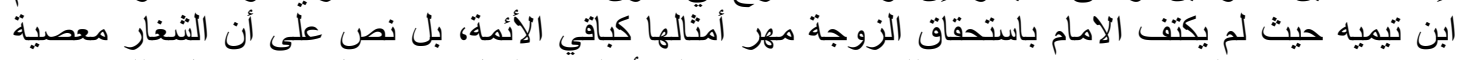

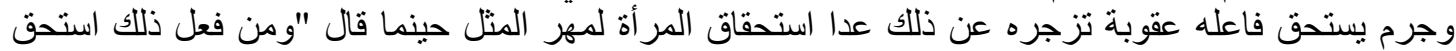

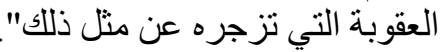

\section{المطويج الصغار الثاني}

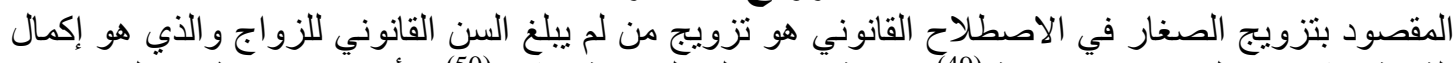

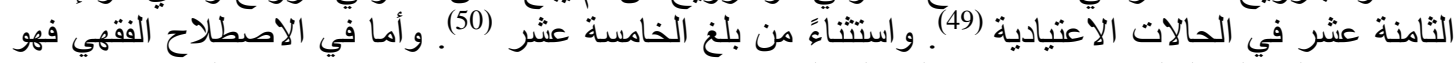

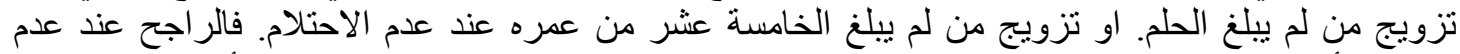

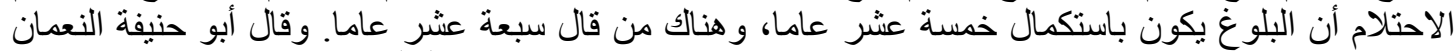

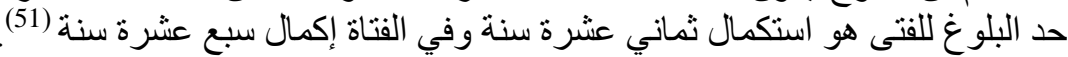

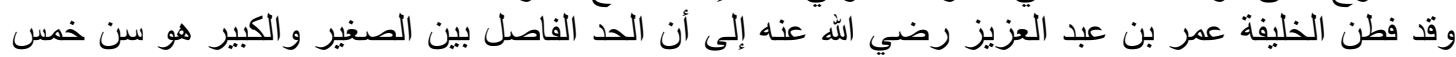

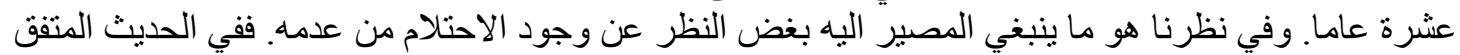

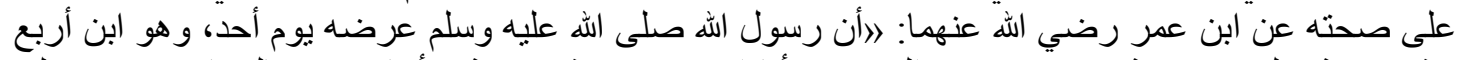

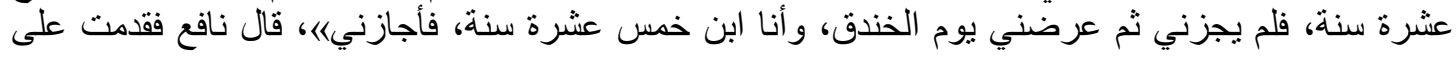

(45) أبو العباس شهاب الدين أحمد بن إدريس بن عبد الرحمن المالكي الثهير بالقرافي (المتوفى: 684هـ)،

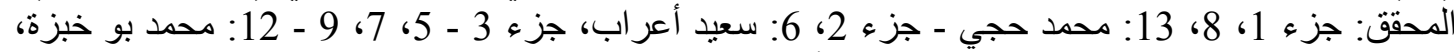

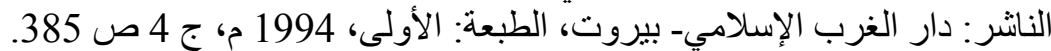

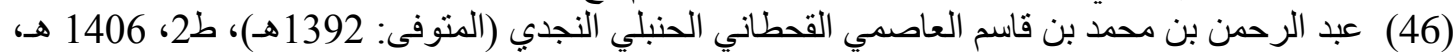

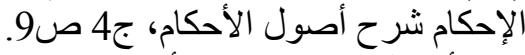
(47)أبو القاسم، محمد بن ألمد الحمد جن محمد بن عبد الله، ابن جزي الكلبي الغرناطي (المتوفى: 741هـ)، القوانين

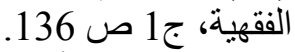

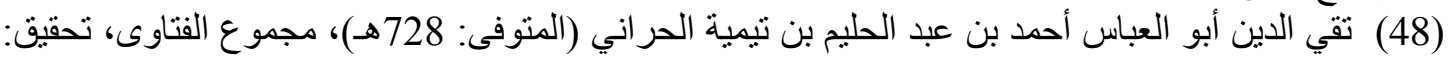

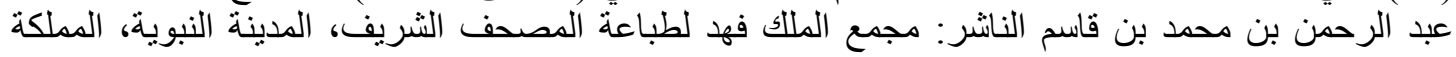

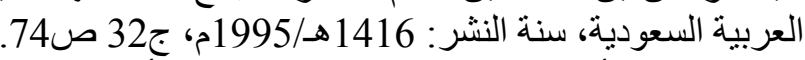

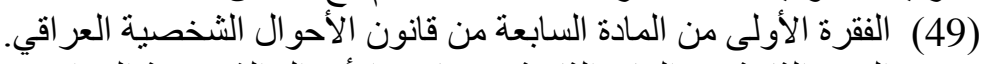

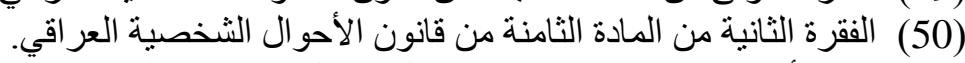

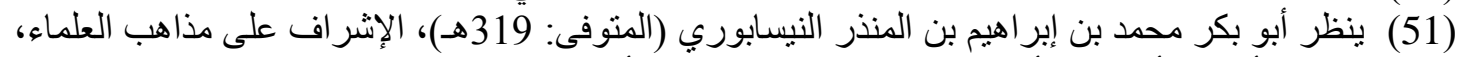

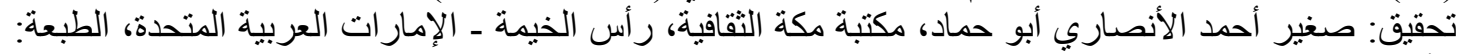

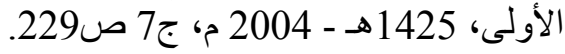




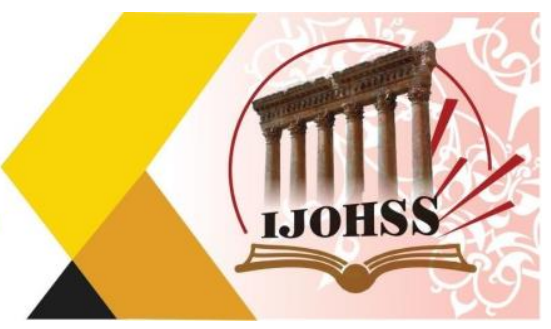

عمر بن عبد العزيز و هو خليفة، فحدثته هذا الحديث فقال: 》إن هذا لحد بين الصغير و الكبير ، وكتب إلى عماله أن

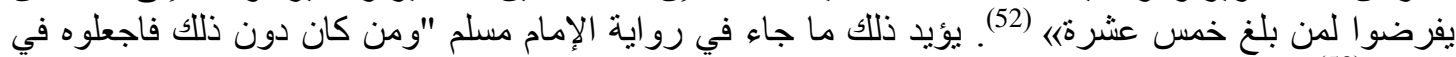

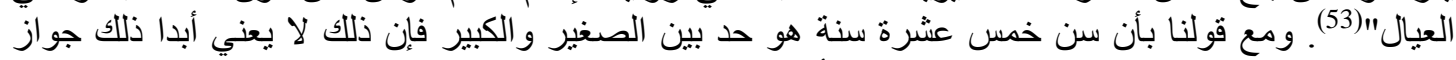

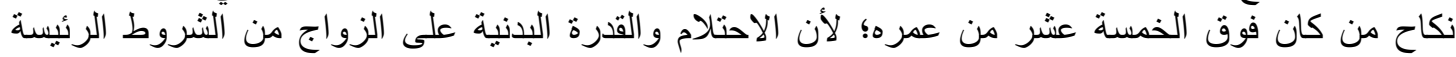

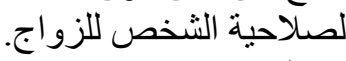
إن المشرع في قانون مناهضة العضد العنف الأسري عدّ تزويج الصغار عنفاً أسرياً معاقبا عليه في المادة الثانية الفقرة

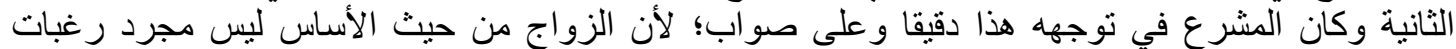

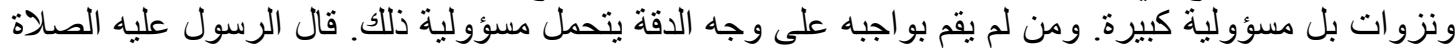

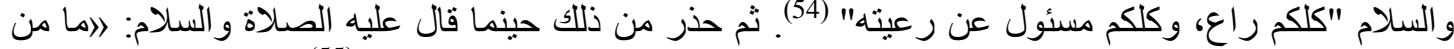

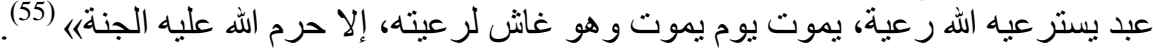

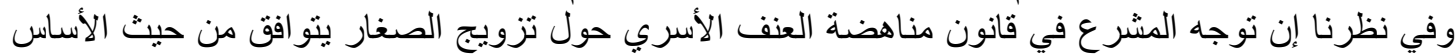

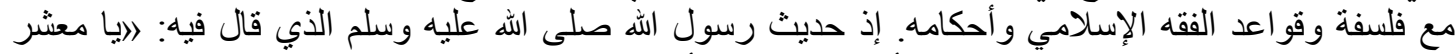

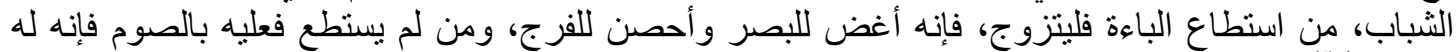

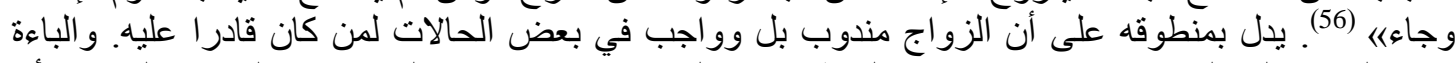

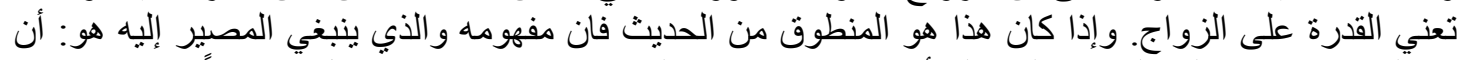

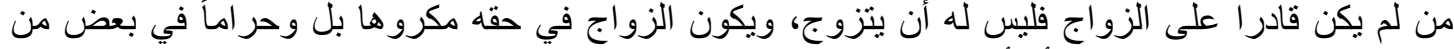

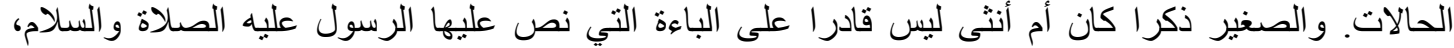

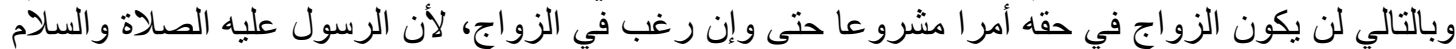

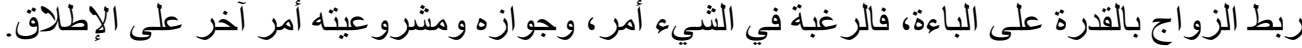

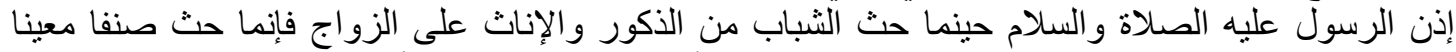

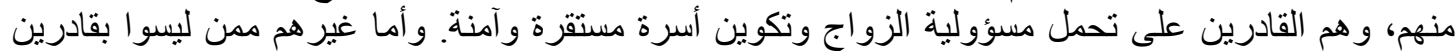

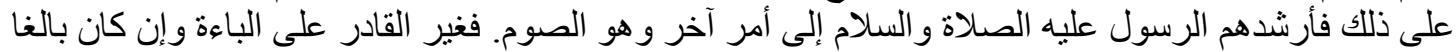

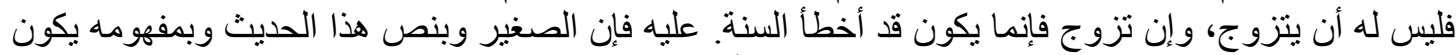

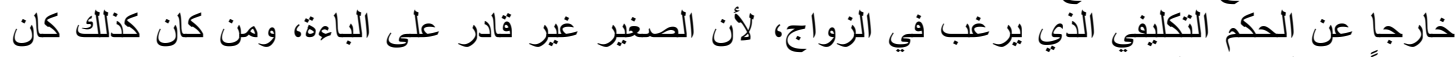

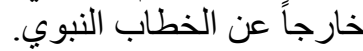

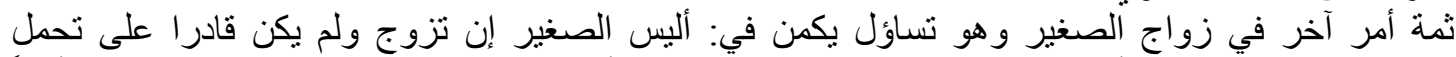

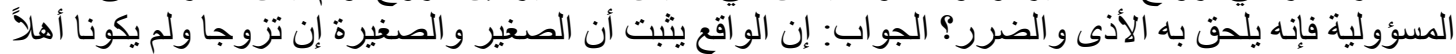

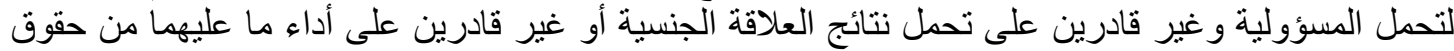

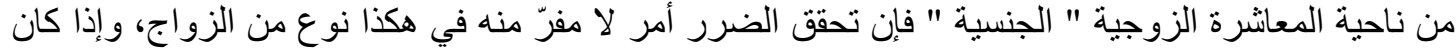

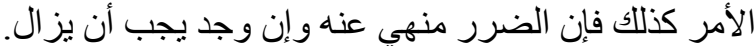

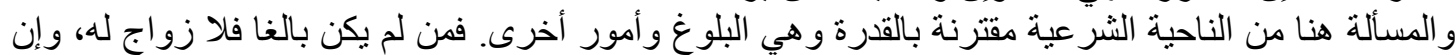

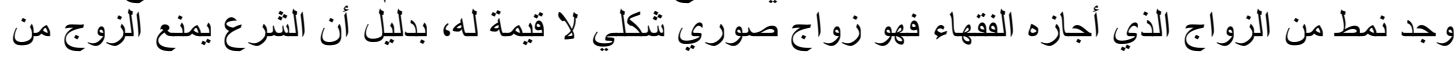

(52) الامام البخاري، صحيح البخاري، مصدر سابق، ج3 ص177. الامام مسلم، صحيح مسلم، مصدر سابق،

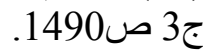

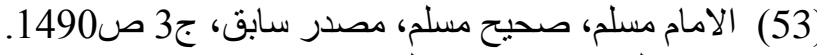

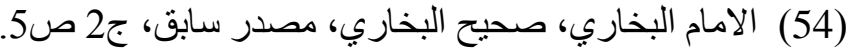

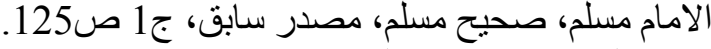

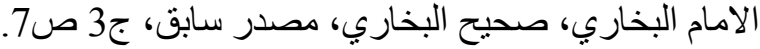




\section{المجلة الحولية للملوم الأسانسية والإمتصاعية}

International Journal of Humanities and Social Sciences website:www.ijohss.com Email:editor@ijohss.com ISSN: $2415-4822$

العداد (19) مارس 2021 Volume (19) March 2021

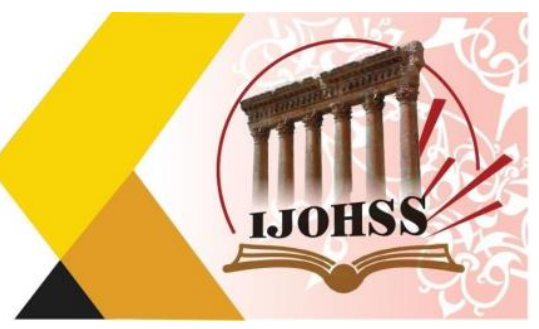

وطء الزوجة غير المطيقة على الوطء. فالحديث دليل على أنه لا يؤمر به إلا القادر على ذلك وقد قالوا: "من لم يقدر عليه، فالنكاح مكروه في الزئه حقه" (57).

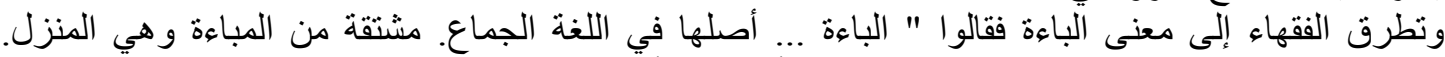

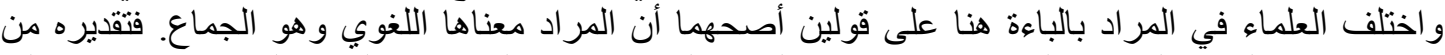

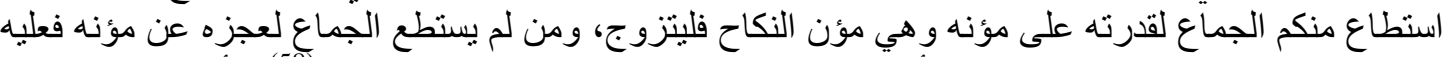

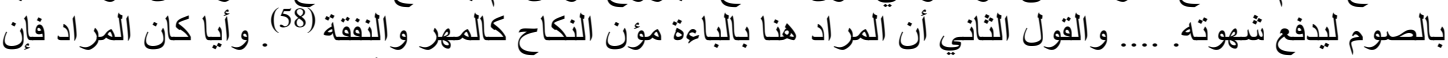

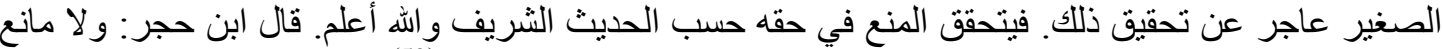

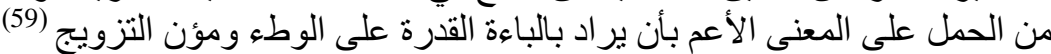

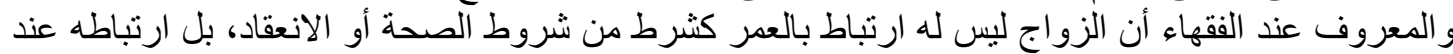

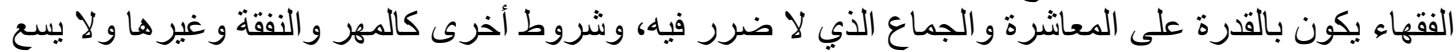

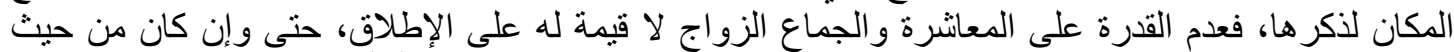

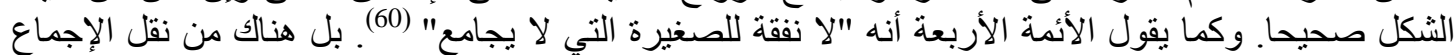

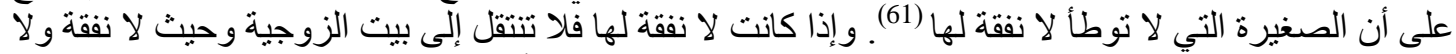

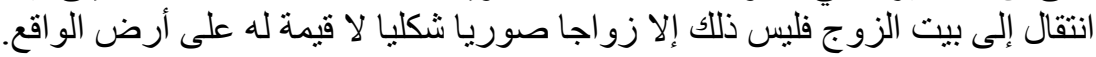

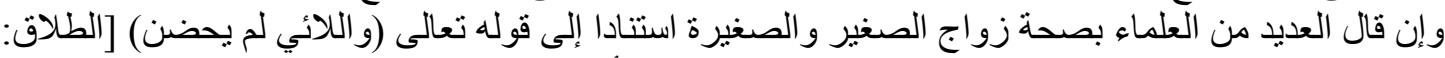

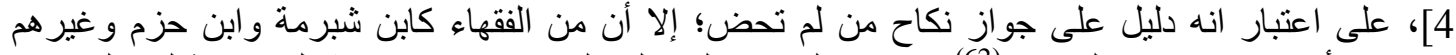

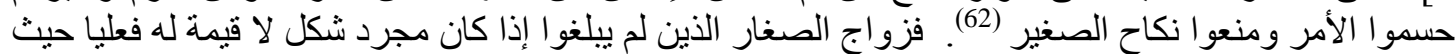

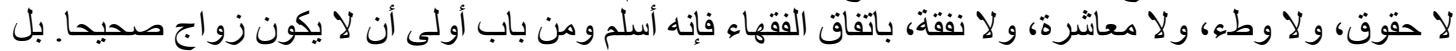

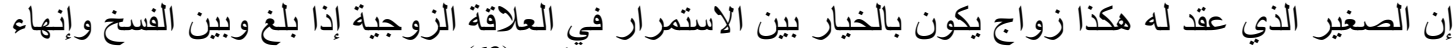
تللك العلاقة الزوجية. وقال ابن حزم عن تزويج الصغير هو "مفسوخ أبدًا"(63).

(58) ابن دقيق العيد، مطبعة السنة المحمدية، إحكام الإحكام شرح عمدة الأحكام، بدون طبعة وبدون تاريخ، ج2 ص ص (168)

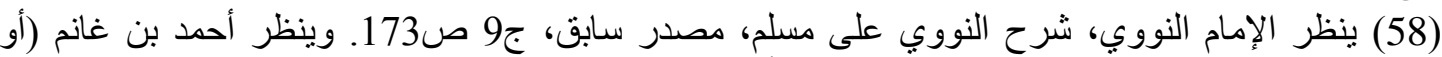

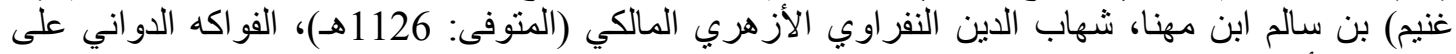

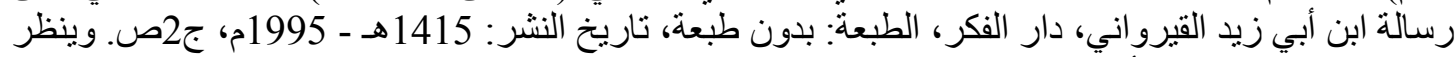

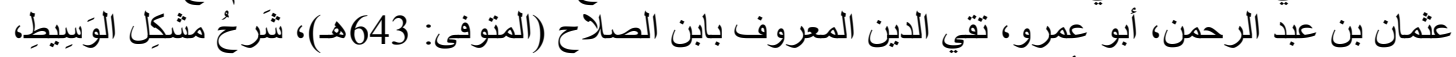

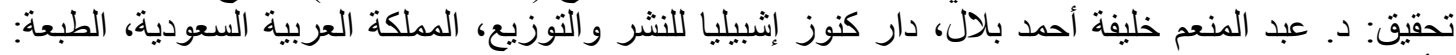

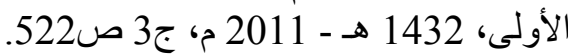
(59) المجموع شرح المهذب (مك (مع تكملة السبكي و المطيعي))، أبو زكريا محيي الدين يحيى بن شرف النووي

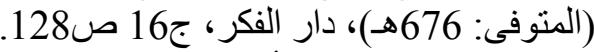

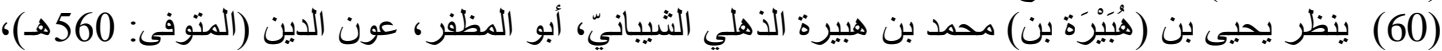
اختلاف الأئمة العلماء، تحقيق: السيد يوسف أحمد، دار الكتب العلمية ـ لبنان / بيروت، الطبعة: الأولى، 1423هـ الطئ

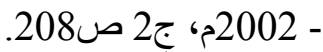
(61) د. أسامة بن سعيد القحطاني وآخرون، موسوعة الإجماع في الفقه الإسلامي، دار الفضيلة للنشر

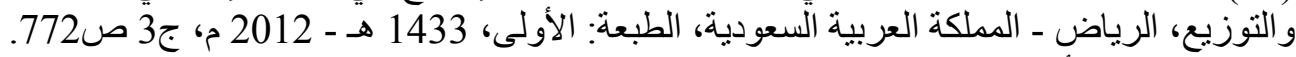

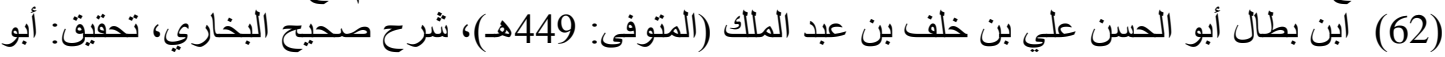

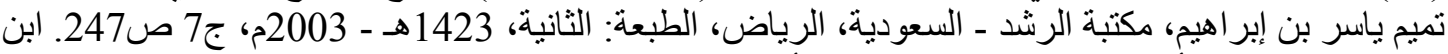

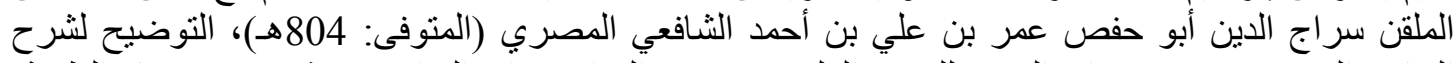

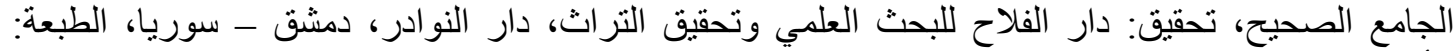

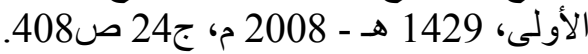

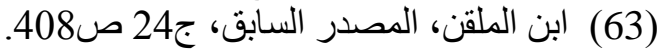




\section{المجلة الحولية للملوم الأسانسية والإمتصاعية}

International Journal of Humanities and Social Sciences website:www.ijohss.com Email:editor@ijohss.com مارس 2021

العداد (19) ISSN: $2415-4822$

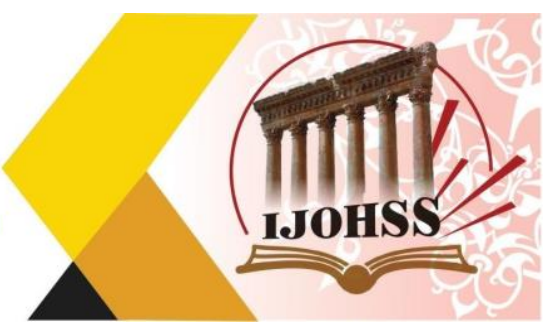

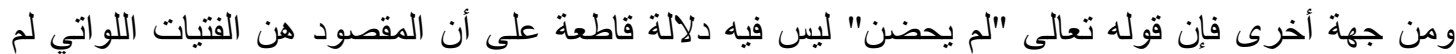

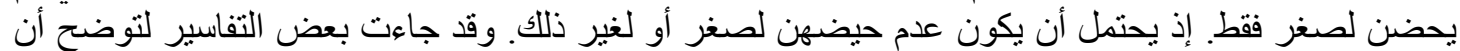

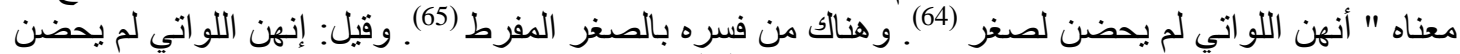

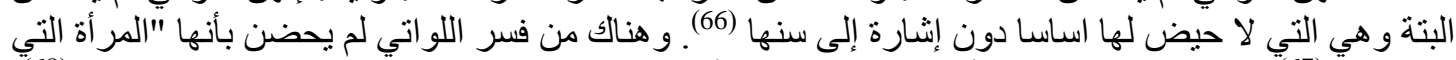

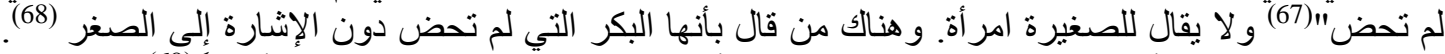

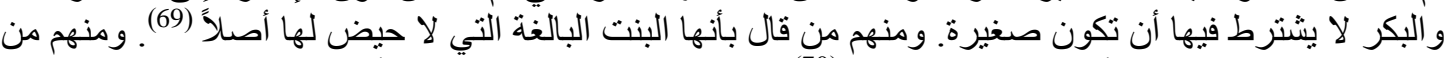

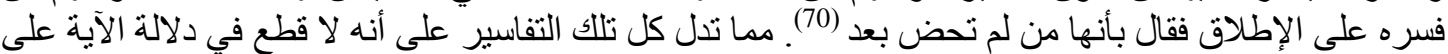

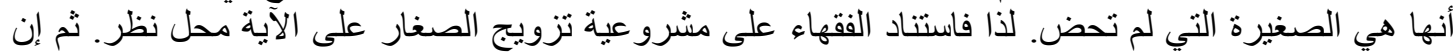

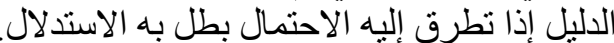

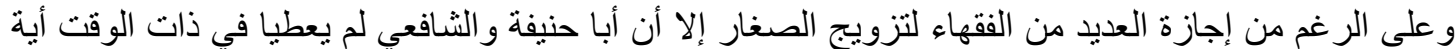

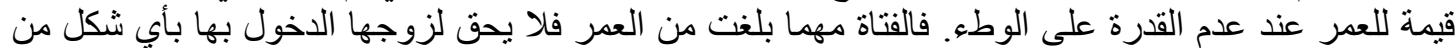

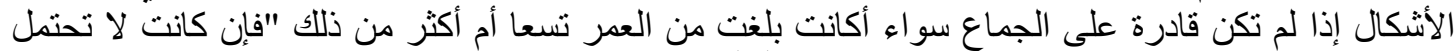

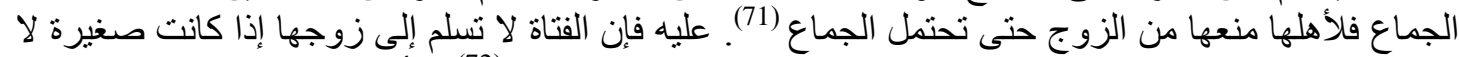

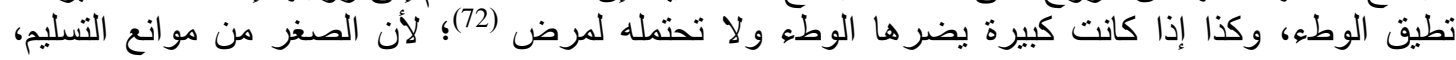

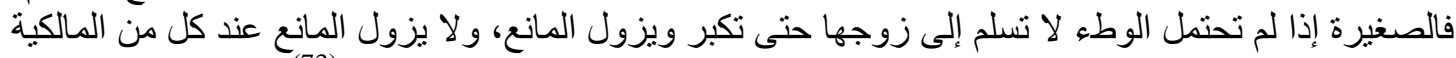

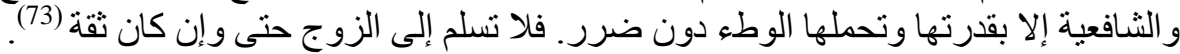

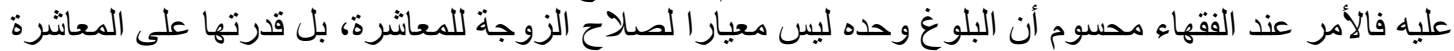

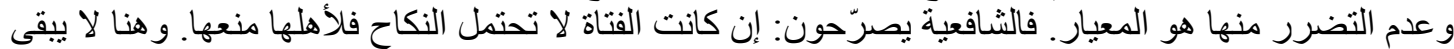

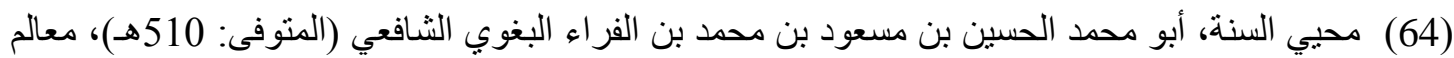
التنزيل في تفسير القرآن = تفسير البغوي، تحقيق: عبد الرزاق المهدي، دار إحياء التراث العربي -بيروت، التهي،

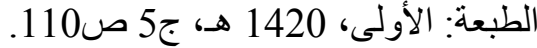

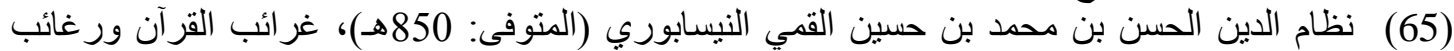
الفرقان " تفسير النبسابوري"، تحقيق: الثيخ زكرياً عميرات دار الكتب العلمية - بيروت، الطبية الطبعة: الأولى -

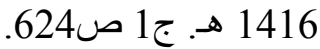
(66) أبو حيان محمد بن يوسف بن علي بن يوسف بن حيان أثثر الدين الأندلسي (المتوفى: 745هـ)، البحر

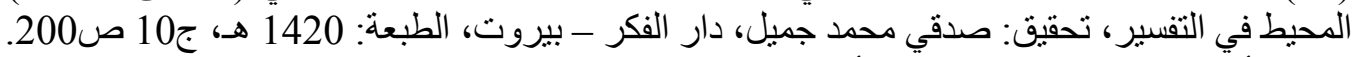

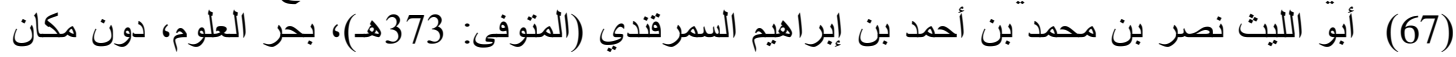

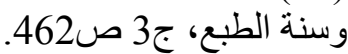
(68) أ. د. حكمت بن بشعبير بن بن باسين، موسوعة الصحيح المسبور من التفسير بالمأثور، دار المآثر للنشر و التوزيع و الطباعةـ المدينة النبوية

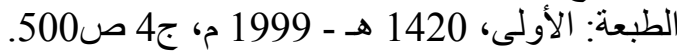

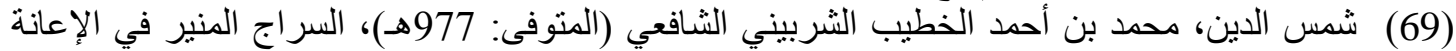

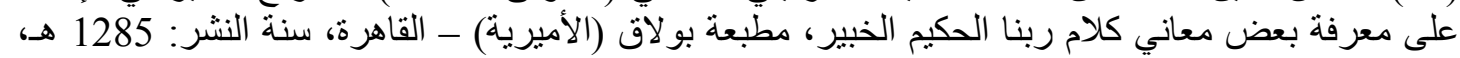

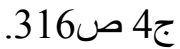
(70) ناصر الدين أبو سعيد عبد الله بن عمر بن محمد الثيرازي البيضاوي (المتوفى: 685هـ)، أنوار التنزيل

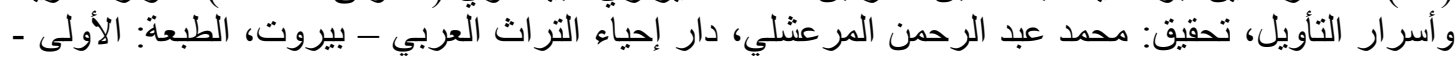

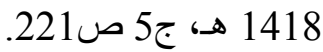

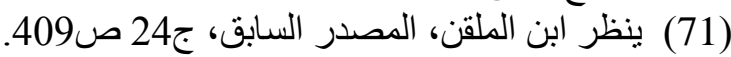

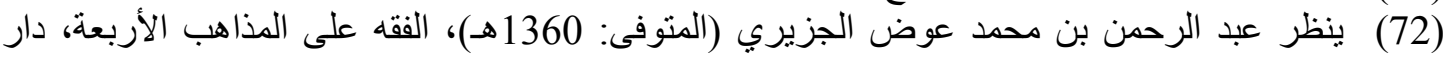

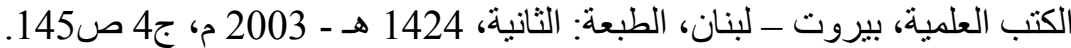
(73) ينظر الموسو عة الفقهية الكويتية، مصدر سابق، ج30 ص122. 


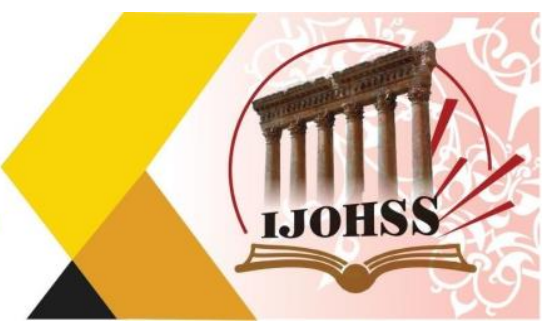

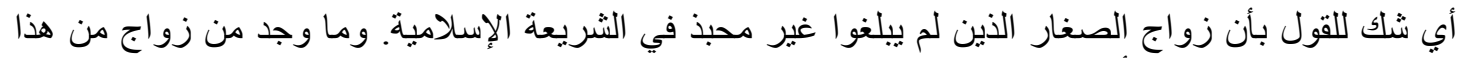

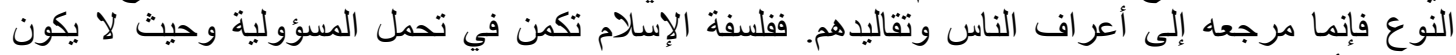

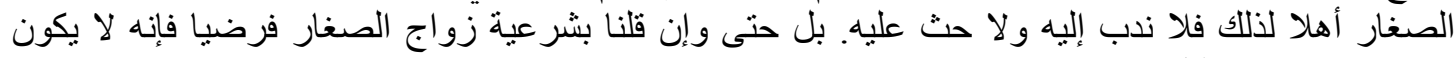

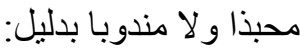

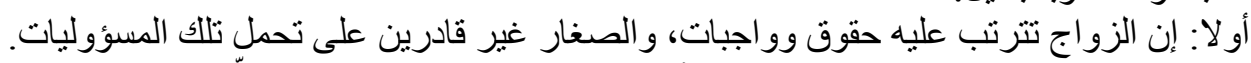

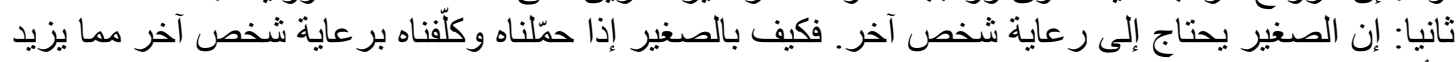

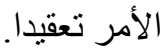
ثالثا: إن الأضرار المترتبة على زواج الصغار أصبح أمر ا مفروغا منهه ومقطوعا به، وشيء كذا لا يجوز الإقدام عليه. رابعا: استنادا إلى قاعدة درء المفاسد مقدم على جلب المصالح، إذ المفاسد المثرتبة على زواج الصغار أكثر من

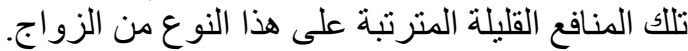

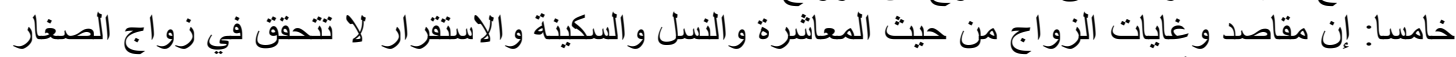

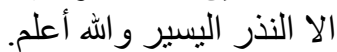

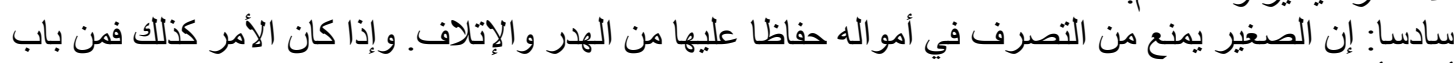

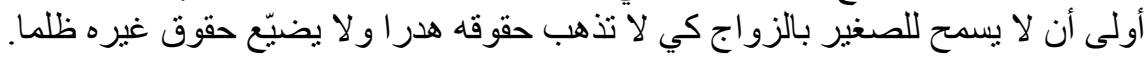

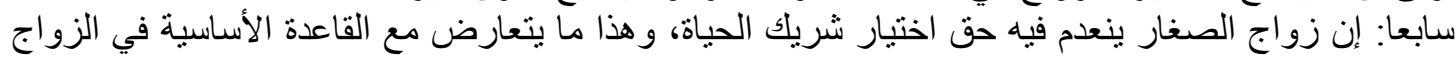

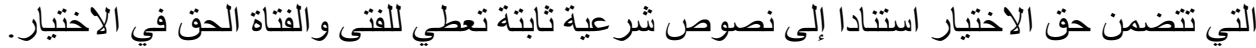
و لا يقاس تزويج الصغار على زواج الرسول عليه الصلاة والسلام من السيدة عائشة رضي اللئي الله عنها، لسببين

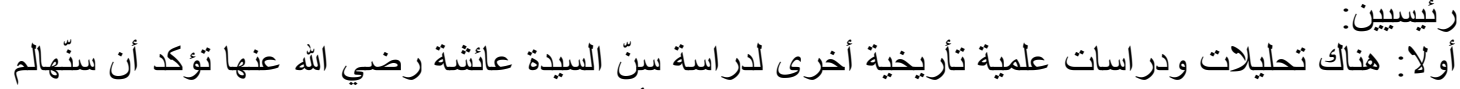

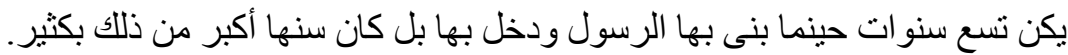

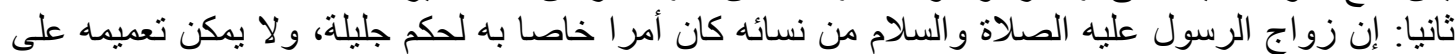

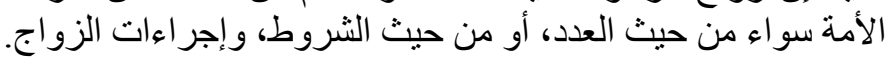

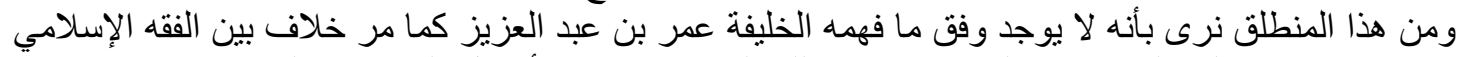

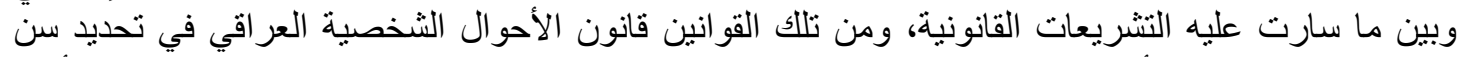

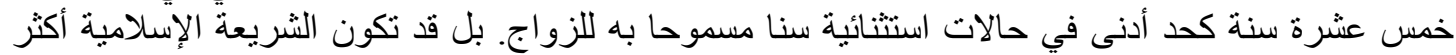

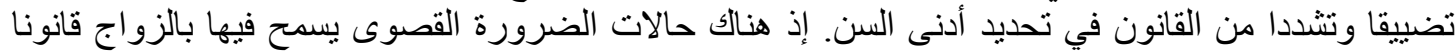

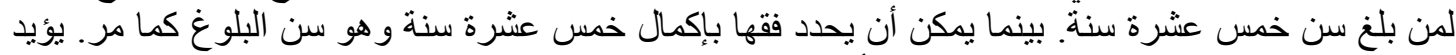

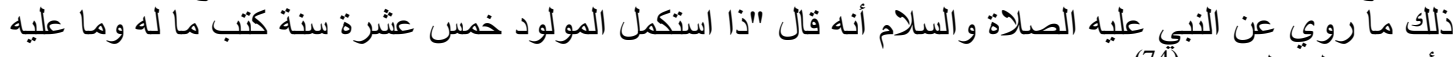
و وأقيمت علية الحدود" (74).

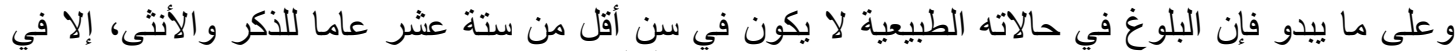

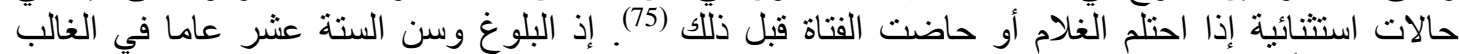

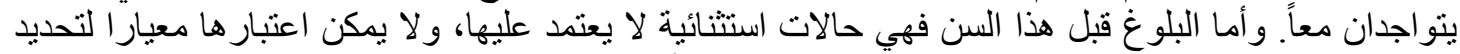

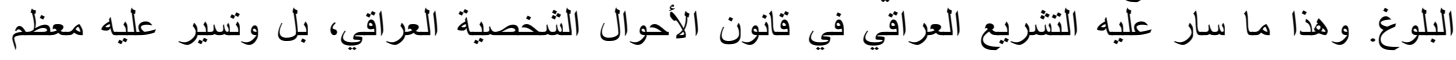

(74) ينظر نيل الأوطار، محمد بن علي بن محمد بن عبد الله الثوكاني اليمني (المنوفى: 1250 هـ)، تحقيق:

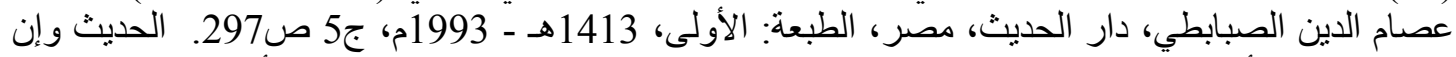
كان ضعيفا إلا أنه يتفق مع ما ورد في الطي الصحاح وما ذكره الخليفة عمر بن الطب، عبد العزيز من أن الحد الفاصل بين (75) ينظر أبو عبد الله محمد بن إدريس الثنافعي المطلبي القرشي المكي (المنوفى: 204هـ)، تفسير الإمام

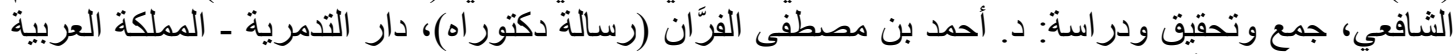

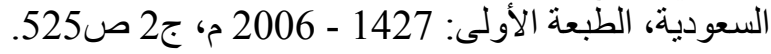




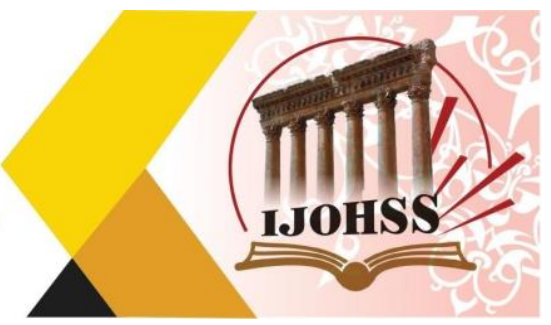

تتريعات الأسرة. لذا فإن التو افق بين الفقه الإسلامي وبين اتجاه المشرع الكوردستاني في قانون مناهضة العنف

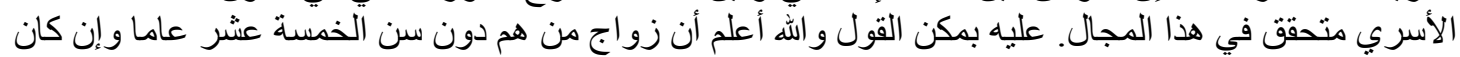

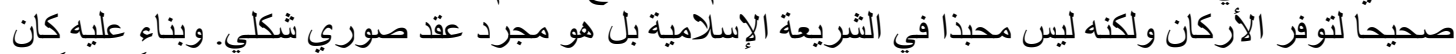

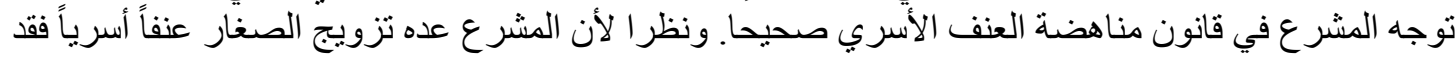

\section{المطلب الثالث \\ التزويج بلالا عن الدية الملثة}

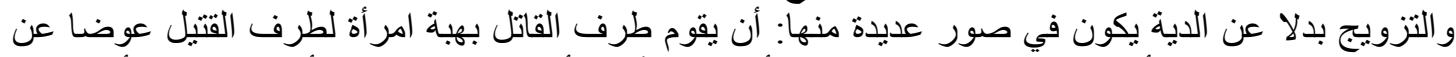

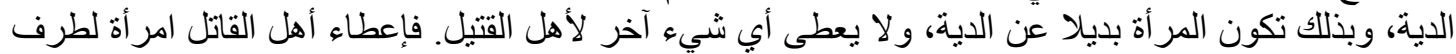

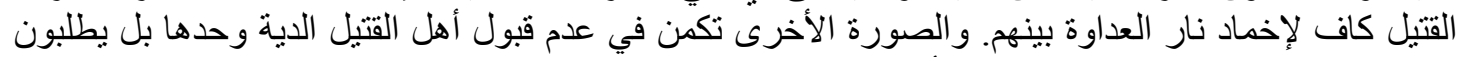

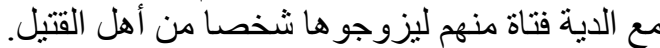

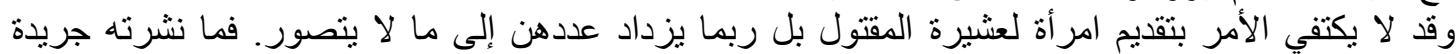

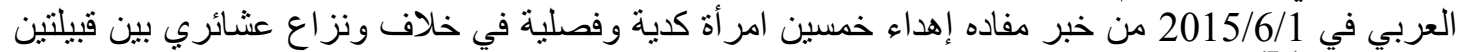

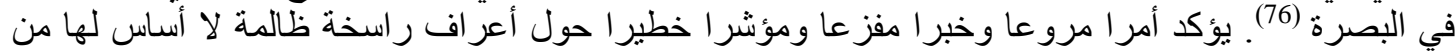

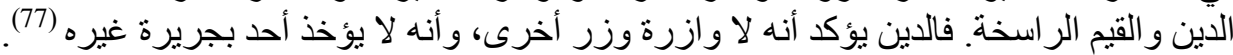

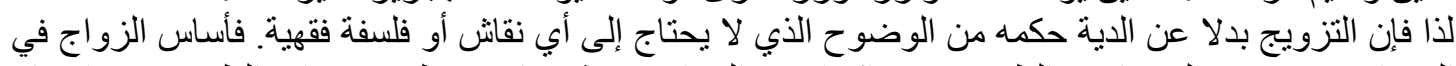

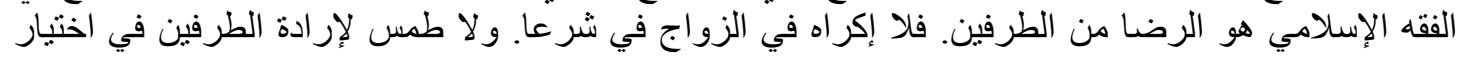

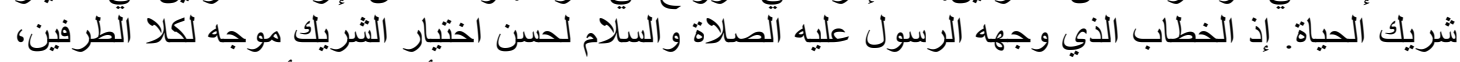

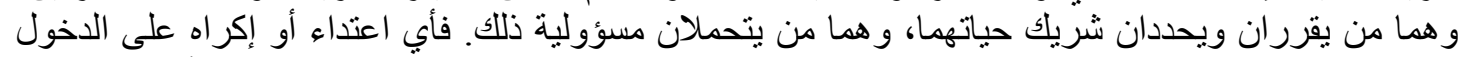

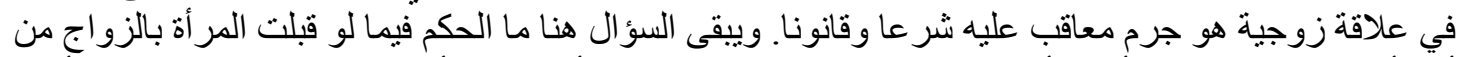

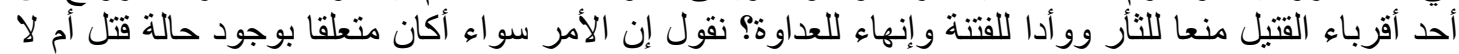

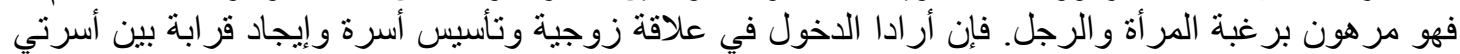

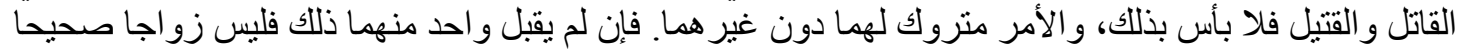

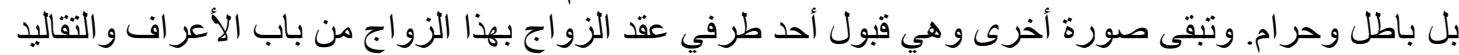

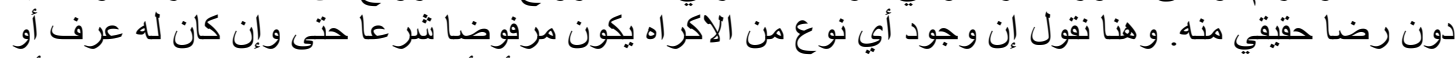

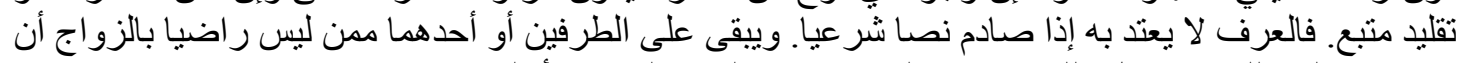

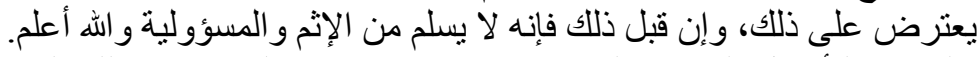

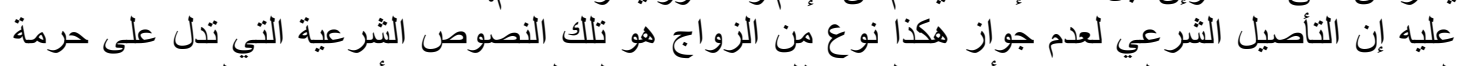

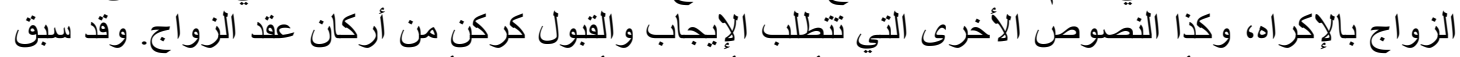

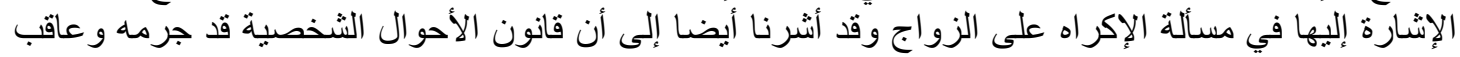

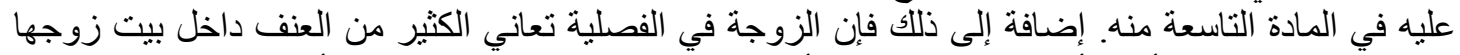

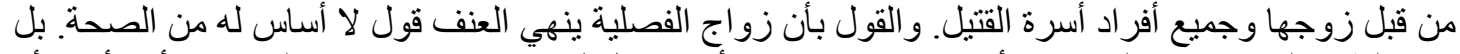

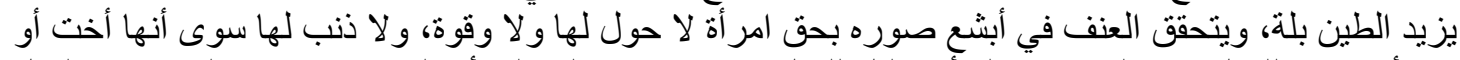

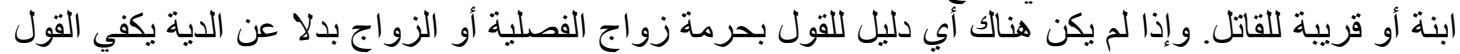

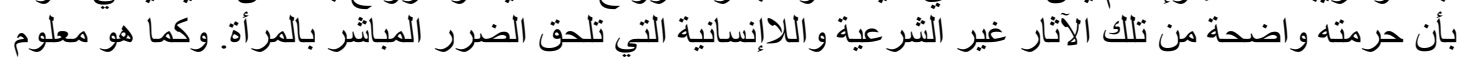

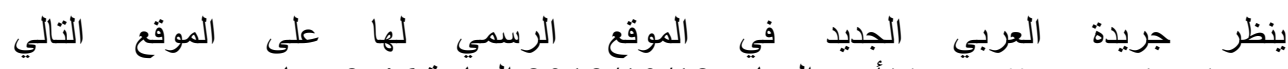

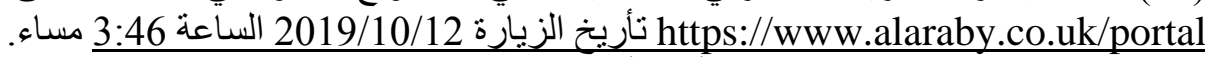

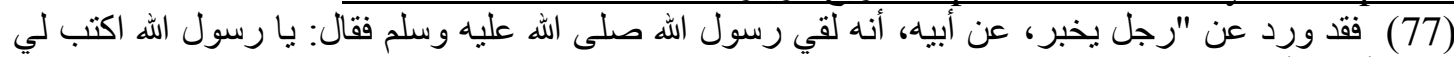

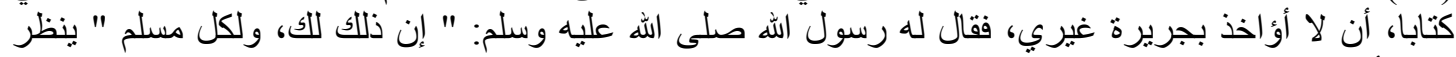

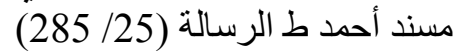




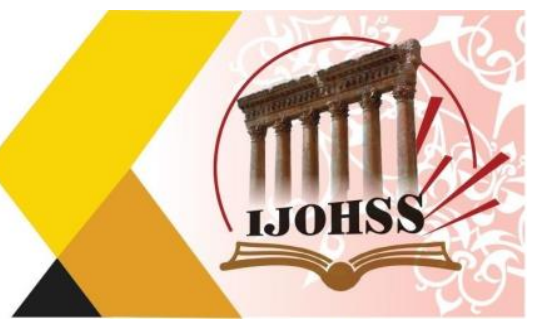

فإن الزواج إذا اقترن به أي ضرر يكون حكمه إما مكروها أو حراما، وفي مثل هذه الحالة لا نتردد في القول

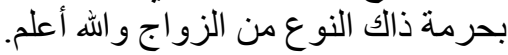

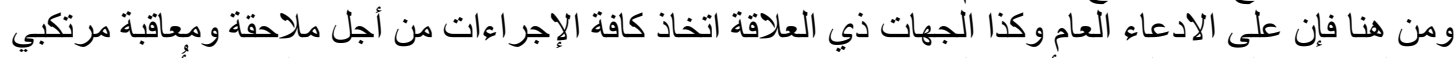

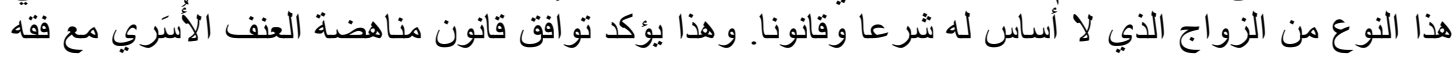

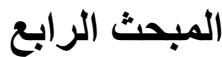

\section{العنف الأسري في الحقوق الزوبة الزوبية}

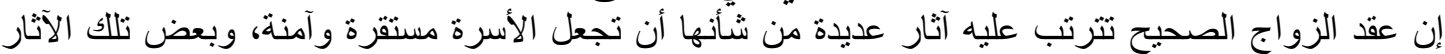

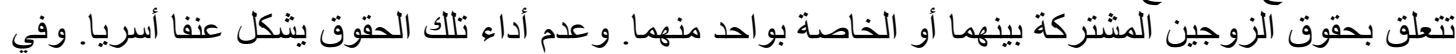

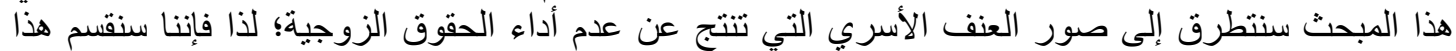
المبحث إلى مطلبين نتحدث في المطلب الأول عن قطع صلة الرحم. الرّن بينما نتطرق في المطلب الثاني إلى الإكر اه

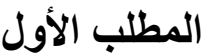

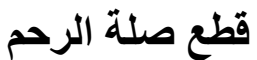

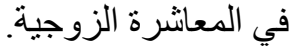

لم يوضح المشرع في قانون مناهضة العنف الاسري مفهوم قطع صلة الرحم، و و إنما أتى بهذه المفردة مطلقا. مما

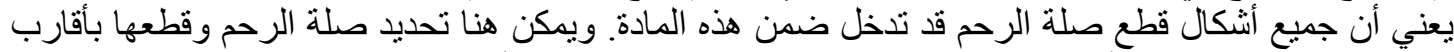

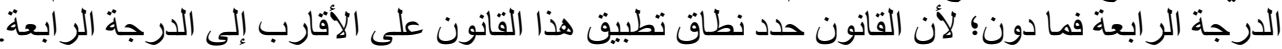

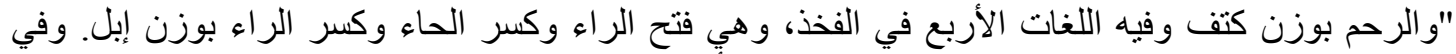

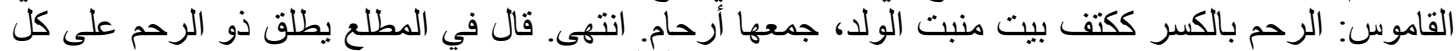

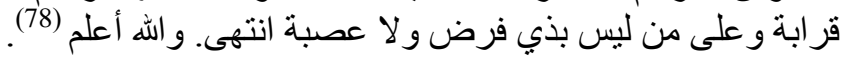

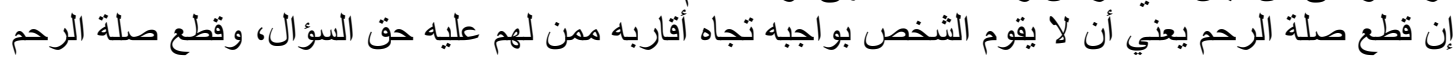

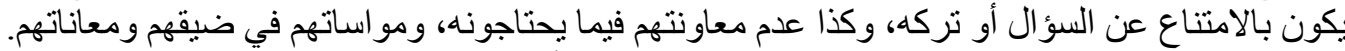

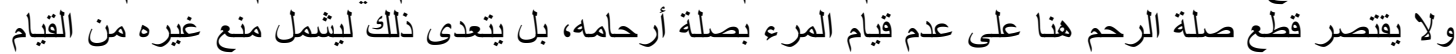

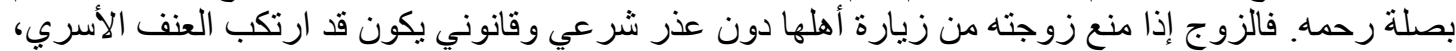

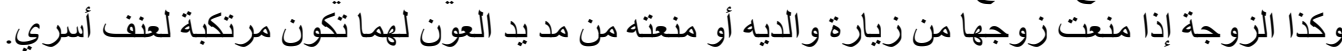

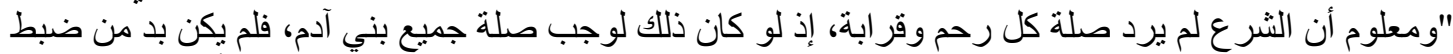

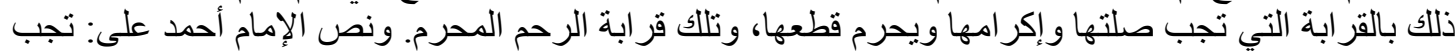

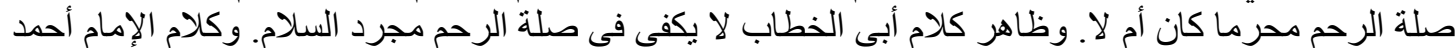

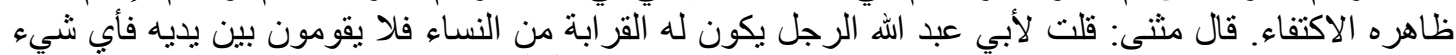

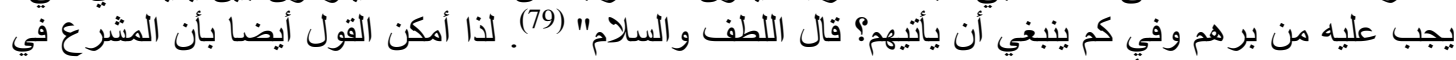

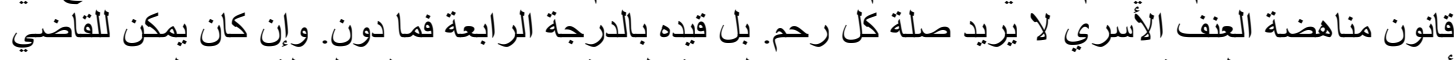

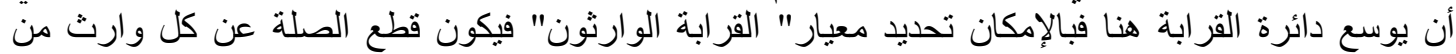

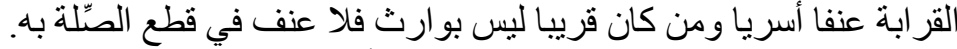

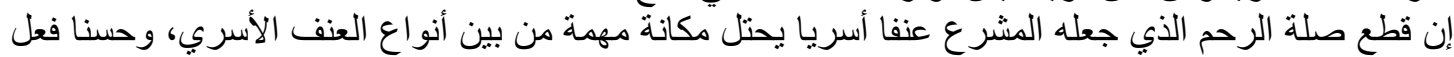

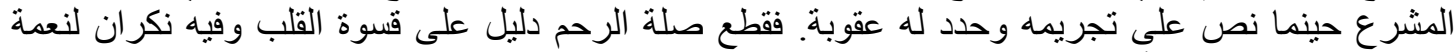

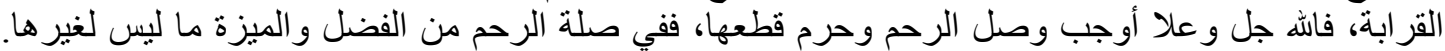

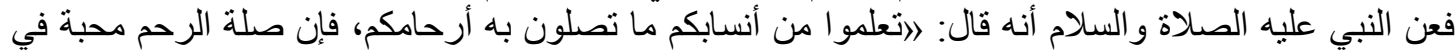

(78) ينظر شمس الدين، أبو العون محمد بن أحمد بن سالم السفاريني الحنبلي (المتوفى: 1188هـ)، غذاء إلهاء

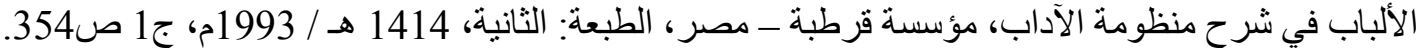

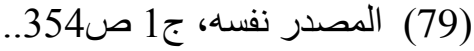




\section{المجلة الحولية للملوم الأسانسية والإمتصاعية}

International Journal of Humanities and Social Sciences website:www.ijohss.com Email:editor@ijohss.com ISSN: $2415-4822$

العداد (19) مارس 2021

Volume (19) March 2021

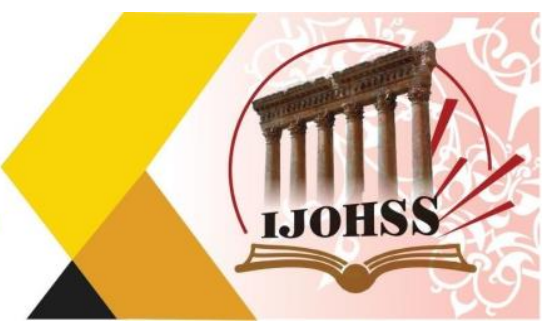

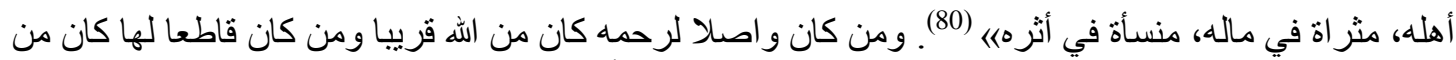

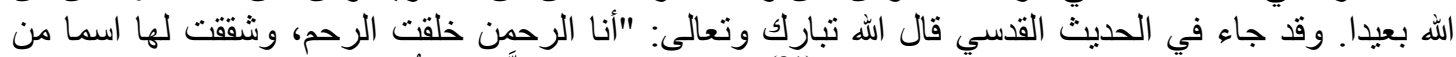

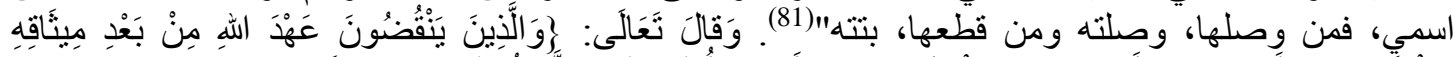

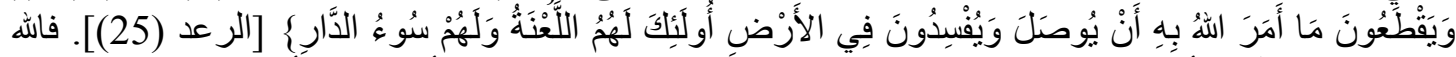

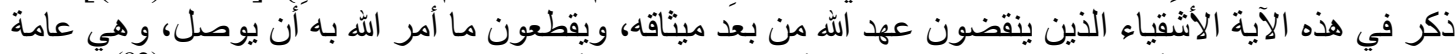

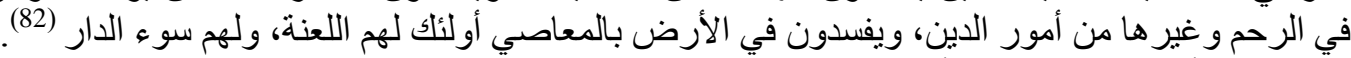

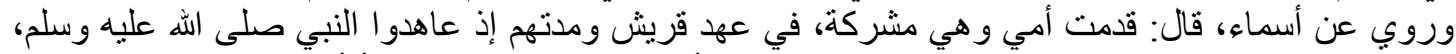

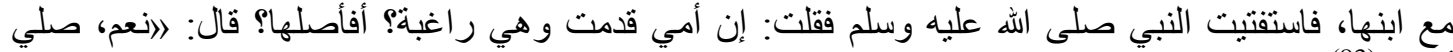

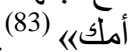

قطيعة الرحم من الكبائر.

ذكر ها الحجاوي في منظومته المشتملة على الكبائر ، وكذلك اعتبر ها ابن حجر الهيثمي من الكبائر و عدها الكبيرة

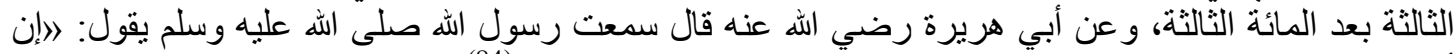

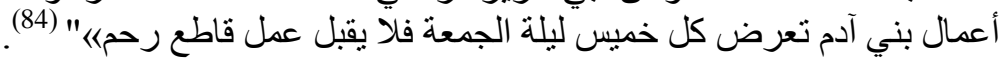

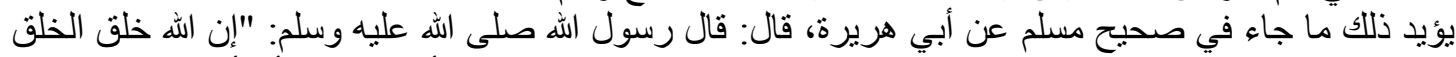

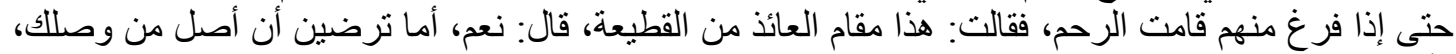

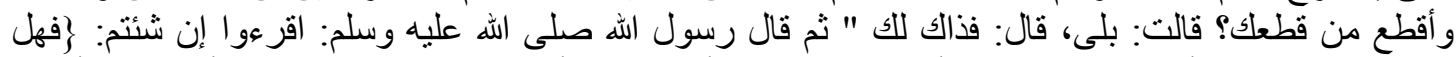
عسيتم إن توليتم أن تفسدوا في الأرض وتقطعوا أرحامكم، أولنك الذين لعنهم الله فأصمهم وأعمى

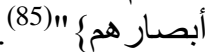

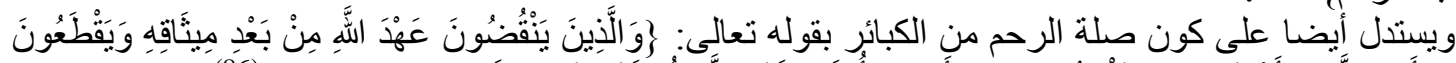

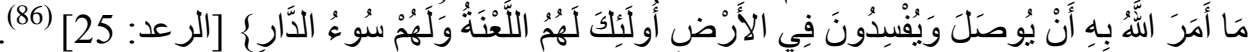

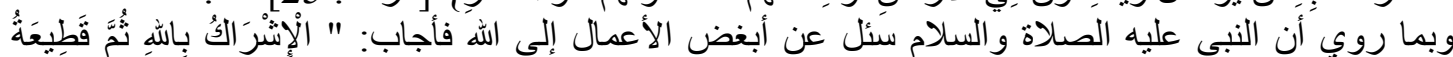

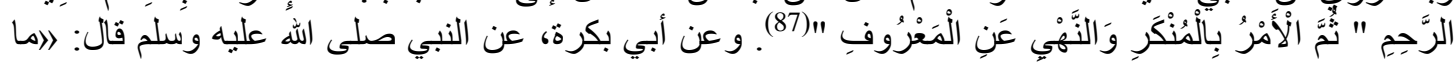

(80) مسند الإمام أحمد بن حنبل، أبو عبد الله أحمد بن محمد بن حنبل بن هلال بن بن أسد الثيباني (المتوفى:

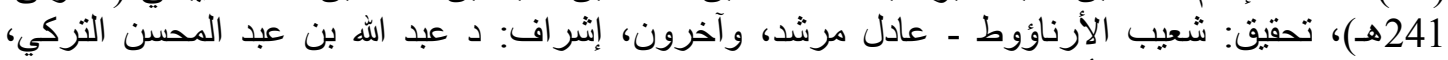

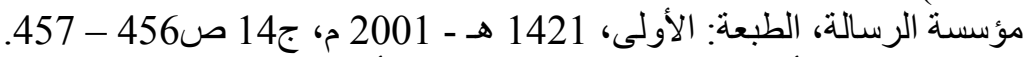

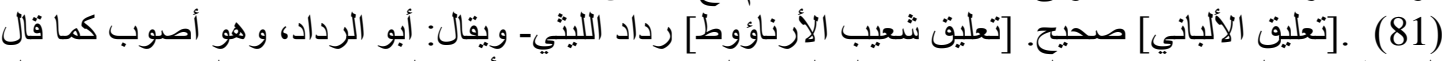

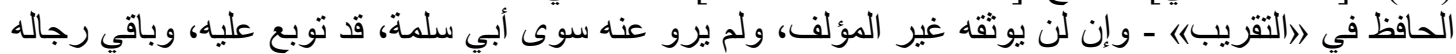

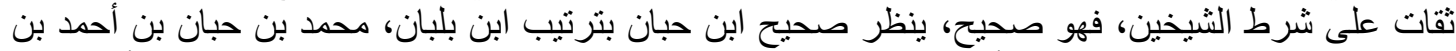

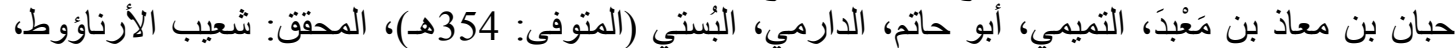

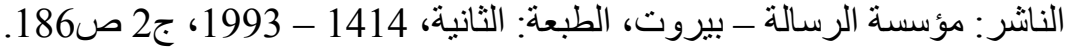

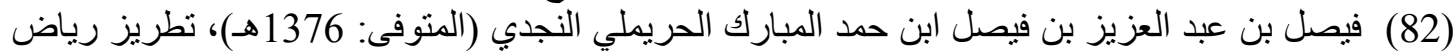

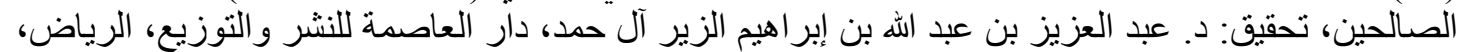

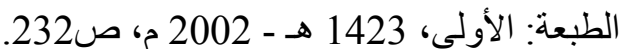

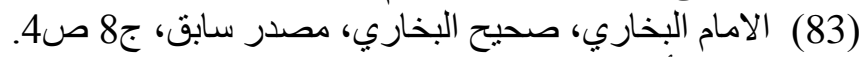

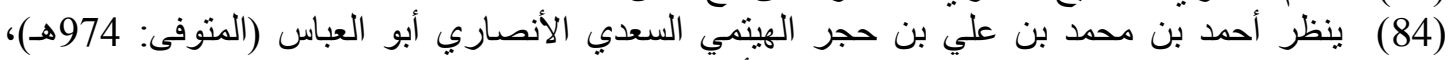

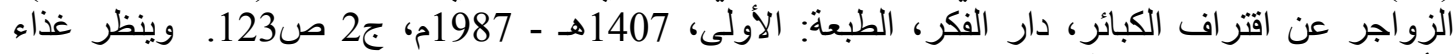

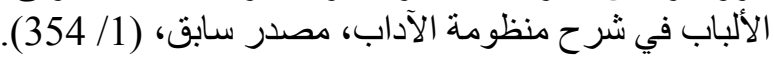

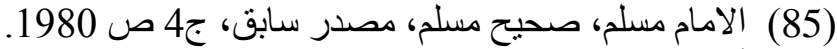

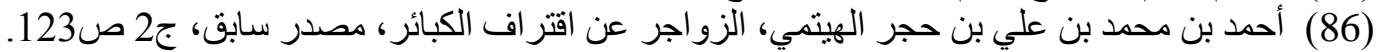

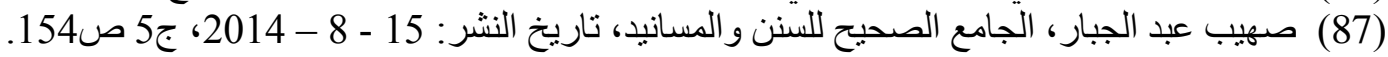




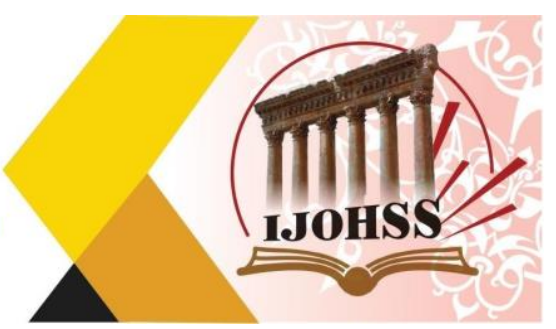

من ذنب أجدر أن يعجل لصاحبه العقوبة مع ما يدخر له، من البغي وقطيعة الرحمه (88). وقال رسول اله صلى

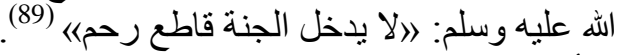

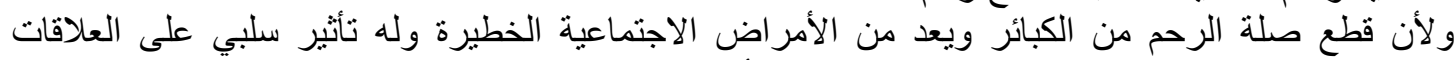

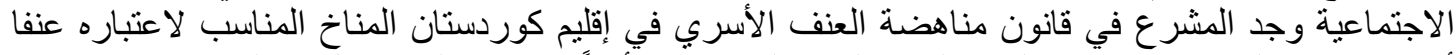

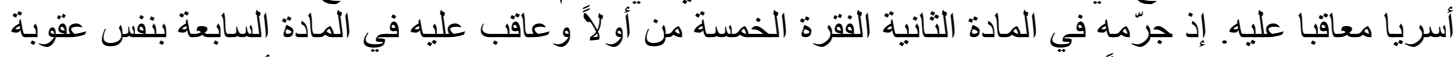

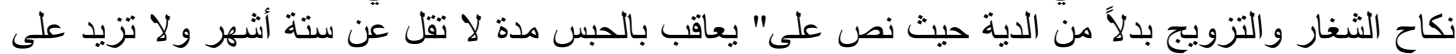
ثلاث سنوات وبغر امة لا تقل عن مليون دينار و لا تزيد على التى خمسة ملايين دينار او بإحدى هاتين العقوبتين كل

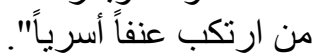

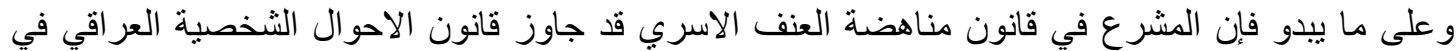
تأثره بفقه الاسرة في هذه النقطة تحديدا. إذ لا يوجد في قانون الانئ الاحو ال الثخصية ما يشير الى حرمة قطع صلة

\section{المطاب الثاني \\ المعاثرة الزوجية بالإكراه}

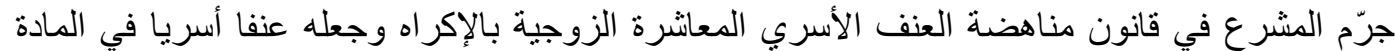

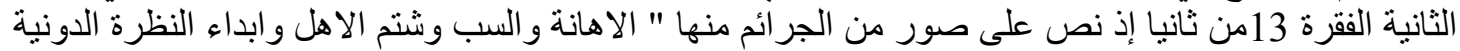

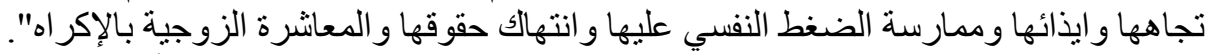

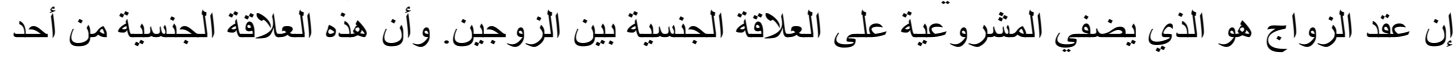

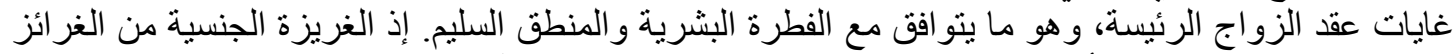

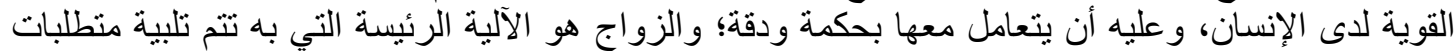

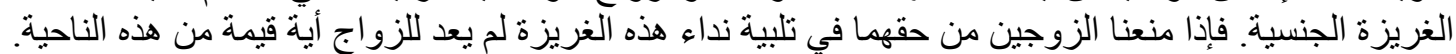

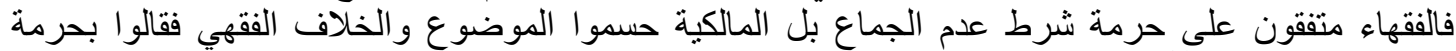

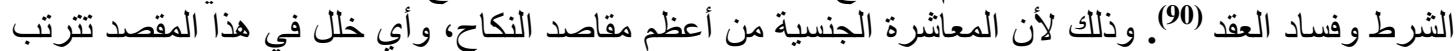

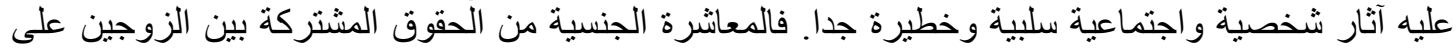

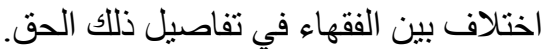
و الذي يبدو لنا أنه ما كان ينبغي للمشر عاهيل أن بنص على المعانشرة الزوجية بالإكر اه في الفقرة السابقة، وذللك لأمور

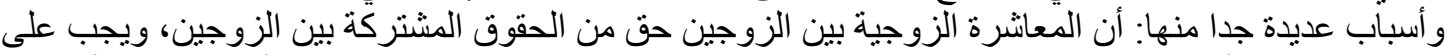

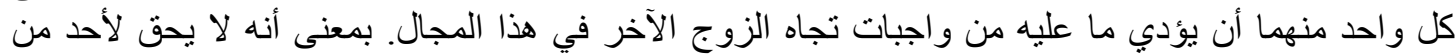

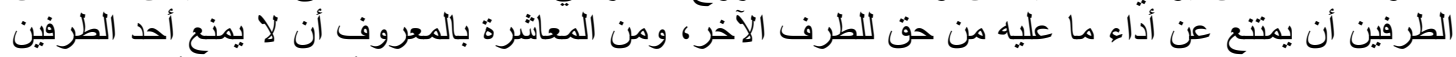

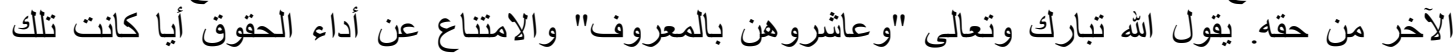

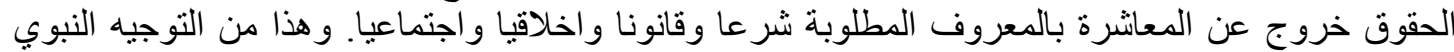

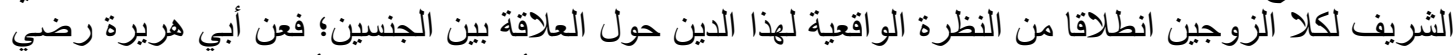

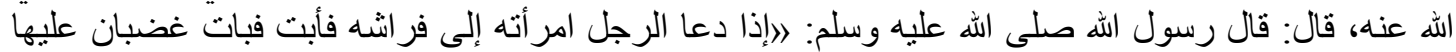

(88) محمد بن إسماعيل بن إبر اهيم بن المغيرة البخاري، أبو عبد الله (المنوفى: 256هـ)، الأدب المفرد، تحقيق:

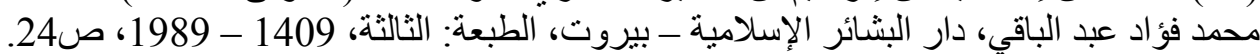

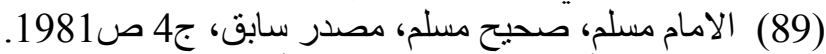

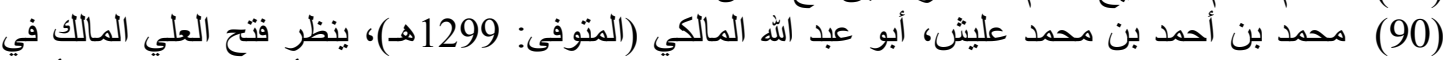

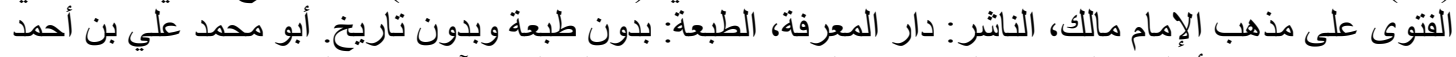

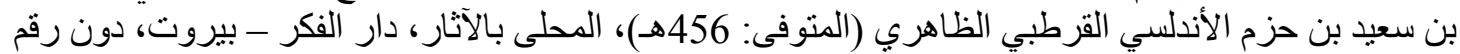

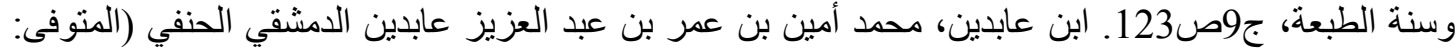

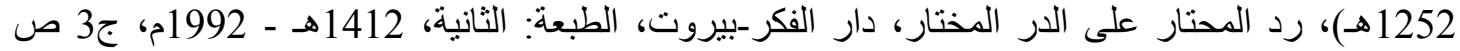




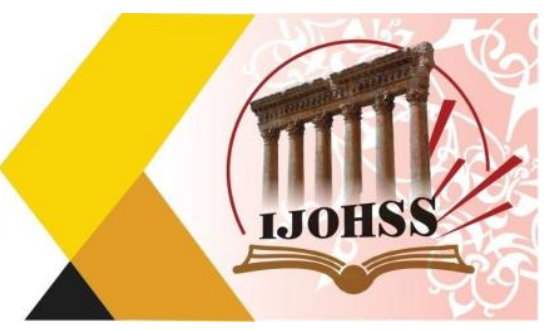

لعنتها الملائكة حتى تصبحه) (91). وروي أن رسول اله صلى الله عليه وسلم قال: "ثلاثة لا تقبل منهم صلاة، و ولا

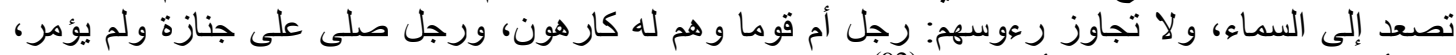

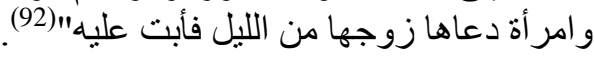

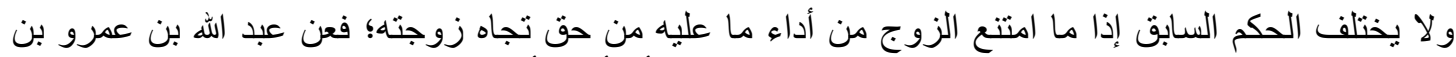

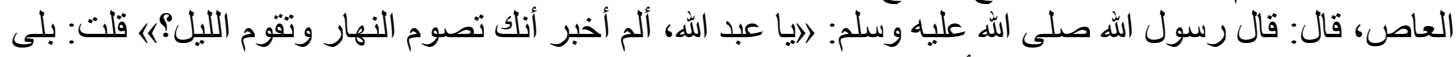

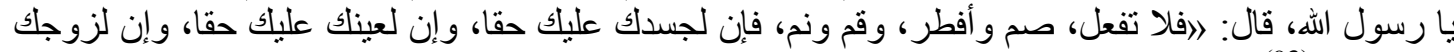
عليك حقاه (93)

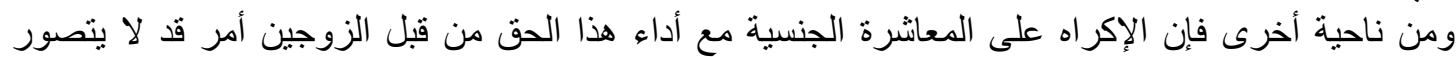

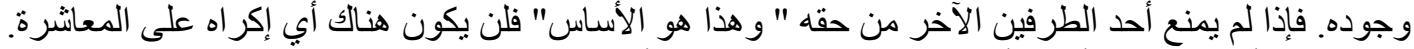

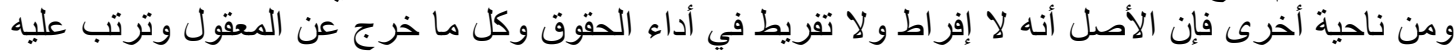

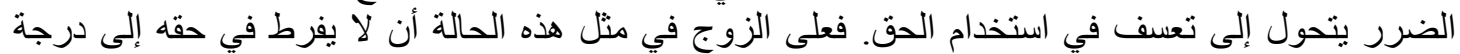

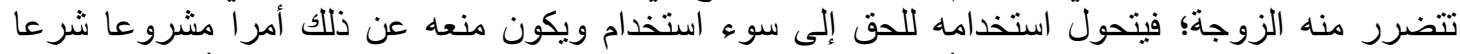

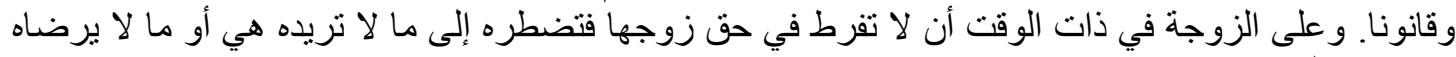

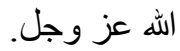

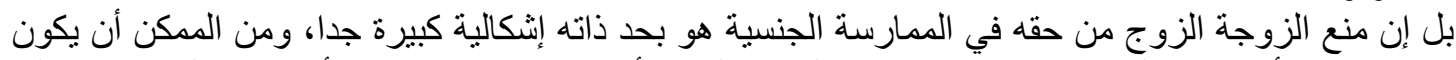

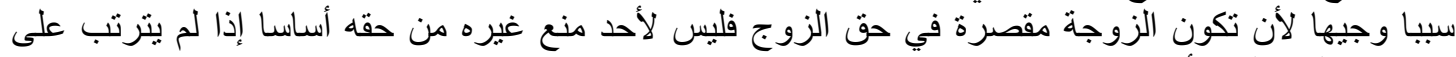

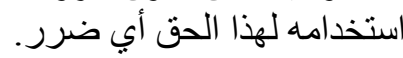

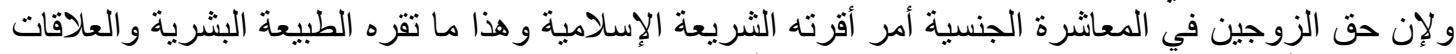

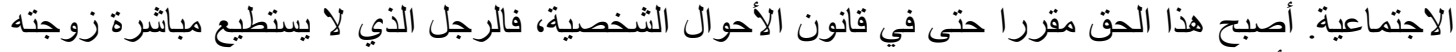

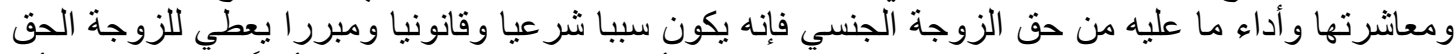

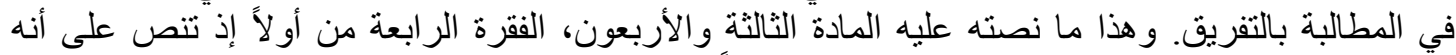

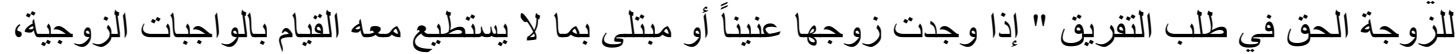

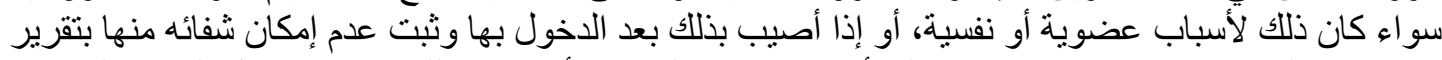

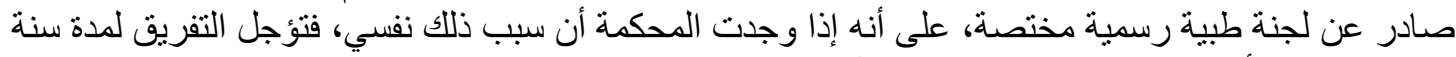

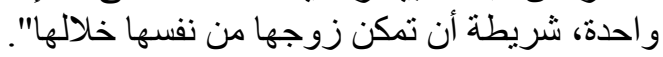

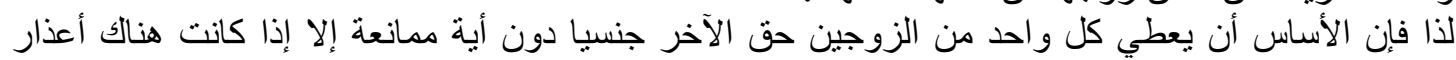

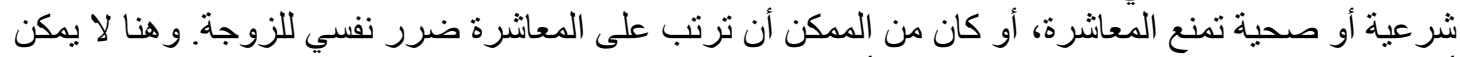

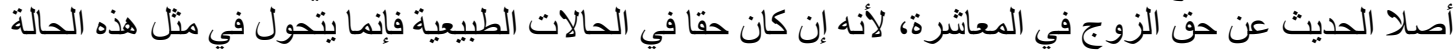

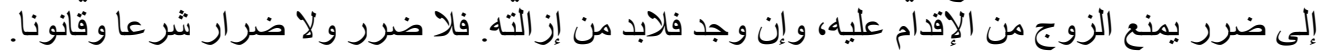

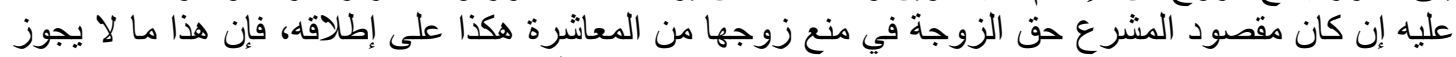

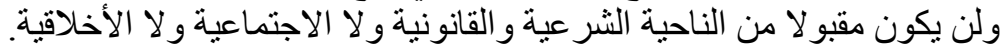

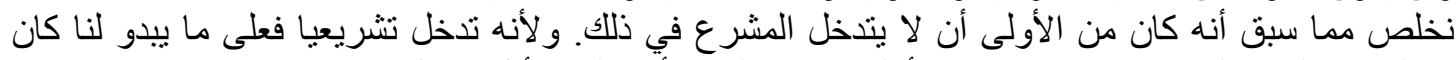

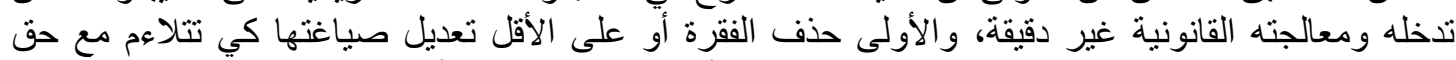

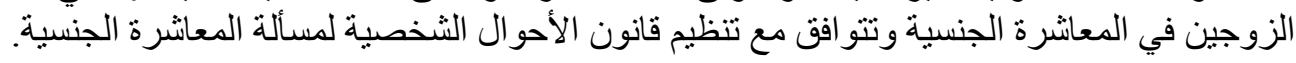

(91) الامام البخاري، صحيح البخاري، مصدر سابق، ج7 ص17. الامام مسلم، صحيح مسلم، مصدر سابق،

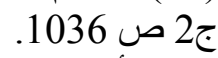
(92) أبو بكر محمد بن إسحاق بن خزيمة بن المغيرة بن صالح بن بكأ بكر السلمي النيسابوري (المتوفى: 311هـ)،

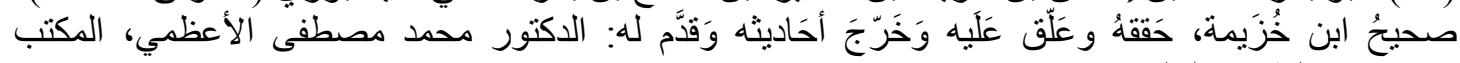

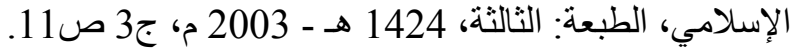

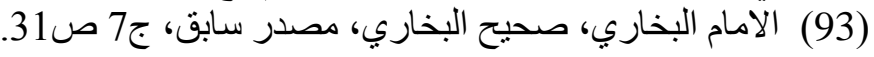




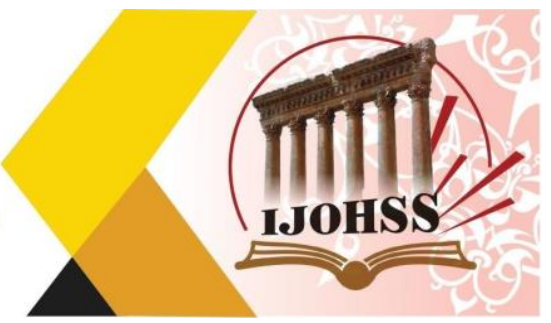

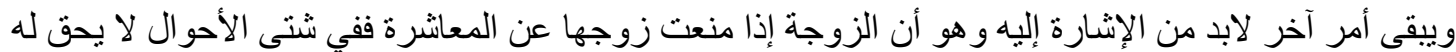

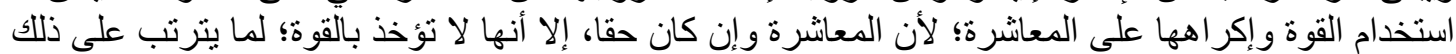

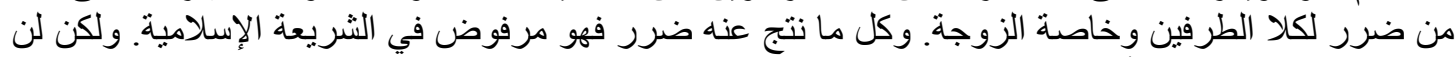

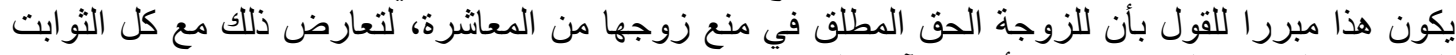

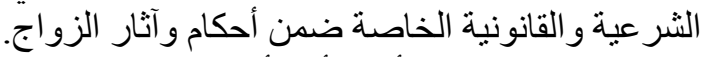

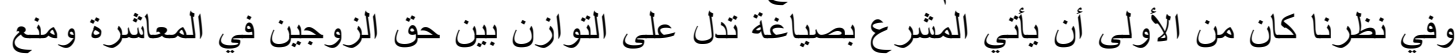

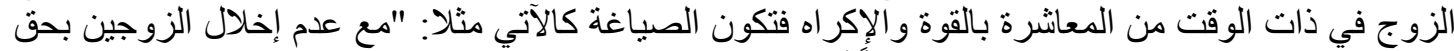

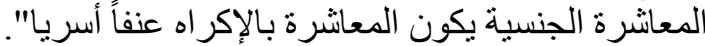

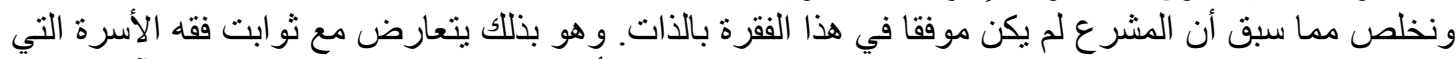

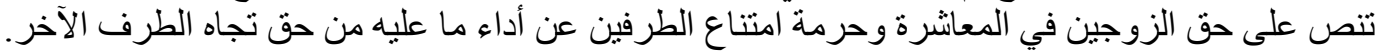

الخاتمة

بعد ان انتهيت من كتابة هذا البحث أود أن ألخص أهم النتائج في النقاط التالية:

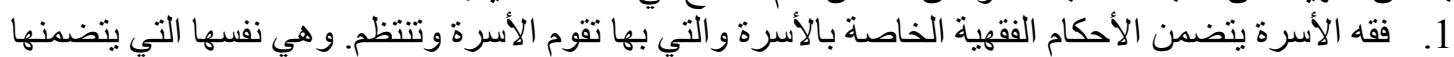

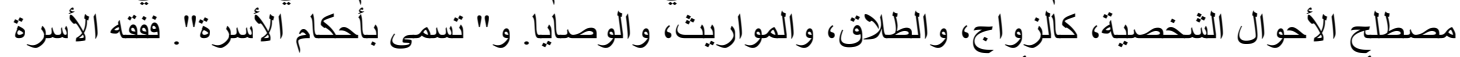

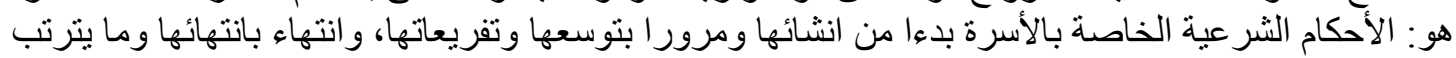

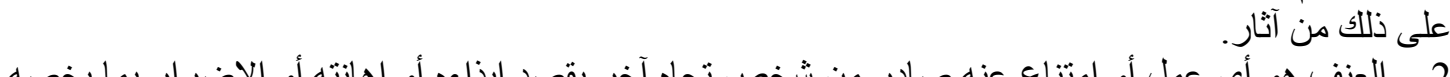

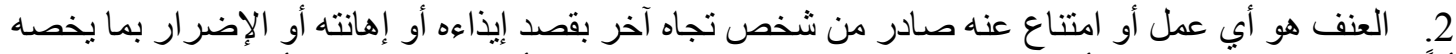

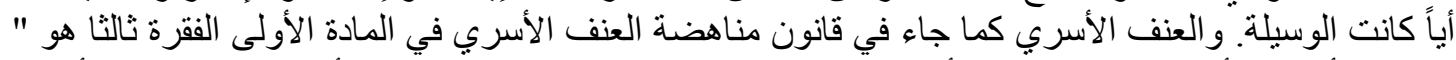

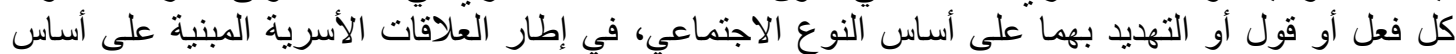

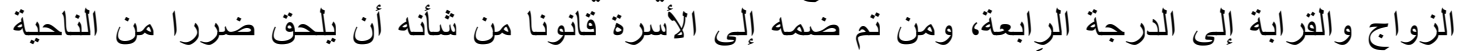

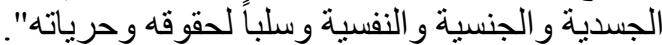
3. العنف الأسري يشكل خرقا للاستقرار وتهديدا للمؤسسة الأسرية التي هي أساس المجتمع. وتمتد آثار العنف

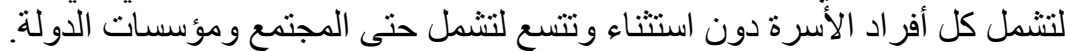

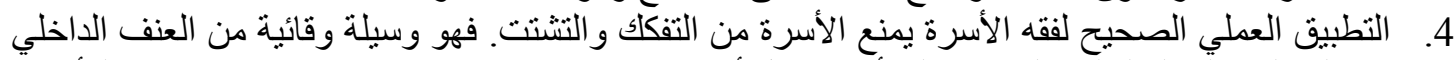

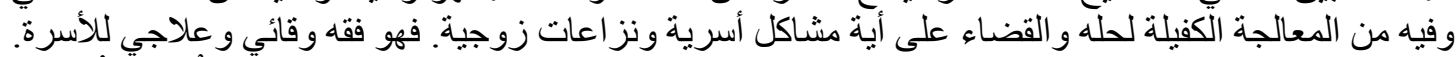

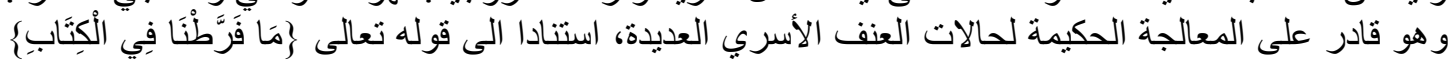

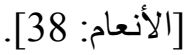

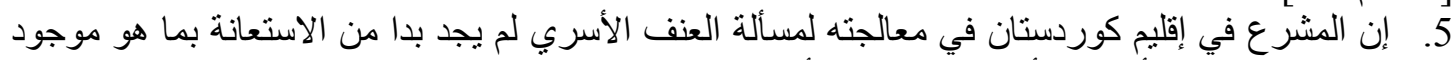

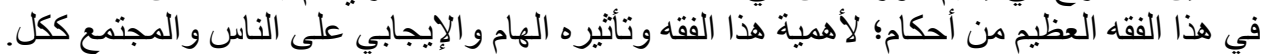

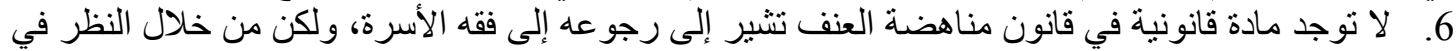

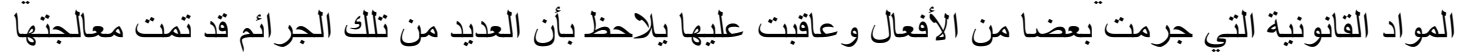
في فقه الأسرة، والبعض منها موجة الفرود في قانون الأحوال الثخصية العر اقي ذي الرقم 188 لسنة 1959 المستمد من أحكام الشريعة الإسلامية.

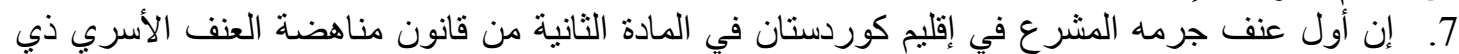

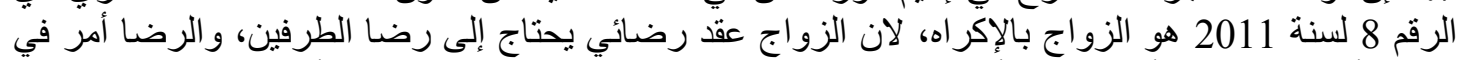

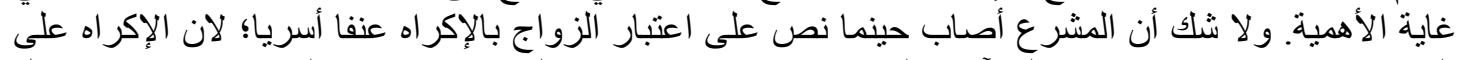

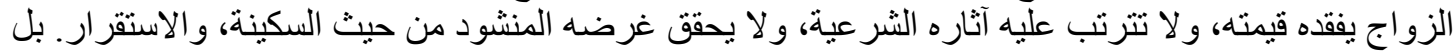

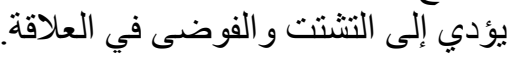

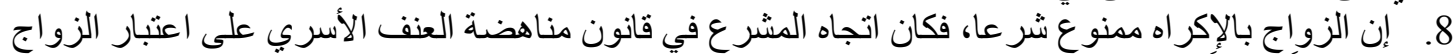

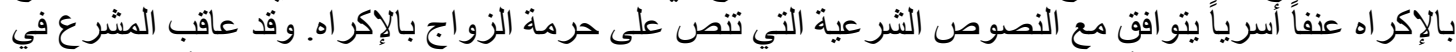

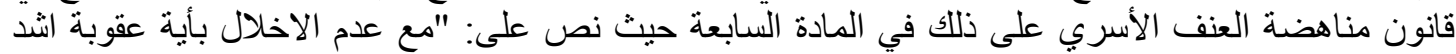




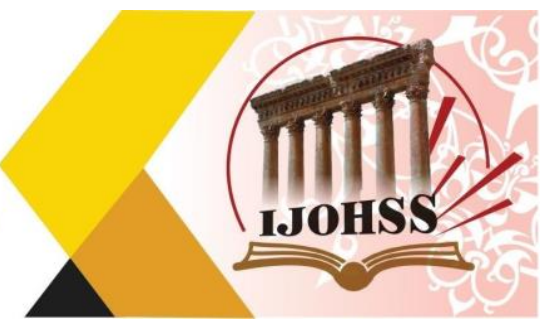

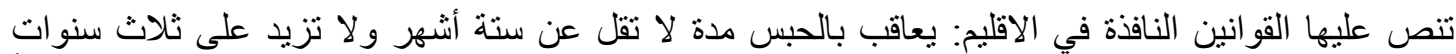

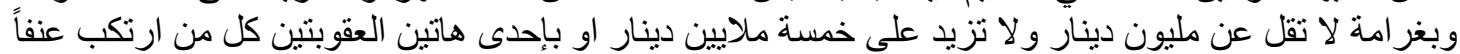

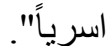

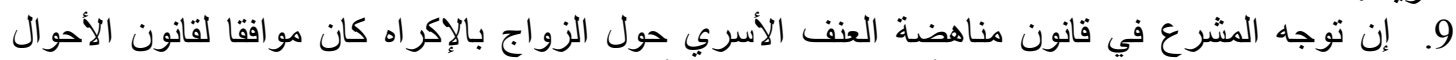

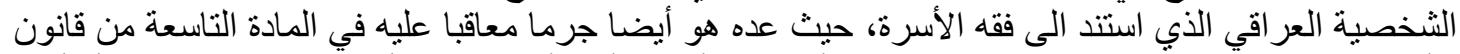

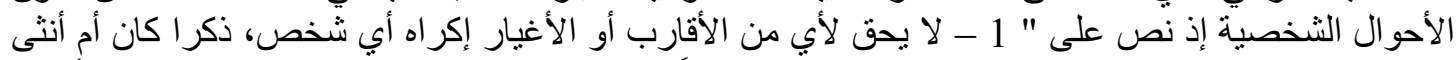

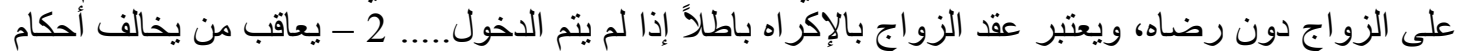

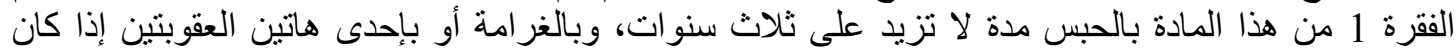

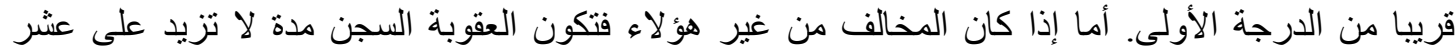

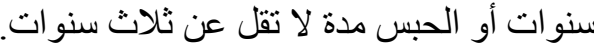

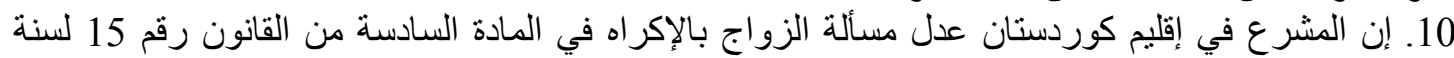

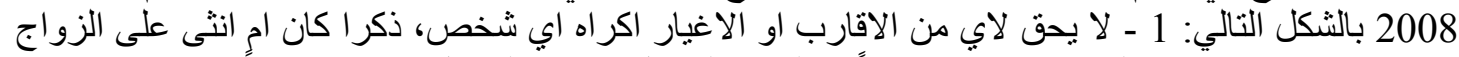

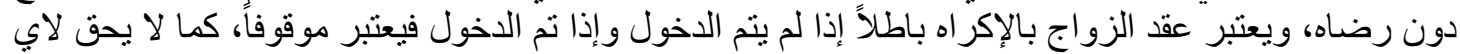

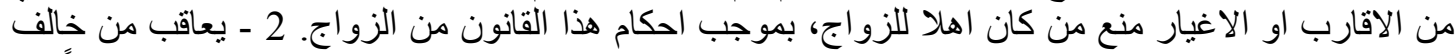

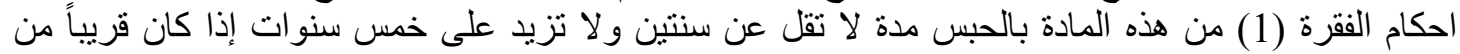

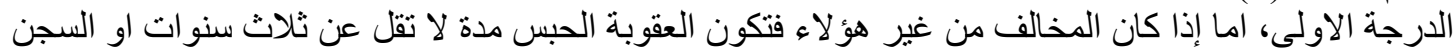

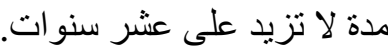

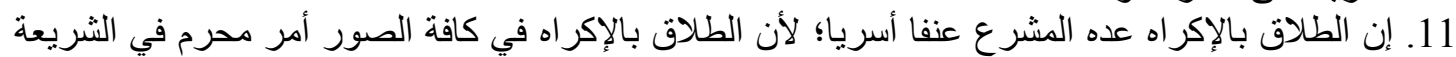

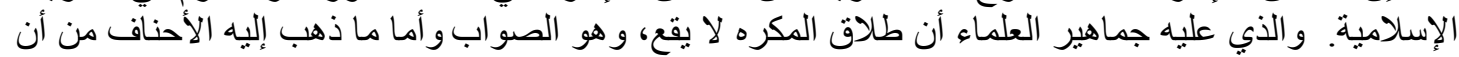

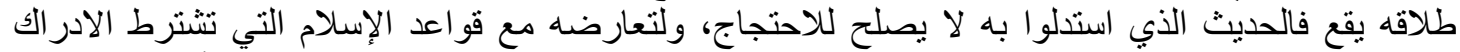

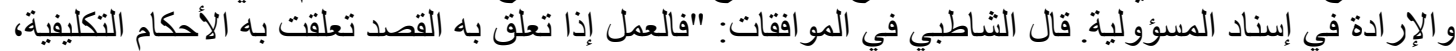
و إذا عري عن القصد لم يتعلق به شيء المئ منها".

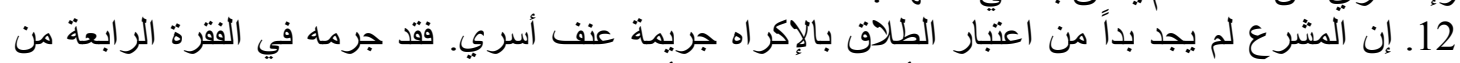

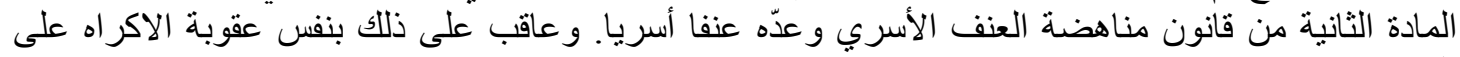

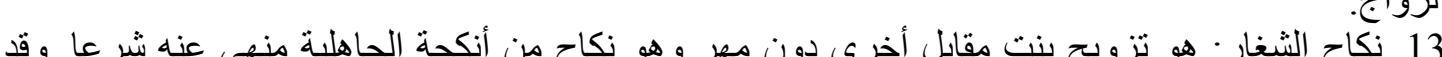

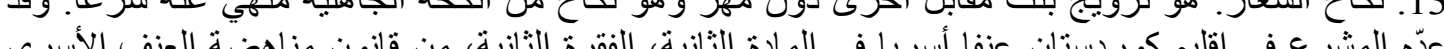

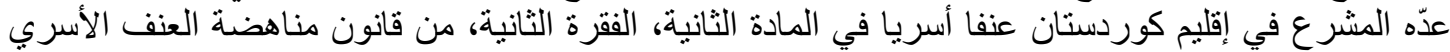

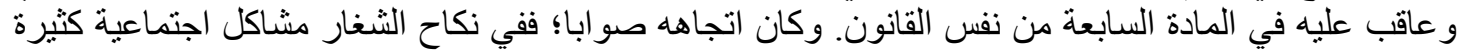

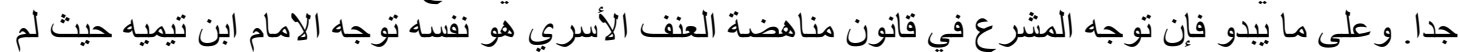

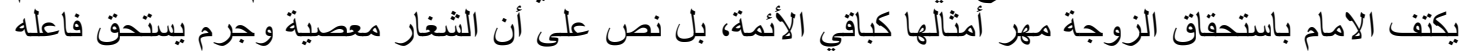
عقوبة تزجره عن ذللك عدا استحقاق المر أة لمهر المثل حينما قال "ومن فعل ذللك استحق العقوبة التي تزجره عن التحن

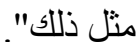

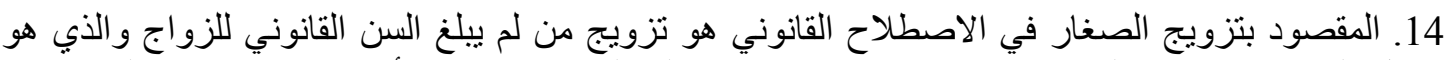

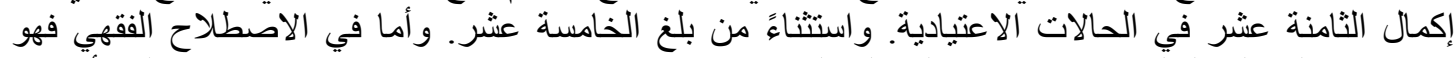

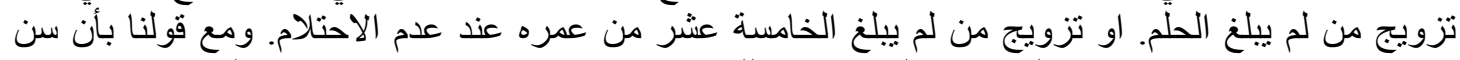

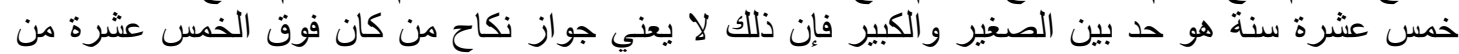

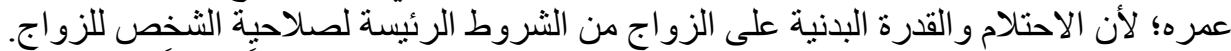

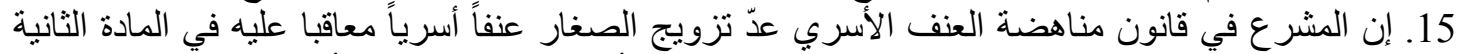

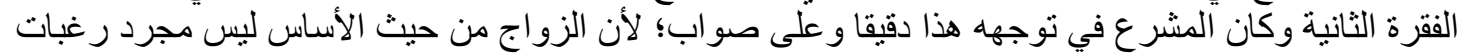

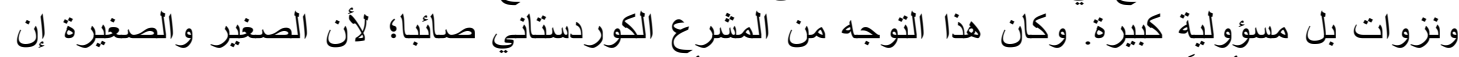
تزوجا ولم يكونا أهلاً لتحمل المسؤولية وغير قادرين على أداء ما عليهما من حقوق من ناحية المعاثرة الزوانية الزئية 


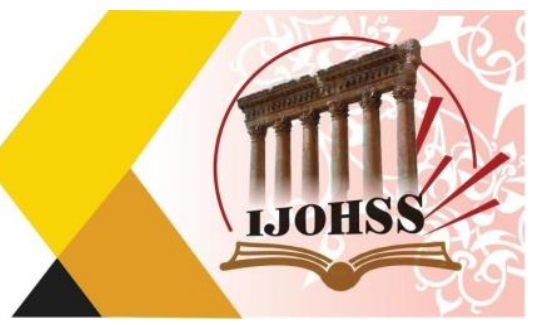

" الجنسية " فإن تحقق الضرر أمر مفروغ منه، و الضرر منهي عنه و إن وجد يجب أن يزال. قال ابن حزم عن تزويج الصغير هو "مفسوخ أبدًا".

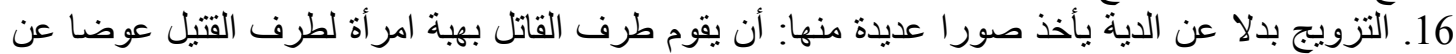

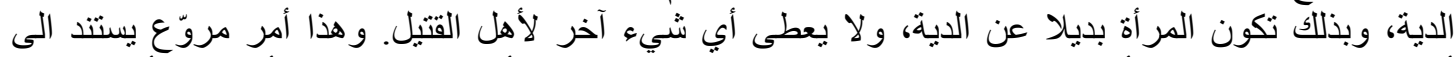

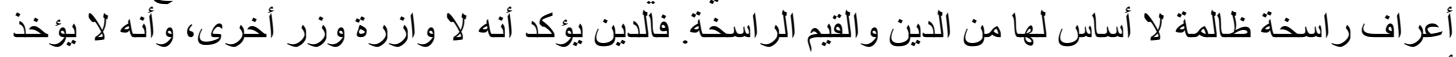
أحد بجريرة غيره. 17. لم بوضح المشرع فيره في قانون مناهضة العنف الاسري مفهوم قطع صلة الرحم، مما بعني أن جميع أشكال

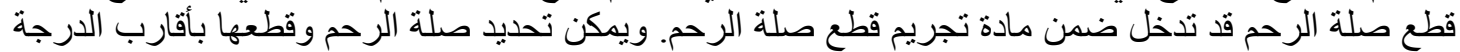

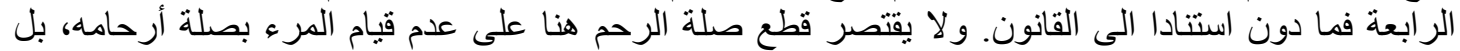

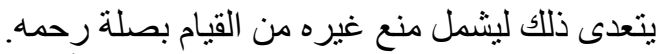

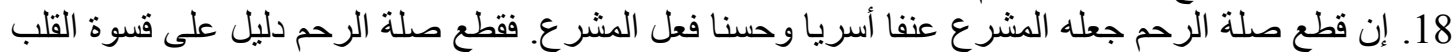

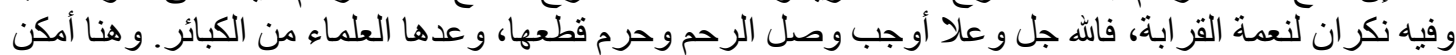

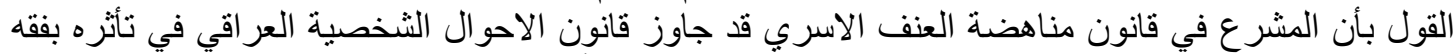

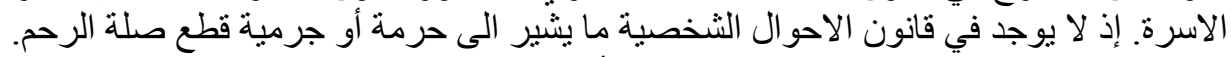

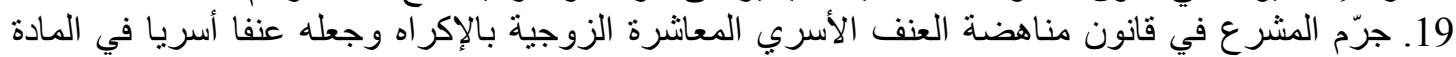

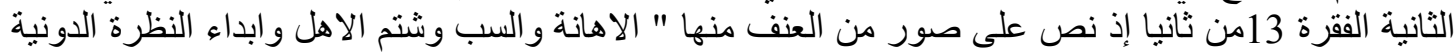

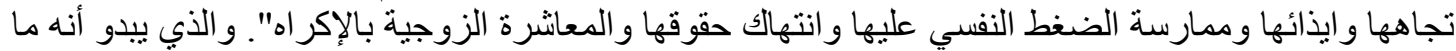

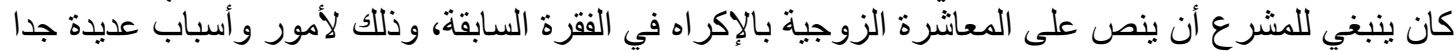

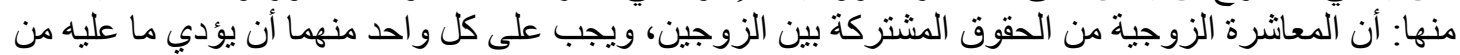

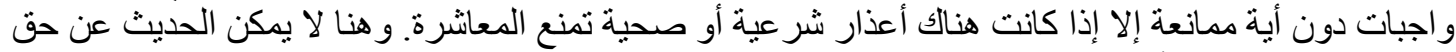

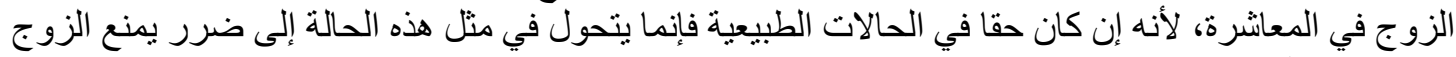

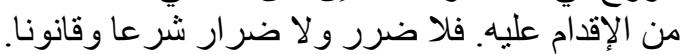

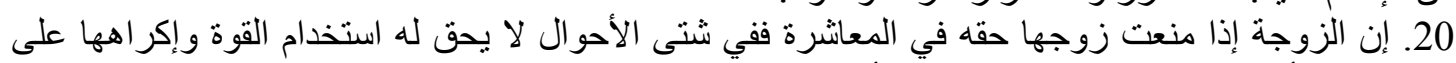

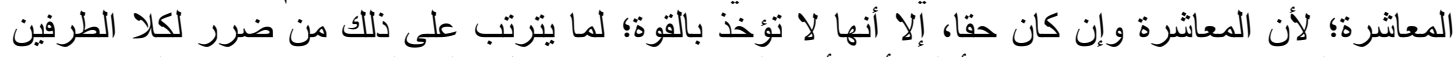

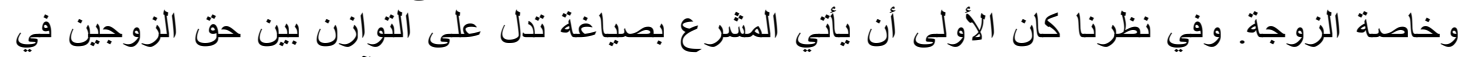

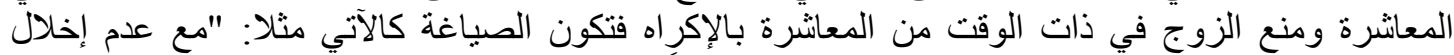

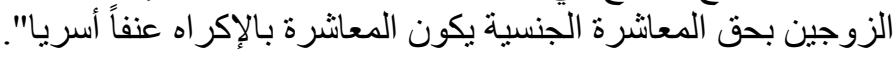

المصادر بعد القرآن الكريم

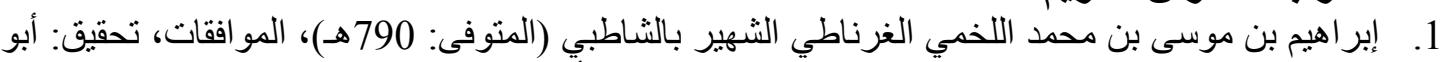

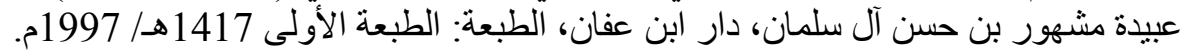
2.

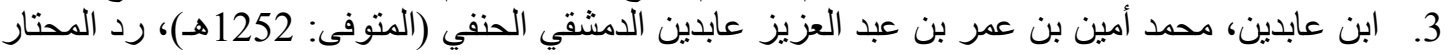

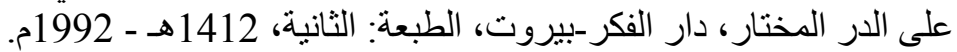

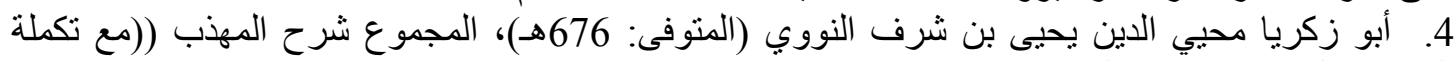
السبكي و المطيعي))، دار الفكر.

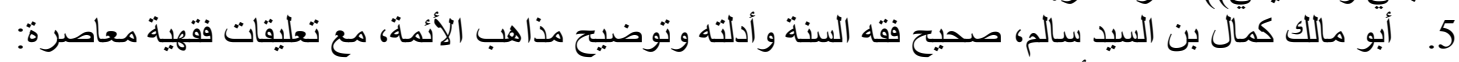

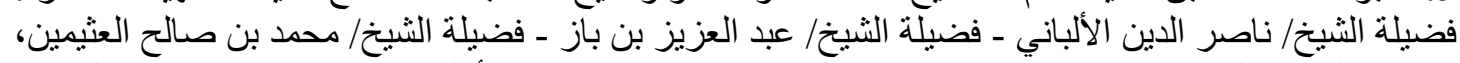

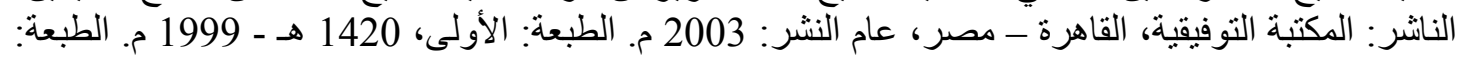

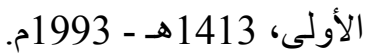




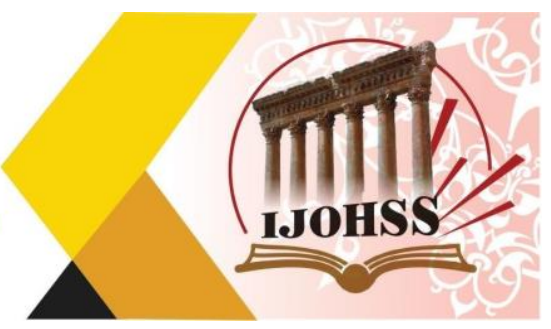

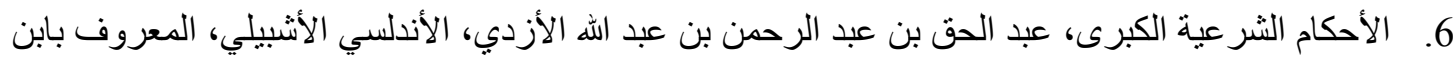

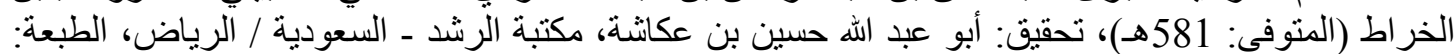

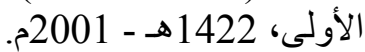

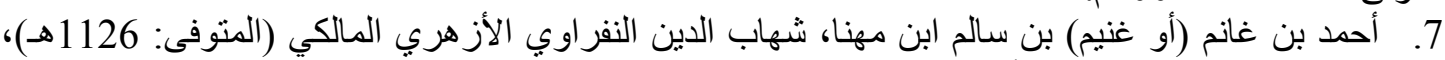

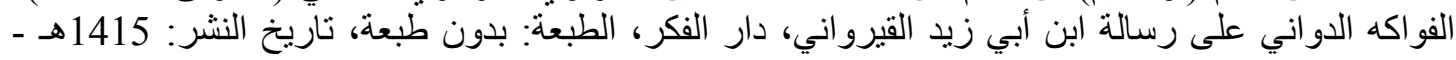
1995م. 195

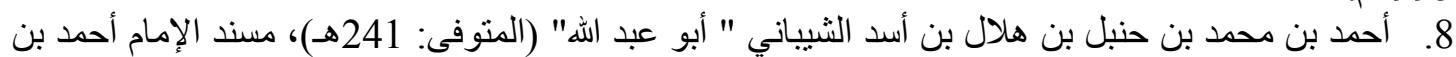

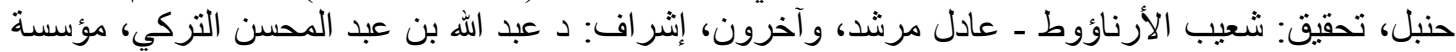

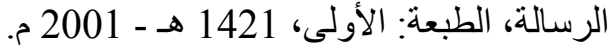
9. أحمد بن محمد بن علي بن حجر الارلئ الهيتمي السعدي الأنصاري أبو العباس (المتوفى: 974هـ)، الزواجر عن

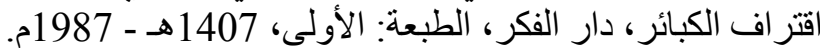

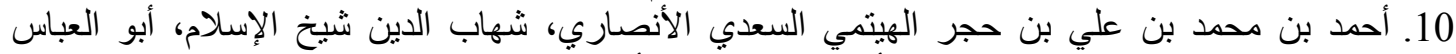

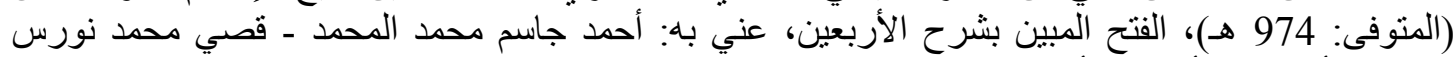

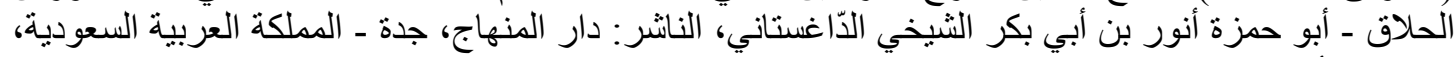

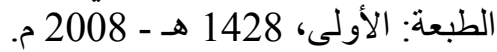

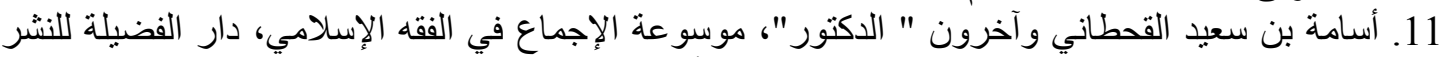

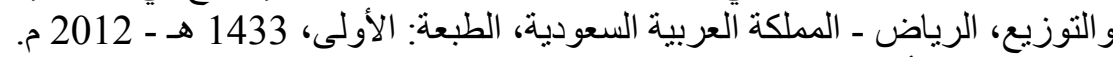

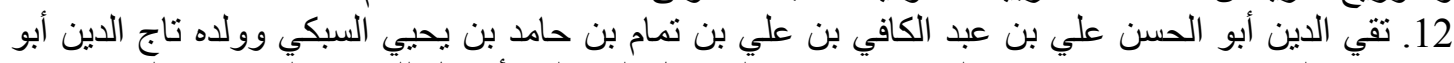

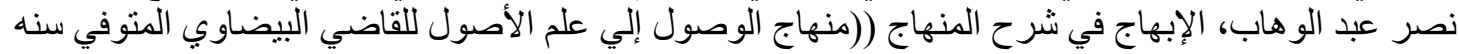

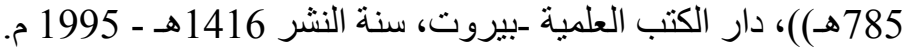

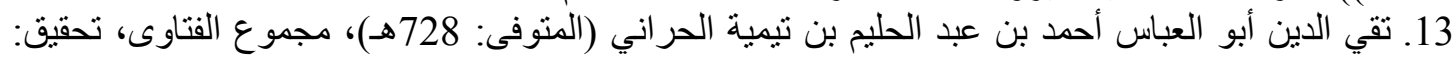
عبد الرحمن بن محمد بن قاسم العي العي 14. تقي الدين أبو العباس أحمد بن عبد الحليم بن تيمية الحراني (المتوفى: 728هـ)، مجموع الفتاوى، تحقيق الحقيق:

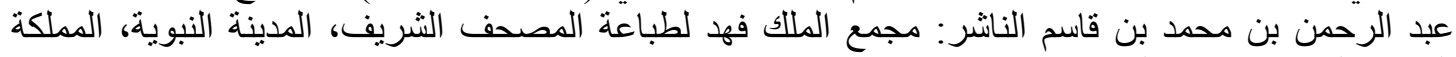

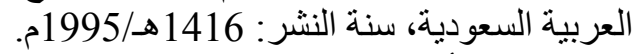

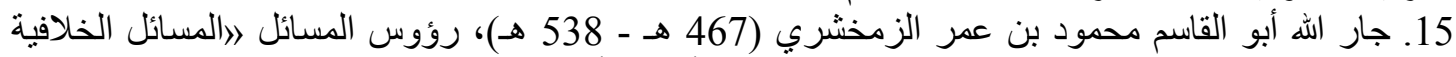

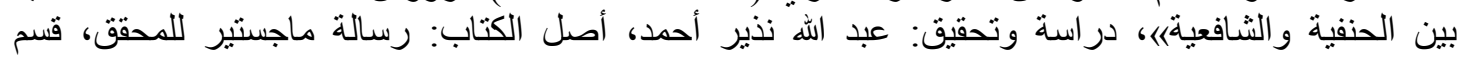

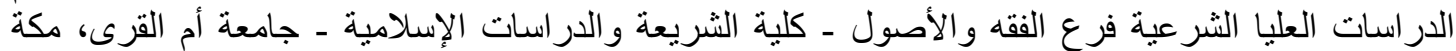

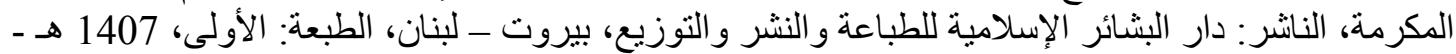

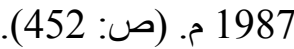

16. 19ريدة العربي الجديد في الموقع الرسمي لها على الموقع التالي

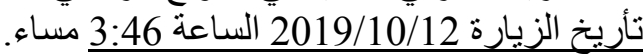

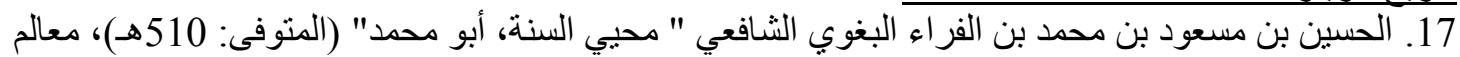

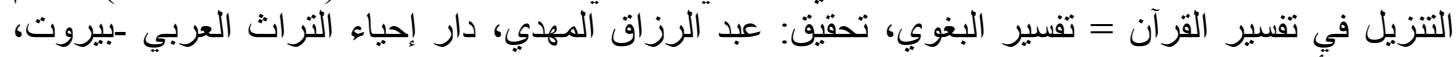

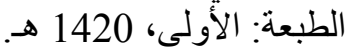
18. حكمت بن بشير بن باسين "الأستاذ الدكتور"، موسوعة الصحيح المسبور من التفسير بالمأثور، دار المآثر

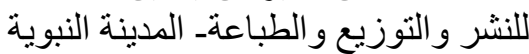
19. حمد بن محمد بن إبر اهيم بن الخطاب "أبو سليمان البستي البعة المعروف بالخطابي" (المتوفى: 388هـ)، معالم

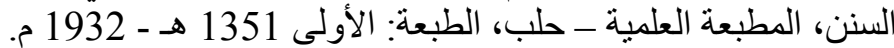

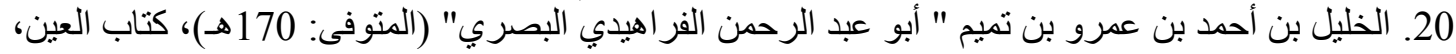
تحقيق: د مهدي المخزومي، د. إبر اهيم السامر ائي، دار ومكتبة الهن الهلال. 


\section{المجلة الحولية للملوم الأسانسية والإمتصاعية}

International Journal of Humanities and Social Sciences website:www.ijohss.com Email:editor@ijohss.com مارس 2021 العداد (19) ISSN: $2415-4822$

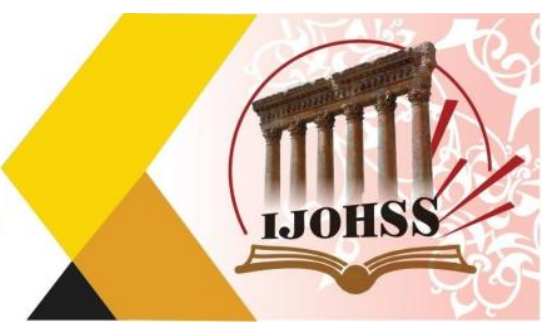

21. د. فريدة جاسم، العنف الأسري ضد المرأة وآليات الحماية المؤسية، دراسة ميدانية لعينة من النساء

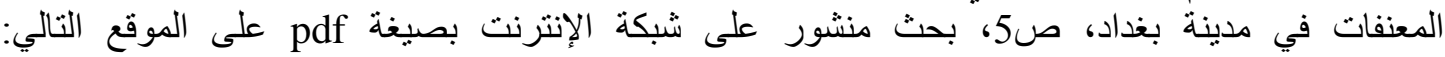
.http://iwsaw.lau.edu.lb/files/Faridajassem2.pdf

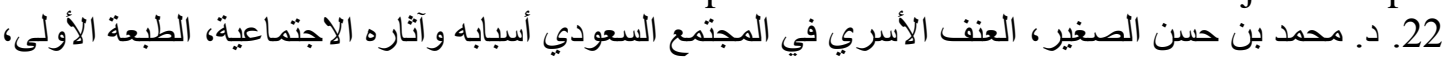

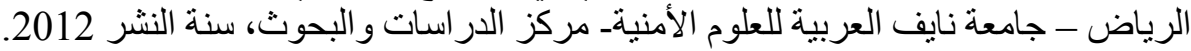

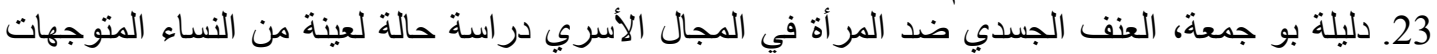

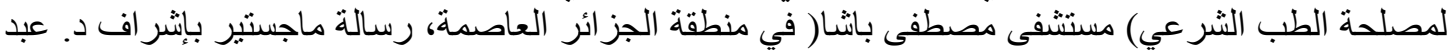

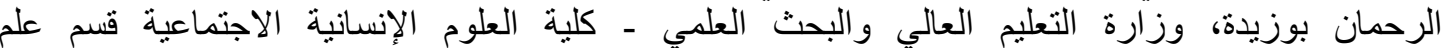

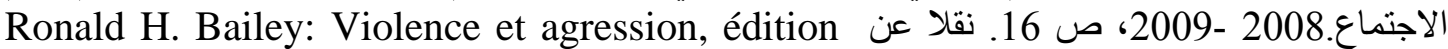
Time Life, Paris, 1977, p 10. 24. ريحاني الزهرة، العنف الأسري ضد المر أة و علاقته بالاضطر ابات السيكوسو ماتية، رسالة ماجستير مقدمة الإسية

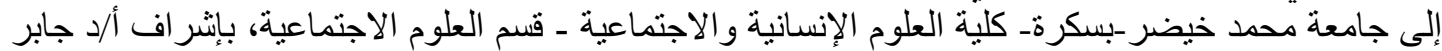

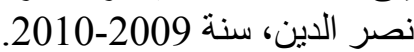

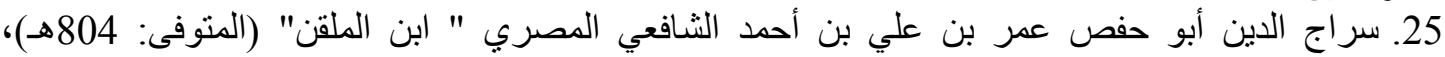

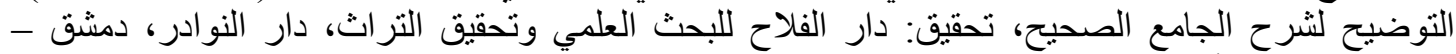

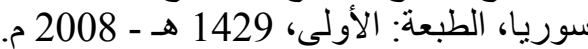
26. سر اج الدين أبو حفص عمر بن علي بل بن أحمد الثافعي المصري " ابن الملقن" (المتوفى: 804هـ)، البدر

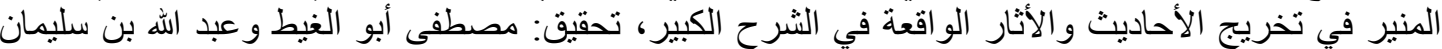

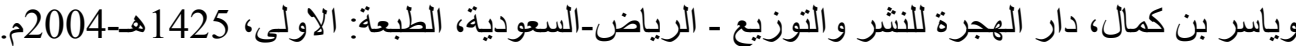

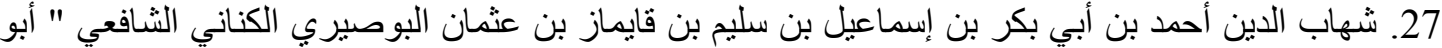

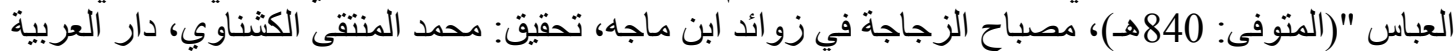

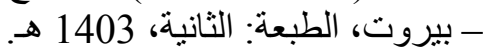

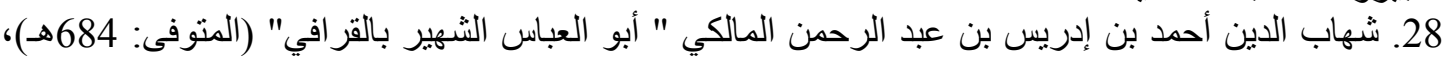

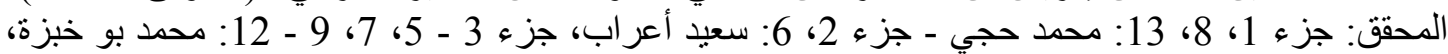

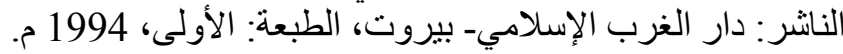

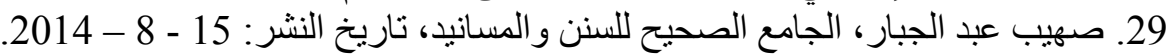

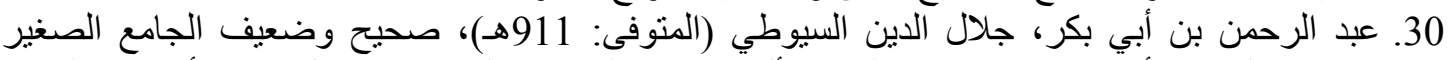

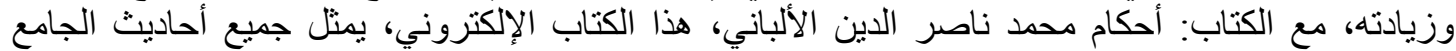

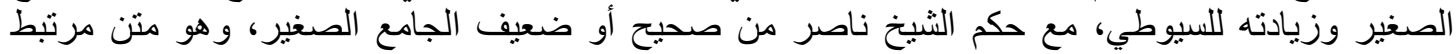
بشرحه، من فيض القدير للمناوي. 31. عبد الرحمن بن محمد بن قاسم العاصمي القحطاني الحنبلي النجدي (المنوفى: 1392هـ)، ط2، 1406 هـ، الإحكام شرح أصول الأحكام. 32. عبد الرحمن بن محمد عوض الإحمام الجزيري (المتوفى: 1360هـ)، الفقه على المذاهب الأربعة، دار الكتب

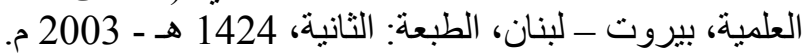

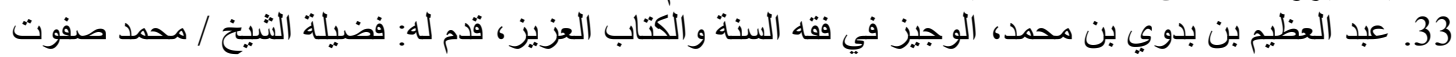

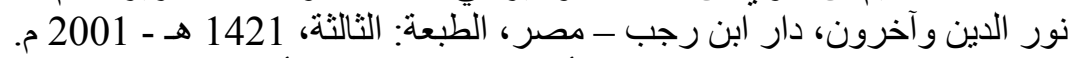

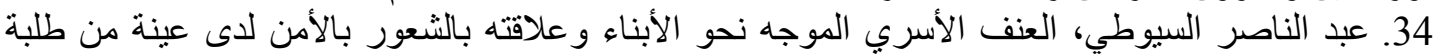

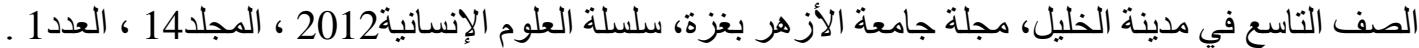

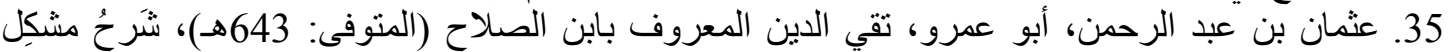

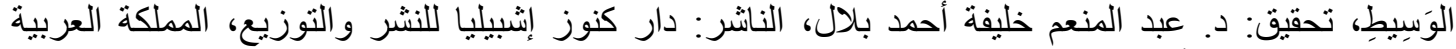
السعودية، الطبعة: الأولى، 1432 هـ - 2011 م. 


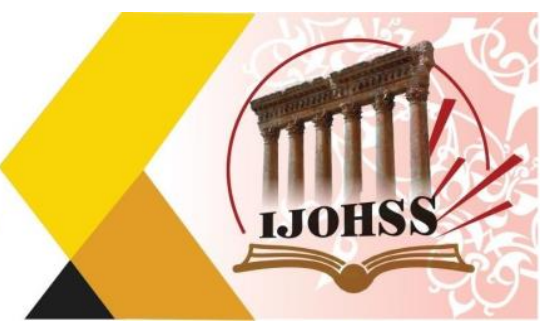

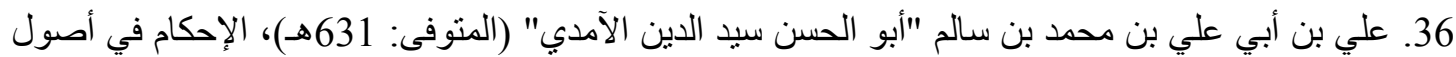

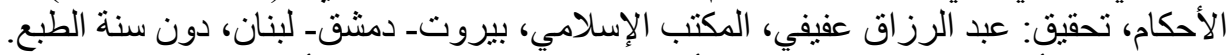

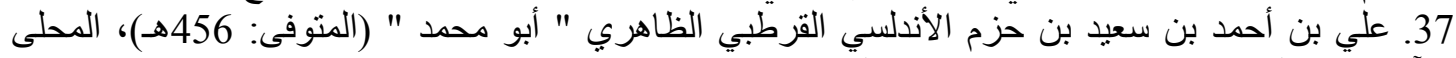

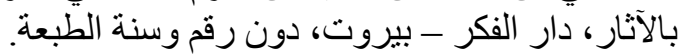

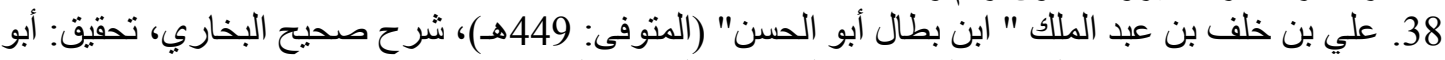

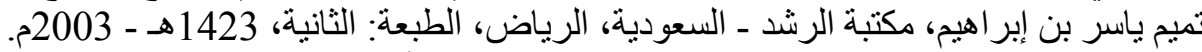

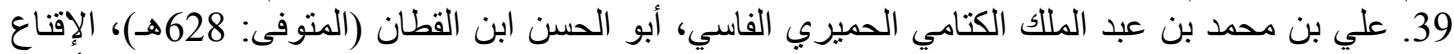
في مسائل الإجماع، تحقيق: حسن فوزي الصعيدي، النانشر: الفاروق الحديثة للطباعة والنشر، الطبعة: الأولى، الألى

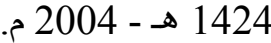
40. فاروق عبد الله كريم " الدكتور"، الوسيط في شرح قانون الأحوال الشخصية العراقي، النانر: الفاروق

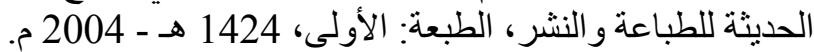

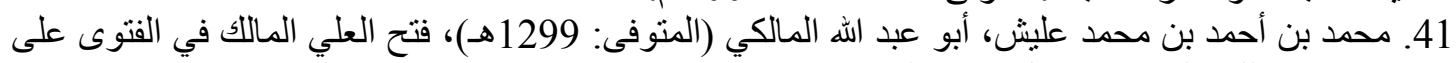

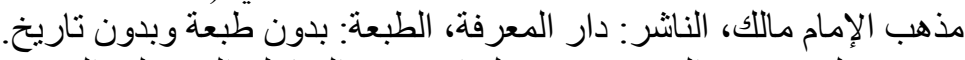

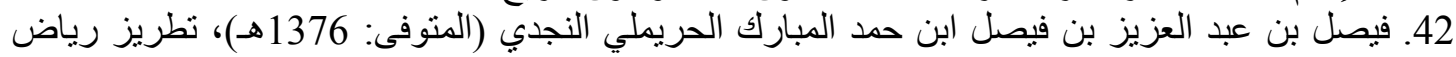

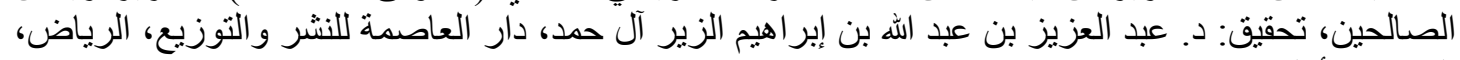

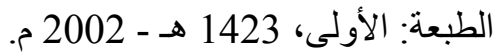
43. فيصل بن عبد العزيز بن فيصل ابن حمد المبارك الحريملي النجدي (المتوفى: 1376هـ)، خلاصة الكلام

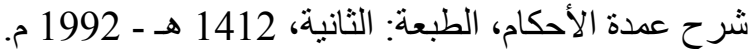
44. قانون مناهضة العنف الاسري-رقم 8 لسنة 2011 صنانة صنادر من برلمان إقليم كوردستان.

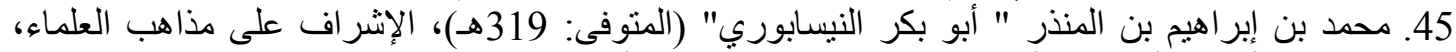

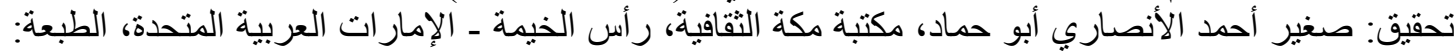

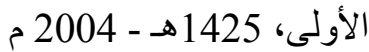
46. محمد بن إبراهيم بن عبد الله التويجري، موسوعة الفقه الإسلامي، بيت الأفكار الدولية، الطبعة: الأولى،

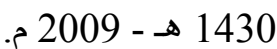

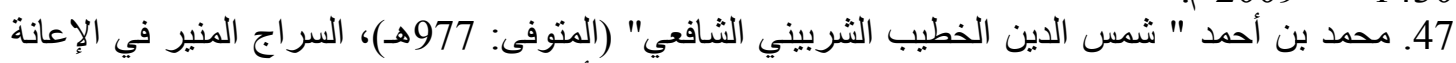

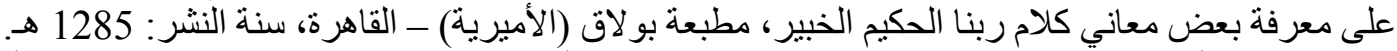

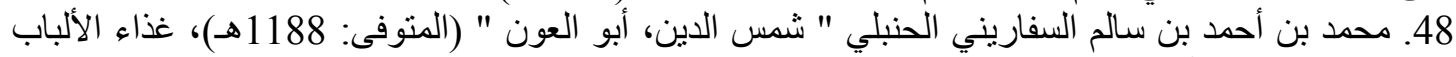

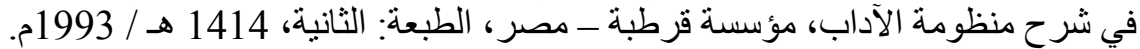
49. محمد بن أحمد بن محمد بن عبد الأب اله "أبو القاسم ابن جزي الكلبي الغرناطي" (المنوفى: 741هـ)، القوانين

50. محمد بن إدريس الثافعي المطلبي القرشي المكي " أبو عبد الله" (المنوفى: 204هـ)، تفسير الإمام الثافعي،

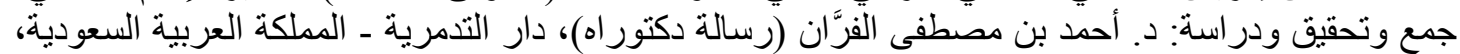

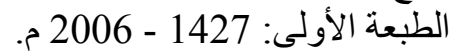

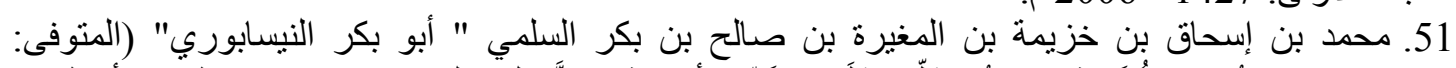

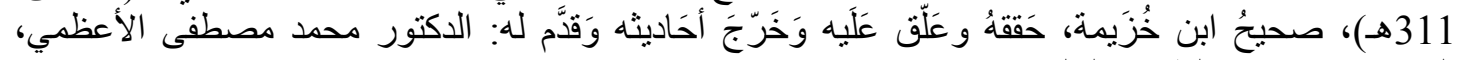

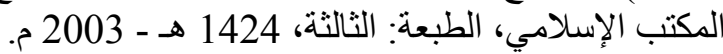

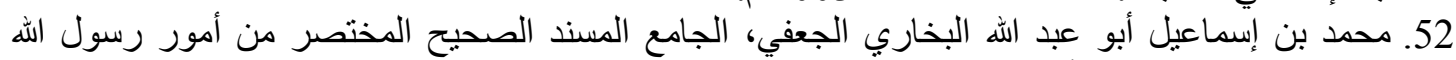

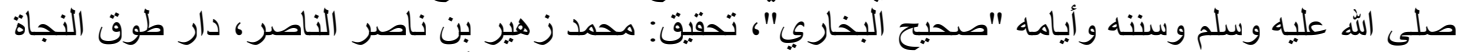

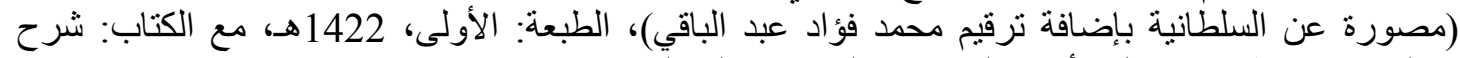

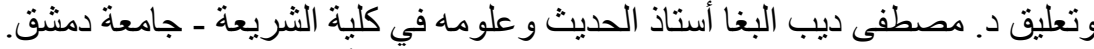

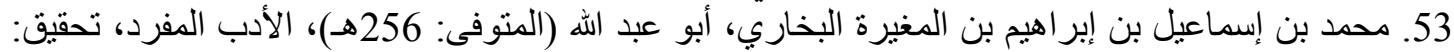
محمد فؤاد عبد الباقي، دار البشائر الإسلامية ـ بيروت، الطبعة: الثبارئ الثالثة، 1409 - 1989. 


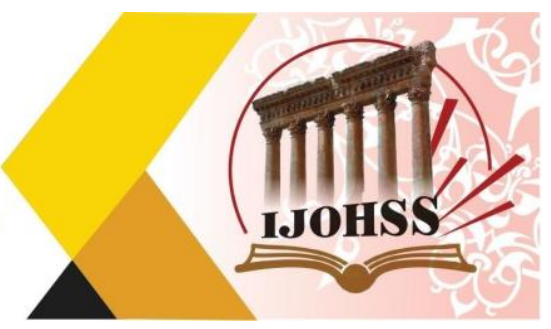

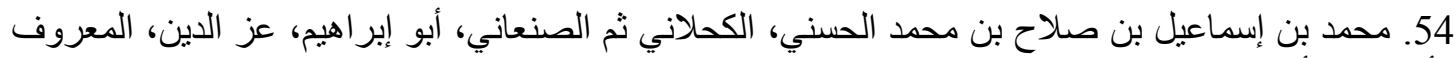

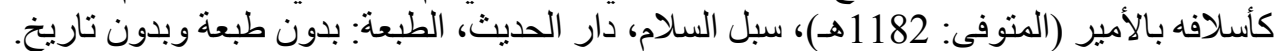

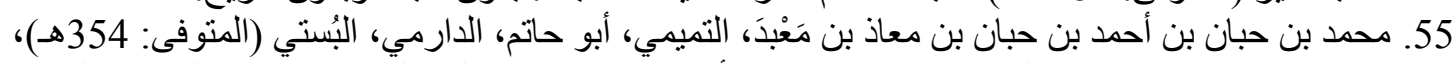

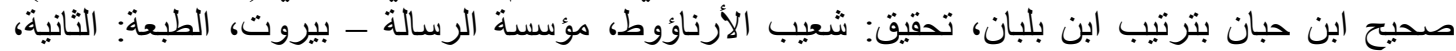
$1993-1414$

56. محمد بن علي بن محمد بن عبد الله الثوكاني اليمني (المتوفى: 1250هـ)، نيل الأوطار، تحقيق: عصام

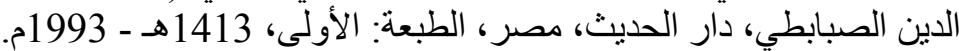
57. محمد بن محمد " أبو حامد الغز الي" (المنوفى: 505هـ)، المستصفى، الحئ، تحقيق: محمد عبد السلام عبد الثشافي، دار الكتب العلمية

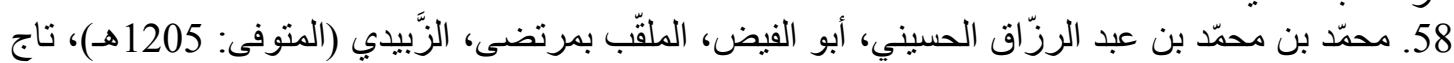

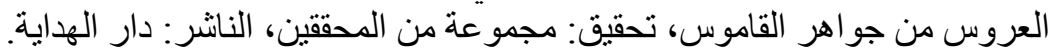

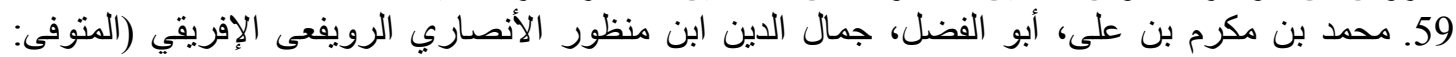

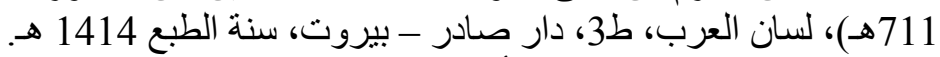

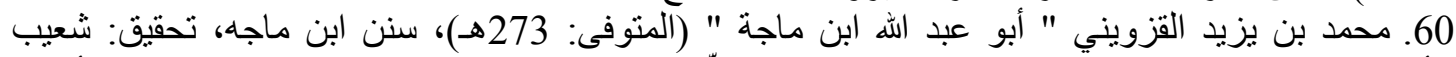

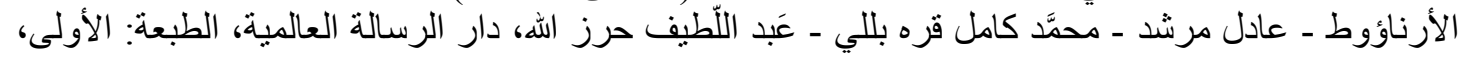

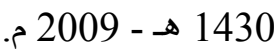
61. محمد بن يوسف بن علي بن بوسف بن بن حيان أثثير الدين " أبو حيان الأندلسي" (المتوفى: 745هـ)، البحر

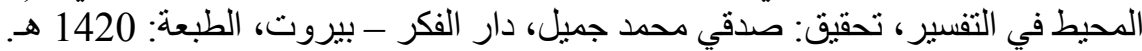

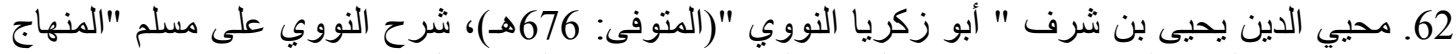

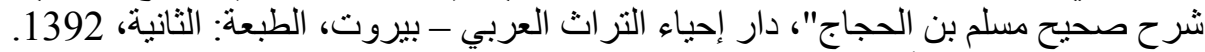

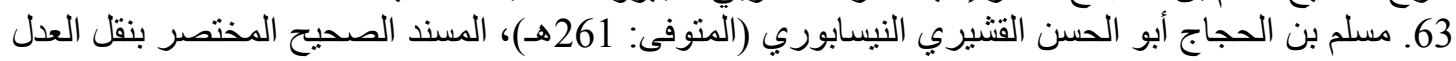

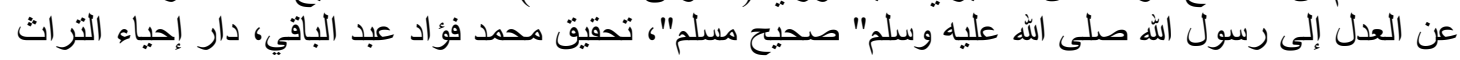

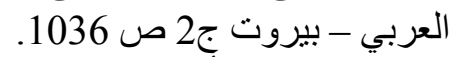
64. نأصر الدين أبو سعيد عبد الله بن عمر بن محمد الثيرازي البيض البيضاوي (المتوفى: 685هـ)، أنوار التنزيل

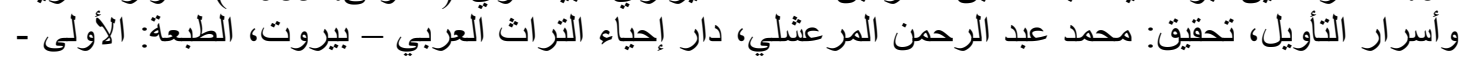
1418 هـ 1418 65. نايف بن محمد المرواني "العقيد الدكتور"، العنف الأسري در اسة مسحية تحليلية في منطقة المدينة المنورة،

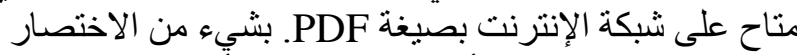

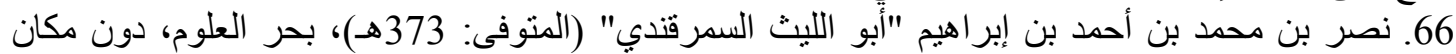

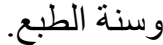
67. نظام الدين الحسن بن محمد بن حسين القمي النيسابوري (المتوفى: 850هـ)، غرائب القرآن ورغائب الفرقان، تحقيق: الثيخ زكريا عمير الزين الزين

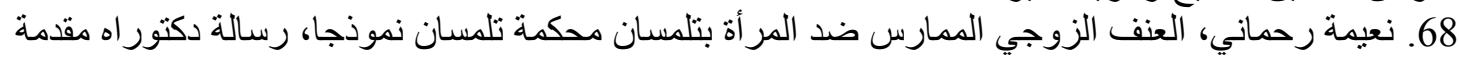

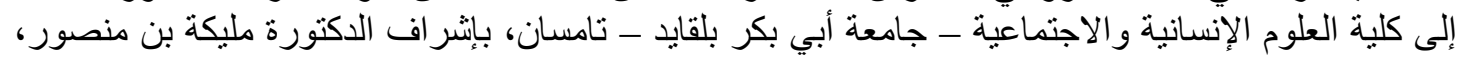

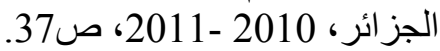

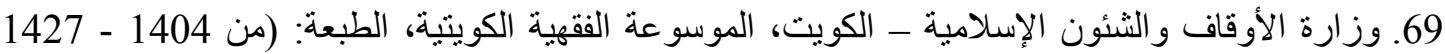

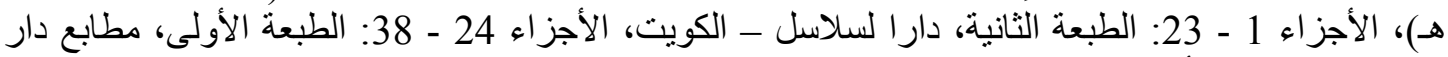

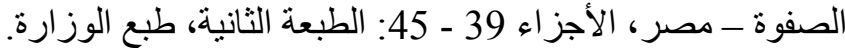

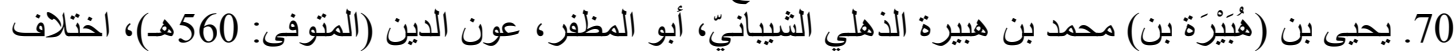

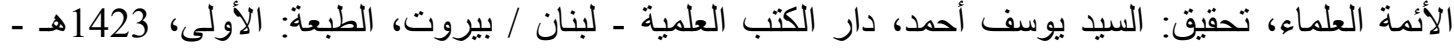




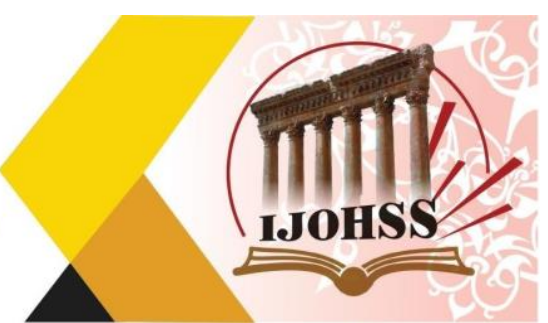

\section{Sources after the Holy Quran}

1. Ibrahim bin Musa bin Muhammad Shatibi (deceased: 790 AH), Almowafaqat, edited by: Abu Ubaidah Mashhur bin Hassan Al Salman, Ibn Affan House, Edition: First Edition 1417 AH / 1997 CE. 2. Ibn Daqiq Al-Eid, Al-Sunnah AlMuhammadiyah Press, Ihkam Al-Ahkam, Sharh Umdat Al Ahkam, without edition and without date.

3. Ibn Abdin al-Hanafi (deceased: 1252 AH), Raddu Al-Muhtaar on al-Dur alMukhtar, Dar al-Fikr - Beirut, second edition, 1412 AH - 1992 AD.

4. Abu Zakaria Muhi al-Din Yahya bin Sharaf al-Nawawi (deceased: $676 \mathrm{AH}$ ), Al Majmoo 'Sharh al-Muhdhab ((with complementing al-Subki and al-Mutai'i)), Dar alFikr.

5. Abu Malik Kamal bin Al-Sayyid Salem, true jurisprudence of the Sunnah and its evidence and clarification of the doctrines of the imams, publisher: Al-Tawfiqiah Library, Cairo - Egypt, year of publication: 2003 AD. Edition: First Edition, 1420 AH - 1999 AD. Edition: First Edition, 1413 AH - 1993 AD.

6. Abd al-Haq bin Abdul Rahman bin Abdullah al-Azdi, known as Ibn al-Kharrat (deceased: $581 \mathrm{AH}$ ), Al Ahkam Al sharya Al Kobra, edited by: Abu Abdullah Hussain bin Okasha, Al-Rushd Library - Saudi Ariabia / Riyadh, Edition: First, 1422 AH - 2001 AD.

7. Ahmad bin Ghanim (or Ghoneim) bin Salem Ibn Muhanna, Shihab al-Din alNafrawi al-Azhari al-Maliki (died: 1126 AH), al-Fawkih al-Dawani on Risala Ibn Abi Zayd al-Qayrawani, Dar al-Fikr, Edition: without edition, publication date: 1415 AH 1995 CE.

8. Ahmed bin Muhammad bin Hanbal "Abu Abdullah" (deceased: $241 \mathrm{AH}$ ), the Musnad of Imam Ahmad bin Hanbal, edited by: Shuaib Al-Arna`out - Adel Murshid, and others, supervised by: Dr. Abdullah bin Abdul Mohsen Al-Turki, founder The Letter, Edition: First, 1421 AH - 2001 AD.

9. Ahmed bin Muhammad bin Ali bin Hajar al-Haytami al-Saadi al-Ansari Abu alAbbas (deceased: 974 AH), Azzawajir an Iqtraf Al Kabair, Dar Al-Fikr, First Edition, 1407 AH - 1987 AD.

10. Ahmed bin Muhammad bin Ali bin Hajar al-Haytami, (deceased: 974 AH), AlFath Al-Mubeen BI sharh Al-Arbaeen. cared by: Ahmad Jassim Muhammad AlMuhammad - Qusay Muhammad Nawras Al-Hallaq - Abu Hamza Anwar Bin Abi Bakr Al-Sheikhi Al-Daghistani, Publisher: Dar Al-Minhaj, Jeddah - Kingdom of Saudi Arabia, Edition: First, 1428 AH - 2008 AD.

11. Osama bin Saeed Al-Qahtani and others, "The Doctor", Encyclopedia of Al Ijmaa in Islamic Jurisprudence, Dar Al-Fadila for Publishing and Distribution, Riyadh Kingdom of Saudi Arabia, First Edition: 1433 AH - 2012 AD.

12. Taqi al-Din Abu al-Hasan Ali bin Abd al-Kafi bin Ali bin Tamam bin Hamid bin Yahya al-Sabki and his son Taj al-Din Abu Nasr Abd al-Wahhab, Al Ibhaj fi sharh Al Minhaj, Dar Al-Kutub Al-Ilmiyya - Beirut, year of publication 1416 AH - 1995 CE. 


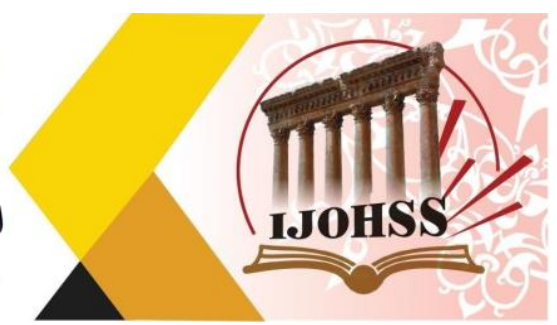

13. Taqi al-Din Abu al-Abbas Ahmad bin Abd al-Halim bin Taymiyyah al-Harrani (deceased: 728 AH), Majmoo 'al-Fatwa, edited by: Abd al-Rahman bin Muhammad bin Qasim.

14. Taqi al-Din Abu al-Abbas Ahmad bin Abd al-Halim bin Taymiyyah (deceased: 728 AH), Majmoo 'al-Fatwa, edited by: Abd al-Rahman bin Muhammad bin Qasim Publisher: King Fahd Complex for the Printing of the Noble Qur'an, Madinah, ksa, year of publication: $1416 \mathrm{AH} / 1995 \mathrm{AD}$.

15. Jarallah Abu al-Qasim Mahmoud ibn Omar al-Zamakhshari (467 AH - 538 AH), Topics of Issues "Roos Al Msaiel Akhilafya Between the Hanafi and Shafi'i", Study and Investigation: Abdullah Nazir Ahmad, Origin of the Book: Master Thesis for the Investigator, Department of Sharia Graduate Studies, Jurisprudence and Usul Branch College of Sharia and Islamic Studies - Umm Al-Qura University, Makkah AlMukarramah, Publisher: Dar Al-Bashayer Al-Islamiya for Printing, Publishing and Distribution, Beirut - Lebanon, First Edition, 1407 AH - 1987 AD. (P .: 452).

16. Al-Araby Al-Jadeed newspaper is on its official website at the following website https://www.alaraby.co.uk/portal Date of visit 10/12/2019 at 3:46 pm.

17. Al-Hussain bin Masoud bin Muhammad bin al-Furra al-Baghawi al-Shafi' $i$ "The One who revives the Sunnah, Abu Muhammad" (died: 510 AH), Tafsir al-Baghawi, edited by: Abd al-Razzaq al-Mahdi, House of Revival of Arab Heritage - Beirut, edition: first, $1420 \mathrm{H}$.

18. Hikmat bin Bashir bin Yassin, "Professor The Doctor", Encyclopedia of Al-Sahih Al-Masbor from Tafsir AL Mathoor, Dar Al-Ma'ather for Publishing, Distribution and Printing - Madinah

19. Hamad bin Muhammad bin Ibrahim bin al-Khattab, "Abu Sulayman al-Basti, known as al-Khattabi" (deceased: 388 AH), Maalim Al Sunan, Scientific Press Aleppo, Edition: First 1351 AH - 1932 CE.

20. Al-Khalil bin Ahmed bin Amr bin Tamim "Abu Abdul Rahman Al-Farahidi AlBasri” (died: 170 AH), Al-Ain's book, edited by: Dr. Mahdi Al-Makhzoumi, d. Ibrahim al-Samarrai, the Crescent House and Library.

21. Dr. Farida Jassim, Domestic Violence Against Women and Institutional Protection Mechanisms, A Field Study of a Sample of Battered Women in the City of Baghdad, Page 5, Research published on the Internet in pdf format at the following website: http://iwsaw.lau.edu.lb/files/Faridajassem2. pdf.

22. Dr. Muhammad Bin Hassan Al-Sagheer, Domestic Violence in Saudi Society, Its Causes and Social Effects, First Edition, Riyadh - Naif Arab University for Security Sciences - Center for Studies and Research, year of publication 2012.

23. Dalila Bou Jumaa, Physical violence against women in the family, a case study of a sample of women heading for the Forensic Medical Authority (Mostafa Pasha Hospital) in the Algiers region, a master's thesis under the supervision of Dr. Abderrahmane Bouzida, Ministry of Higher Education and Scientific Research Faculty of Humanities and Social Sciences, Department of Sociology. 2008-2009, p. 


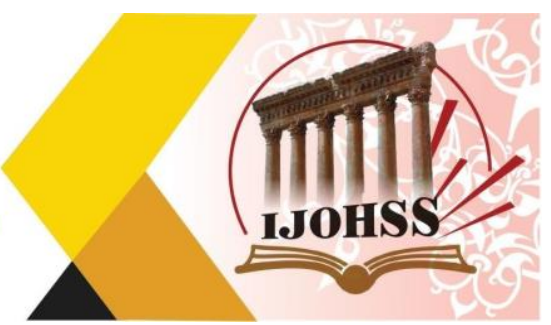

16. Quoted from Ronald H. Bailey: Violence et agression, édition Time Life, Paris, 1977, p 10.

24. Rihani Al-Zahra, Domestic Violence Against Women and Its Relation to Psychosomatic Disorders, Master Thesis submitted to Muhammad Khaider University-Biskra- College of Humanities and Social Sciences - Department of Social Sciences, under the supervision of Prof. Dr. Jaber Nasreddin, 2009-2010.

25. Siraj al-Din Abu Hafs Omar bin Ali bin Ahmad al-Shafi'i al-Masri "Ibn alMalqin" (died: 804 AH), Explanation of the Explanation of Al-Sahih Al-Jami', edited by: Dar Al-Falah for Academic Research and Heritage Verification, Dar Al-Nawader, Damascus - Syria, Edition: First, 1429 AH 2008 AD.

26. Siraj al-Din Abu Hafs Umar bin Ali bin Ahmad al-Shafi'i al-Masri "Ibn alMalqin" (died: $804 \mathrm{AH}$ ), Al-Badr al-Munir fi takhrij al hadiths and al aathar in al sharh al kabeer, edited by: Mustafa Abul Gheit, Abdullah bin Suleiman and Yasser bin Kamal, Dar Al-Hijrah for publication And Distribution - Riyadh-Saudi Arabia, First Edition, 1425 AH-2004AD.

27. Shihab al-Din Ahmad bin Abi Bakr bin Ismail bin Salim bin Qaymaz bin Othman al-Busiri al-Kanani al-Shafi'i "Abu al-Abbas" (deceased: 840 AH), Misbah al zujaja fi Zawaid Ibn Majah, edited by: Muhammad al-Muntqa al-Kashnawi, Dar al-Arabiya - Beirut, second edition: 1403 AH.

28. Shihab al-Din Ahmad bin Idris bin Abd al-Rahman al-Maliki "Abu al-Abbas the famous Qarafi" (deceased: $684 \mathrm{AH}$ ), The Investigator: Part 1, 8, 13: Muhammad Hajji - Part 2, 6: Saeed Aarab, Part 3 - 5, 7, 9 - 12: Muhammad Boukhabza, Publisher: Dar Al Gharb Al Islami - Beirut, Edition: The First, 1994 AD. 29. Suhaib Abdul-Jabbar, Al-Jami al-Sahih for al-Sunan wa al-Masanid, Publication date: 15-8-2014.

30. Abd al-Rahman bin Abi Bakr, Jalal al-Din al-Suyuti (died: 911 AH), sahih wa daeef al jami al sagheer w zyadatoho, with the book: Ahkam Muhammad Nasir al-Din al-Albani, this e-book, represents all the hadiths of al-Jami al-Sagheer and its ziyadat of al-Suyuti, with the ruling of Sheikh Nasir from Sahih Or weak al-Jami 'al-Sagheer, which is a body linked to his explanation, from the abundance of the powerful to the Manawi.

31. Abd al-Rahman bin Muhammad bin Qasim al-Asami al-Qahtani al-Hanbali alNajdi (died: 1392 AH), ed. 2, 1406 AH, Al-Ahkam Explanation of Usul Ahkam.

32. Abd al-Rahman bin Muhammad Awad al-Jaziri (died: 1360 AH), Jurisprudence on the Four Schools, Dar al-Kutub al-Ulmiyyah, Beirut - Lebanon, second edition, $1424 \mathrm{AH}-2003 \mathrm{CE}$.

33. Abd al-Azim bin Badawi bin Muhammad, al-Wajeez in the jurisprudence of the Sunnah and the dear book, presented to him: His Eminence Sheikh / Muhammad Safwat Nur al-Din and others, Ibn Rajab House - Egypt, Edition: Third, 1421 AH 2001 AD.

34. Abdel Nasser Al-Suyuti, Domestic Violence directed at children and its relationship to a sense of security among a sample of ninth grade students in Hebron, 


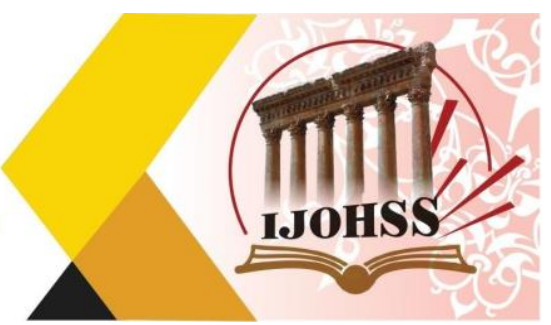

Journal of Al-Azhar University in Gaza, Human Sciences Series 2012, Volume 14, Issue 1.

35. Uthman bin Abd al-Rahman, Abu Amr, Taqi al-Din known as Ibn al-Salah (deceased: 643 AH). Explanation of mushkil al-Waseet, edited by: Dr. AbdulMoneim Khalifa Ahmed Bilal, Publisher: The Treasures House of Seville for Publishing and Distribution, Kingdom of Saudi Arabia, Edition: First, 1432 AH 2011 AD.

36. Ali bin Abi Ali bin Muhammad bin Salem "Abu al-Hasan Syed al-Din al-Amadi" (deceased: $631 \mathrm{AH}$ ), al ihkam fi Usul Ahkam, investigation by: Abd al-Razzaq Afifi, Islamic Office, Beirut - Damascus - Lebanon, without the year of printing.

37. Ali bin Ahmed bin Saeed bin Hazm Al-Andalusi Al-Qurtubi Al-Dhaheri "Abu Muhammad" (deceased: 456 AH), Al-Muhalla in Al-Athar, Dar Al-Fikr - Beirut, without the number and year of the edition.

38. Ali bin Khalaf bin Abdul Malik "Ibn Battal Abu Al-Hassan" (deceased: 449 AH), Explanation of Sahih Al-Bukhari, edited by: Abu Tameem Yasser bin Ibrahim, AlRashed Library - Saudi Arabia, Riyadh, second edition, 1423 AH - 2003 AD.

39. Ali bin Muhammad bin Abd al-Malik al-Kutami al-Hamiri al-Fassi, Abu al-Hasan ibn al-Qattan (deceased: $628 \mathrm{AH}$ ), Al-Iqna 'in matters of ijmaa, edited by: Hassan Fawzi al-Saidi, publisher: Al-Farouq Modern Printing and Publishing, Edition: First, 1424 AH - 2004 AD.

40. Farooq Abdullah Karim "The Doctor", Mediator in Explaining the Iraqi Personal Status Law, Publisher: Al-Farouq Modern Printing and Publishing, First Edition, 1424 AH - 2004 AD.

41. Muhammad bin Ahmed bin Muhammad Alyish, Abu Abdullah al-Maliki (deceased: 1299 AH). Fatuh Al-Ali al-Malik fi al fatwa on the doctrine of Imam Malik, publisher: Dar al-Maarifah, edition: without edition and without date.

42. Faisal bin Abdul Aziz bin Faisal bin Hamad al-Mubarak al-Harimli al-Najdi (deceased: 1376 AH), tatriz Riyadh al-Salihin, edited by: Dr. Abdul Aziz bin Abdullah bin Ibrahim Al-Zeer Al Hamad, Dar Al Asimah Publishing and Distribution, Riyadh, First Edition, 1423 AH - 2002 AD.

43. Faisal bin Abdul Aziz bin Faisal bin Hamad al-Mubarak al-Harimli al-Najdi (deceased: $1376 \mathrm{AH}$ ), Summary of Words - Explaining Omdat Al-Ahkam, Second Edition, 1412 AH - 1992 AD.

44. domestic violence combating law- No. 8 of 2011 issued by the Parliament of the Kurdistan Region. 45. Muhammad bin Ibrahim bin al-Mundhir "Abu Bakr alNisaburi" (died: 319 AH), supervising the doctrines of scholars, edited by: Saghir Ahmad al-Ansari Abu Hammad, Makkah Cultural Library, Ras al-Khaimah - United Arab Emirates, edition: the first, 1425 AH - 2004 CE .

46. Muhammad bin Ibrahim bin Abdullah Al-Tuwaijri, Encyclopedia of Islamic Jurisprudence, International House of Ideas, 1st edition, 1430 AH - 2009 AD. 


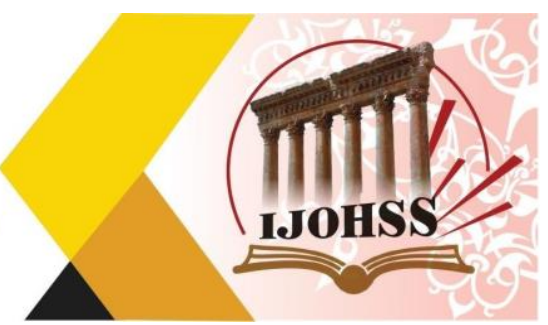

47. Muhammad Ibn Ahmad "Shams al-Din al-Khatib al-Sharbini al-Shafi'i" (deceased: $977 \mathrm{AH}$ ), al Siraj al muneer fi al iaanat ala maarifat baadh maani kalam rabbina al khabeer, Bulaq Press (Al-Amiriya) - Cairo, year of publication: $1285 \mathrm{AH}$. 48. Muhammad bin Ahmed bin Salem al-Saffarini al-Hanbali "Shams al-Din, Abu alAoun" (deceased: 1188 AH), ghidaa al albaab fi sharh mandhomat al adab, Cordoba Foundation - Egypt, second edition, 1414 AH / 1993 AD.

49. Muhammad bin Ahmad bin Muhammad bin Abdullah "Abu al-Qasim Ibn Jazi alKalbi al-Gharnati” (deceased: $741 \mathrm{AH}$ ), al-Qawnin al-Fiqhiyyah.

50. Muhammad ibn Idris al-Shafi'i al-Muttalibi al-Qurashi al-Makki "Abu Abdullah" (died: $204 \mathrm{AH}$ ), tafseer al Imam al-Shafi'i, collection, investigation and study: Dr. Ahmad Ibn Mustafa Al-Farran (PhD Thesis), Dar Al-Tadmuriyyah - Kingdom of Saudi Arabia, First Edition: 2006 - 1427 AD.

51. Muhammad bin Ishaq bin Khuzaymah bin al-Mughira bin Salih bin Bakr alSalami "Abu Bakr al-Nisaburi" (died: 311 AH), Sahih Ibn Khuzaymah, edited, commented on, and published his hadiths and presented to him: Dr. Muhammad Mustafa al-Azami, The Islamic Office, 3rd edition, 1424 E - 2003 AD.

52. Muhammad Bin Ismail Abu Abdullah Al-Bukhari Al-Ja'fi, "Sahih Al-Bukhari", edited by: Muhammad Zuhair bin Nasser Al-Nasser, Dar Touq Al-Najat (illustrated on the Sultanate by adding the numbering Muhammad Fuad Abd Al-Baqi), Edition: First, 1422 AH, with the book: Explanation and Commentary by Dr. Mustafa Deeb Al-Bagha Professor of Hadith and its Sciences at the Faculty of Sharia - Damascus University.

53. Muhammad bin Ismail bin Ibrahim bin al-Mughira al-Bukhari, Abu Abdullah (deceased: $256 \mathrm{AH}$ ), Al adab Al mufrad, edited by: Muhammad Fuad Abd al-Baqi, Dar al-Bashaer al-Islamiyya - Beirut, third edition, 1409 - 1989.

54. Muhammad bin Ismail bin Salah bin Muhammad al-Hasani, al-Kahlani, then alSan'ani, Abu Ibrahim, Ezz al-Din, known as his predecessors as the Emir (deceased: $1182 \mathrm{AH})$, Subul al-Salam, Dar al-Hadith, edition: without edition and without date.

55. Muhammad bin Hibban bin Ahmad bin Habban bin Muadh bin Mu'adh, alTamimi, Abu Hatim, al-Darami, al-Busti (died: 354 AH), Sahih Ibn Hibban, arranged by Ibn Bilban, edited by: Shuaib al-Arna'out, Foundation for Resala - Beirut, 2nd edition, 14141993.

56. Muhammad bin Ali bin Muhammad bin Abdullah al-Shawkani al-Yamani (deceased: $1250 \mathrm{AH}$ ), Nail al-Awtar, edited by: Essam al-Din al-Sabbati, Dar alHadith, Egypt, first edition, 1413 AH - 1993 AD.

57. Muhammad bin Muhammad "Abu Hamid al-Ghazali" (deceased: 505 AH), AlMustasfa, investigation by: Muhammad Abd al-Salam Abd al-Shafi, Dar al-Kutub al'Ilmiyya .

58. Muhammad bin Muhammad bin Abd al-Razzaq al-Husayni, Abu al-Fayd, nicknamed Murtada, al-Zubaidi (died: 1205 AH), taj al aroos min jawahir al qamoos, investigation: a group of investigators, publisher: Dar al-Hidaya. 


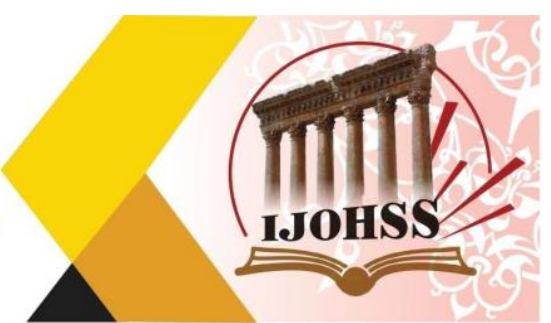

59. Muhammad bin Makram bin Ali, Abu al-Fadl, Jamal al-Din Ibn Manzur al-Ansari al-Ruwa'i al-Afriqi (died: 711 AH), Lisan al-Arab, 3rd Edition, Dar Sader - Beirut, year $1414 \mathrm{AH}$.

60. Muhammad bin Yazid al-Qazwini “Abu Abdullah Ibn Majah" (deceased: 273 AH), Sunan Ibn Majah, edited by: Shuaib al-Arna ut - Adel Murshid - Muhammad Kamil Karah Belli - Abd al-Latif Harz Allah, Dar al-Risalah al-Alamiya, Edition: First, 1430 E - 2009 AD.

61. Muhammad bin Yusuf bin Ali bin Yusuf bin Hayyan Atheer al-Din "Abu Hayyan Al-Andalusi" (deceased: 745 AH), Al-Bahr Al-Muheet fi al tafseer, edited by: Sidqi Muhammad Jamil, Dar Al-Fikr - Beirut, Edition: 1420 AH.

62. Muhyiddin Yahya Bin Sharaf "Abu Zakaria Al-Nawawi” (deceased: $676 \mathrm{AH}$ ), sharh al-Nawawi's ala Muslim "Al-Minhaj Sharh Sahih Muslim ibn Al-Hajjaj”, House of Revival of Arab Heritage - Beirut, Edition: Second, 1392.

63. Muslim bin Al-Hajjaj Abu Al-Hasan Al-Qushayri Al-Nisaburi (died: 261 AH), "Sahih Muslim", edited by Muhammad Fuad Abdul-Baqi, House of Revival of Arab Heritage - Beirut vol 2, p. 1036.

64. Nasir al-Din Abu Saeed Abdullah bin Omar bin Muhammad al-Shirazi al-Baidawi (deceased: $685 \mathrm{AH}$ ), Anwar al-Tanzil wa Asrar al-Ta'wil, edited by: Muhammad Abd al-Rahman al-Maraashli, House of Revival of Arab Heritage - Beirut, Edition: First $1418 \mathrm{AH}$.

65. Nayef bin Muhammad al-Marwani, "Doctor Colonel," Domestic Violence: An Analytical Survey of Al-Madinah Al-Munawwarah Region, available on the Internet in PDF format. With some shortcut .

66. Nasr bin Muhammad bin Ahmed bin Ibrahim "Abu al-Layth al-Samarqandi" (died: $373 \mathrm{AH}$ ), Bahr al-Ulum, without the place and year of printing.

67. Nizam al-Din al-Hasan ibn Muhammad ibn Husayn al-Qummi al-Nisaburi (deceased: 850 AH), Ghraibat al-Qur'an and Raghaib al-Furqan, edited by: Sheikh Zakaria Omairat.

68. Naima Rahmani, Marital Violence against Women in Tlemcen, Court of Tlemcen as an example, a $\mathrm{PhD}$ thesis submitted to the Faculty of Humanities and Social Sciences - Abi Bakr Belkaid University - Tamsan, under the supervision of Dr. Malika Ben Mansour, Algeria, 2010-2011, p. 37.

69. Ministry of Endowments and Islamic Affairs - Kuwait, Kuwaiti Fiqh Encyclopedia, Edition: (from 1404 - 1427 AH), Parts 1 - 23: Second Edition, Dara for Silasil - Kuwait, Volumes 24 - 38: First Edition, Dar Al-Safwa Press - Egypt, Parts 39-45: Second Edition, Ministry reprint.

70. Yahya bin (Hubaira bin) Muhammad bin Hubaira al-Dahli al-Shaibani, Abu alMuzaffar, Aoun al-Din (deceased: $560 \mathrm{AH}$ ), deference of scholars, edited by: Sayyid Yusuf Ahmad, Dar al-Kutub al-Ilmiyya - Lebanon / Beirut, First Edition, 1423 AH 2002. 